SYNTHESIS AND CHARACTERIZATION OF MULTI-HOLLOW OPAQUE POLYMER PIGMENTS

A THESIS SUBMITTED TO

THE GRADUATE SCHOOL OF NATURAL AND APPLIED SCIENCES

OF

MIDDLE EAST TECHNICAL UNIVERSITY

BY

SERDAR ASMAOĞLU

IN PARTIAL FULFILLMENT OF THE REQUIREMENTS

FOR

THE DEGREE OF MASTER OF SCIENCE

IN

CHEMICAL ENGINEERING

JULY 2012 
Approval of the thesis:

\section{SYNTHESIS AND CHARACTERIZATION OF MULTI-HOLLOW OPAQUE POLYMER PIGMENTS}

submitted by SERDAR ASMAOĞLU in partial fulfillment of the requirements for the degree of Master of Science in Chemical Engineering Department, Middle East Technical University by,

Prof. Dr. Canan Özgen

Dean, Graduate School of Natural and Applied Sciences

Prof. Dr. Deniz Üner

Head of Department, Chemical Engineering

Prof. Dr. Güngör Gündüz

Supervisor, Chemical Engineering Dept., METU

Assist. Prof. Dr. Bora Maviş

Co-supervisor, Mechanical Engineering Dept., HU

\section{Examining Committee Members:}

Prof. Dr. Hayrettin Yücel

Chemical Engineering Dept., METU

Prof. Dr. Güngör Gündüz

Chemical Engineering Dept., METU

Assoc. Prof. Dr. Halil Kalıpçılar

Chemical Engineering Dept., METU

Assoc. Prof. Dr. Burcu Akata Kur

Micro and Nanotechnology Dept., METU

Dr. Cevdet Öztin

Chemical Engineering Dept., METU 
I hereby declare that all information in this document has been obtained and presented in accordance with academic rules and ethical conduct. I also declare that, as required by these rules and conduct, I have fully cited and referenced all material and results that are not original to this work.

\author{
Name, Last name : SERDAR ASMAOĞLU \\ Signature
}




\title{
ABSTRACT
}

\section{SYNTHESIS AND CHARATERIZATION OF MULTI-HOLLOW OPAQUE POLYMER PIGMETS}

\author{
Asmaoğlu, Serdar \\ M.Sc., Department of Chemical Engineering \\ Supervisor : : Prof. Dr. Güngör Gündüz \\ Co-Supervisor : Assist. Prof. Dr. Bora Maviş
}

July 2012,115 pages

In the present work, a new generation opaque polymer pigment with multihollow structure was synthesized by suspension polymerization of "Water-in-Oil-in-Water" (W/O/W) emulsion system. Oil phase was methyl methacrylate and ethylene glycol dimethacrylate monomer mixture at 1:1 weight ratio. The dimension and distribution of hollows inside polymer particles are dependent on the size of water droplets which are encapsulated in micelles. For Water-in-Oil (W/O) assembly, a hydrophobic surfactant and hydrophilic co-surfactant (Span 80-Tween 80) combination with a hydrophilic/lipophilic balance (HLB) value between 5-8 was used. The effects of surfactant and co-surfactant composition on the stability of the W/O emulsion and also on the size of water droplets were studied. In addition, the effect of the ultrasonication on the average size of water droplets was investigated. 
The hollow size distribution which may possibly give the maximum scattering efficiency was predicted by a mathematical model based on the Mie scattering. The optimum size distribution for W/O emulsion was obtained at the monomer/surfactant/water ratio of 75.5/9.4/15.1 after ultrasonication for 30 seconds at $80 \mathrm{~W}$ power.

The $\mathrm{W} / \mathrm{O} / \mathrm{W}$ emulsion was prepared by dispersing the $\mathrm{W} / \mathrm{O}$ emulsion in aqueous solution of hydrophilic Triton X-405. The influence of surfactant concentration and mechanical mixing on monomer droplets was investigated by size measurement and optical microscopy. After stabilizing with $1 \% \mathrm{w} / \mathrm{w}$ polyvinylpyrrolidone (PVP) solution, the W/O/W emulsion was polymerized at $55^{\circ} \mathrm{C}$ for $20 \mathrm{~h}$. The surface morphology of synthesized polymer pigments was analyzed by scanning electron microscopy (SEM) and the inner hollow structure was confirmed by transmission electron microscopy (TEM). The analysis indicated that multihollow opaque polymer pigments were successfully synthesized.

The opacity, the L*a*b* color, and the gloss properties of polymer pigments were examined by spectrophotometer and glossmeter. The opacity values were assessed by contrast ratio measurements, and the synthesized polymer pigments provided up to $97.3 \%$ opacity ( $50 \% \mathrm{v} / \mathrm{v}$ solid content). In addition, the pigments exhibited low gloss values, and yielded matt films.

Keywords: water-in-oil emulsion, water-in-oil-in-water emulsion, emulsion stability, multihollow polymer, opaque polymer pigment, polymethyl methacrylate. 


\title{
ÇOK BOŞLUKLU OPAK POLİMER PİGMENTLERİN ELDESİ VE ÖZELLİKLERİNİN BELİRLENMESİ
}

\author{
Asmaoğlu, Serdar \\ Yüksek Lisans, Kimya Mühendisliği Bölümü \\ Tez Yöneticisi : Prof. Dr. Güngör Gündüz \\ Ortak Tez Yöneticisi : Yrd. Doç. Dr. Bora Maviş
}

Temmuz 2012, 115 sayfa

Bu çalışmada, "Su-içinde-Yağ-içinde-Su" (S/Y/S) emülsiyonunun süspansiyon polimerleştirilmesi ile çok boşluklu yapıda yeni nesil opak polimer pigmentler elde edilmiştir. Yağ fazı ağırlıkça 1:1 oranında metilmetakrilat ve etilen glikol dimetakrilat monomerlerinden oluşmaktadır. Polimerlerin içerisindeki boşlukların boyut ve dağılımları miseller tarafından sarılmış olan su damlacıklarının boyutlarına bağlıdır. Bu çalışmada, hidrofobik ve yardımcı hidrofilik yüzey aktif madde (Span 80-Tween 80 ) karışımı hidrofilik/lipofilik denge (HLB) değeri 5 ve 8 arasında değiştirilerek kullanılmıştır. Yüzey aktif madde karışımının "Yağ-içinde-Su" (Y/S) emülsiyon kararlılı̆ı ve su damlacığı boyutu üzerindeki etkisi incelenmiştir. Ultrosonikasyon değişkenlerinin su damlacığı ortalama boyutu üzerindeki etkileri araştırımıştır. 
Olası en yüksek saçıım verimini sağlabilecek boşluk boyutlarının dağıımı Mie saçılımının matematiksel modellemesi yapılarak belirlenmiştir. En uygun W/O emülsiyonu damlacık boyutu dağılımı, monomer, yüzey aktif madde ve su oranı 75.5/9.4/15.1 olacak şekilde $80 \mathrm{~W}$ güç ve 30 saniye süreyle ultrasonic karıştırmayle elde edilmiştir.

S/Y/S emülsiyonu, Y/S emülsiyonun sulu hidrofilik Triton X-405 çözeltisinin içerisinde dağııılmasıyla hazırlanmıştır. Yüzey aktif madde derişimi ve mekanik karıştırma değişkenlerinin monomer damlacığı üzerindeki etkileri boyut ölçümleri ve optic mikroskop gözlemleriyle incelenmiştir. W/O/W emülsiyonu \% 1'lik polivinilpirolidon çözeltisiyle kararlılaştırımasının ardından $55{ }^{\circ} \mathrm{C}$ sıcaklıkta 20 saat süreyle polimerleştirilmiştir. Elde edilen polimer pigmentlerin yüzey özellikleri taramalı electron mikroskobu ile incelenmiş (SEM) ve içlerindeki boşluk yapıları geçirimli electron mikroskobu (TEM) ile doğrulanmışıır. Yapılan analizler çok boşluklu opaK polimer pigmentlerin başarıyla elde edildiğini göstermiştir. Polimer pigmentlerinin opaklık, L*a*b* renk ve parlaklık özellikleri spektrofotometre ve glosmetre ile incelenmiştir. Opasite değerleri kontrastlık oranı ölçümleriyle belirlenmiş ve elde edilen polimer pigmentler \% 97.3'e kadar (katı üzerinden hacimce $\% 50$ oranında) opaklık sağlamışlardır. Ayrıca pigmentler düşük parlaklık değeri göstermiş ve mat film oluşturmuşlardır.

Anahtar sözcükler: yağ-içinde-su emülsiyonu, su-içinde-yağ-içinde-su emülsiyonu, emülsiyon kararlıı̆ı, çok boşluklu polimer, opak polimer pigment, polimetil metakrilat 
To my endless love Özlem 


\section{ACKNOWLEDGEMENTS}

I owe my deepest gratitude to my supervisor Prof. Dr. Güngör Gündüz for his expertise and support throughout my studies. I also want to thank him for giving me the chance to work under his supervision. He guided and helped me with his deepest knowledge at all points of this study. He inspired me in a number of ways including not only my thesis work, but also my future career as a chemical engineer.

I would like to offer my sincere thanks to my co-supervisor Assist. Prof. Dr. Bora Maviş for his invaluable guidance, endless helps, great ideas and encouragement throughout my thesis.

I would like to express my sincere thanks to Prof. Dr. Üner Çolak for his invaluable advice, support, understanding, and kindly attitude in every aspect.

Thanks are not enough to my laboratory friends Gülden Eroğlu, Nagehan Keskin, Anisa Çoniku, İdil Öğretim, and Yasemin Sönmez for their collaborative, motivating and friendly manner. Special thanks go to Ekin Karakaya for her understanding, encouragement and friendship. I would like to thank Sevinç Sevim Kahya for helping me get through the difficult times, listen me every time that a need and being a special friend for me. I also wish to express my thanks to İrem Vural and Korhan Sezgiker for their supports and friendship. 
My deepest gratitude is to my parents Hüseyin Asmaoğlu and Nacife Asmaoğlu, my brothers Serhat Asmaoğlu, Mücahit Enes Asmaoğlu, and my sister Tuğçe Asmaoğlu for their very special care, understanding, and for their faith in me. At every step of my life, they were just beside me with their endless love, patience, and encouragement.

I owe my loving thanks to Özlem Erkan, who is the most precious one for my life. I am grateful for her biggest support all the way not only through my master studies but also through my life. The words are not enough to express my appreciation to her for all her sacrifices, persistent confidence in me and deepest love.

I would like to thank to Mesut Eren from Betek Paint and Chemical Inc., for supplying me paint materials necessary in my thesis.

The supports received from The Scientific and Technical Research Council of Turkey (TÜBİTAK) (Project Number: 110T768) and Middle East Technical University (METU) (Scientific Research Projects: BAP-03-04-2011-001) are gratefully acknowledged. 


\section{TABLE OF CONTENTS}

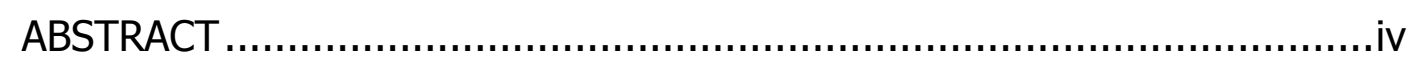

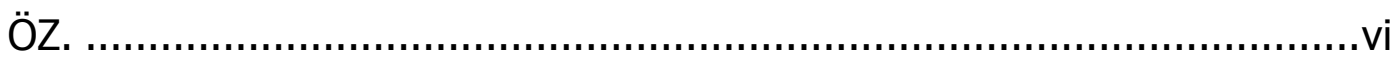

ACKNOWLEDGEMENTS.............................................................

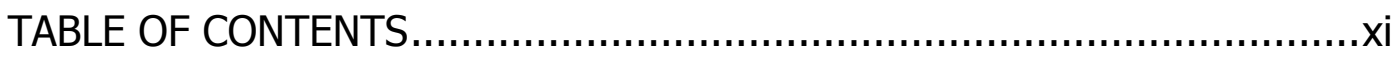

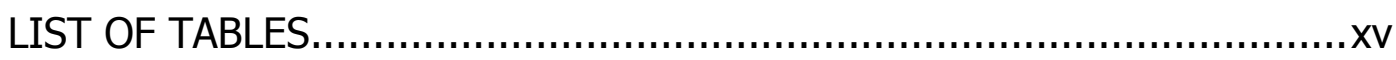

LIST OF FIGURES .................................................................

LIST OF SYMBOLS AND ABBREVIATIONS ...................................... xix CHAPTERS

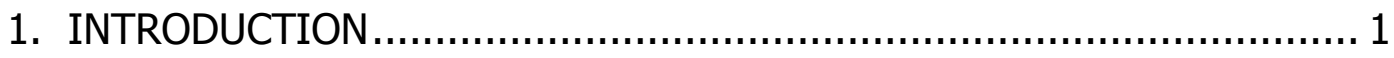

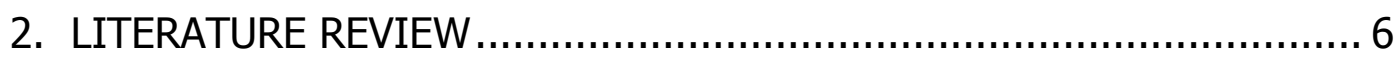

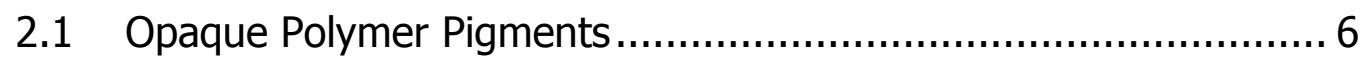

2.2 Light Scattering ................................................................. 10

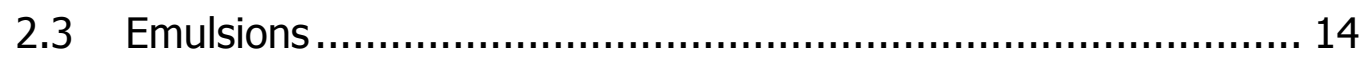

2.3.1 Water-in-Oil (W/O) Emulsion ........................................... 15

2.3.2 Stability of W/O Emulsion .............................................. 17

2.3.2 Water-in-Oil-in-Water (W/O/W) Emulsion ......................... 31

2.3.3 Stability of Water-in-Oil-in-Water (W/O/W) Emulsion .......... 33

2.4 Polymerization of W/O/W Emulsion ...................................... 36

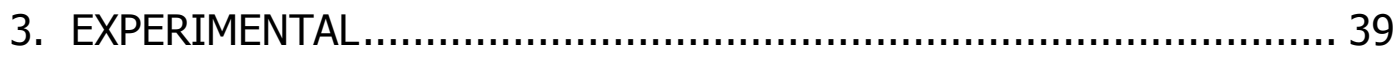

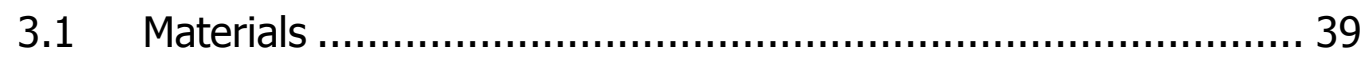




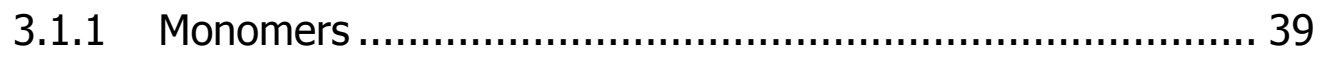

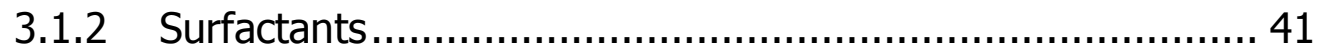

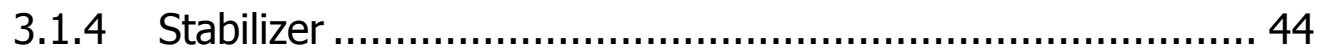

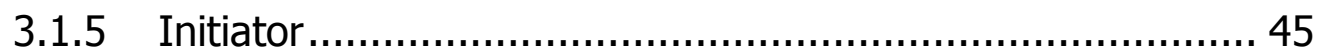

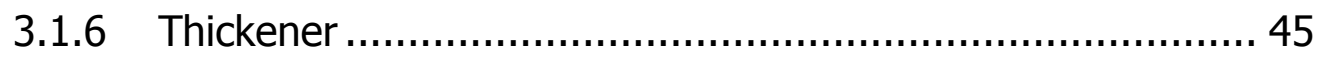

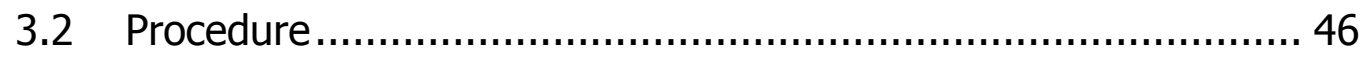

3.2.1 Preparation of Water-in-Oil Emulsion................................ 46

3.2.2 Preparation of Water-in-Oil-in-Water Emulsion................... 51

3.2.3 Stabilization of Water-in-Oil-in-Water Emulsion ................... 52

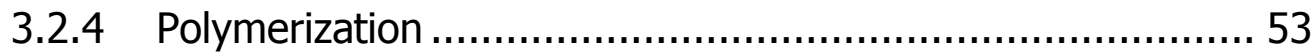

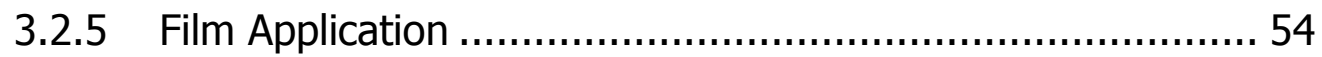

3.3 Characterization Methods .................................................... 55

3.3.1 Dynamic Light Scattering (DLS) Size Measurement ............. 55

3.3.2 Scanning Electron Microscopy (SEM) …........................... 56

3.3.3 Transmission Emission Microscopy (TEM) ......................... 56

3.3.4 Fourier Transform Infrared (FTIR) Spectroscopy ................. 56

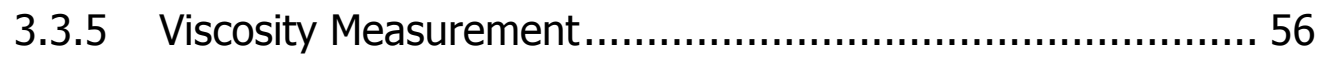

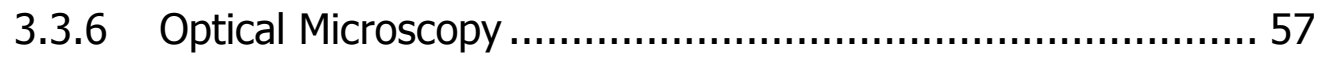

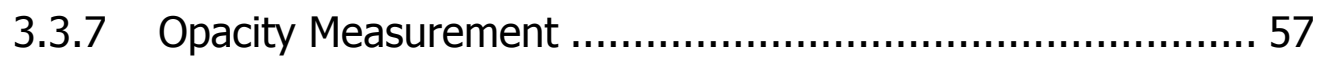

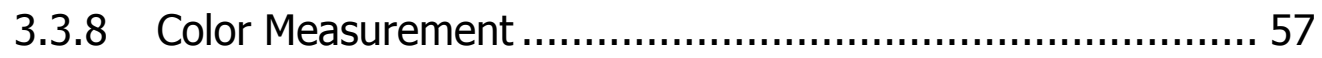

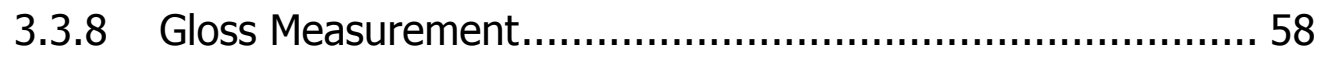

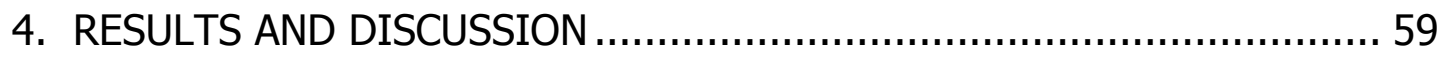

4.1 Preliminary Studies on Surfactant Selection ........................... 59 
4.2 Effect of Hydrophilic-Lipophilic Balance (HLB) Value on Emulsion Stability..... 62

4.3 Phase Stability Diagram for W/O Emulsion ............................... 66

4.3.1 Effect of Surfactant 66

4.4 Effect of Ultrasonication Parameters on W/O Emulsion Droplet Size. 72

4.4.1 Effect of Ultrasonication Power ..................................... 73

4.4.2 Effect of Time of Ultrasonication ..................................... 74

4.5 Mathematical Modeling of Scattering Efficiency ....................... 75

4.6 W/O Emulsion Preparation with Required Droplet Size............... 78

4.7 Effect of Hydrophilic Surfactant Concentration on W/O/W Emulsion Droplet Size............................................................... 79

4.8 Effect of Mixing Parameters on W/O/W Emulsion Droplet Size ... 82

4.8.1 Effect of Mechanical Mixing Speed ................................... 82

4.8.2 Effect of Time of Mechanical Mixing …............................ 85

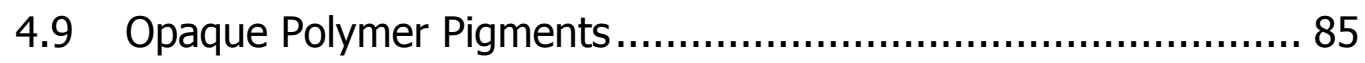

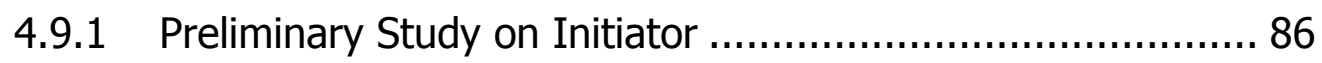

4.9.2 FTIR Spectrum of Polymer Pigment................................... 88

4.10 Morphology of Opaque Polymer Pigments ........................... 88

4.10.1 Effect of the Inner Water Phase Ratio ............................. 89

4.10.2 Effect of Surfactants Used in W/O Emulsion..................... 93

4.10.3 Effect of Thickener....................................................... 94

4.11 Opacity Measurements ….................................................. 96

4.12 Effect of the Amount of Pigment on Paint Opacity .................. 97

4.13 Gloss Measurements....................................................... 98 
$4.14 \quad$ L*a*b Color Measurement ........................................... 98

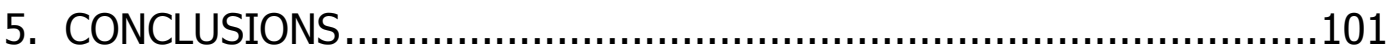

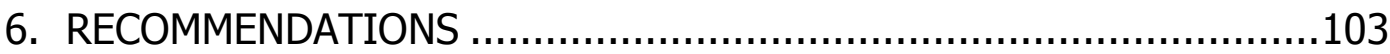

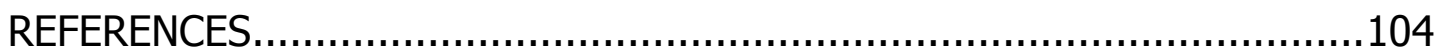

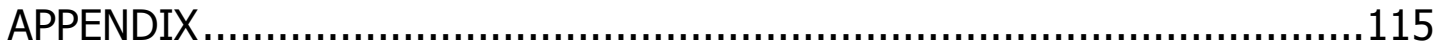

A. MATLAB CODES FOR SCATTERING EFFICIENCY CALCULATOR..........115 


\section{LIST OF TABLES}

\section{TABLES}

Table 2.1 Refractive index and density of some white pigments.

Table 2.2 Ranges of HLB and corresponding emulsion and application $[14,77]$ 27

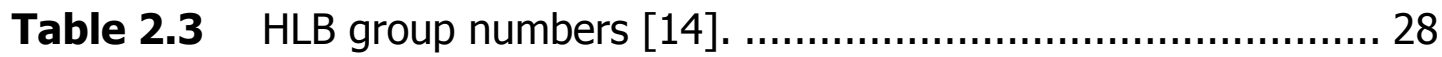

Table 3.1 Properties of MMA used in this study............................... 40

Table 3.2 Properties of EGDMA used in this study. ............................ 41

Table 3.3 Properties of Span 80 used in this study. ............................ 42

Table 3.4 Properties of Tween 80 used in this study........................... 43

Table 3.5 Properties of Triton X-405 used in this study........................ 44

Table 3.6 Surfactant ratios at given HLB values................................. 47

Table 3.7 Composition of prepared W/O emulsions............................. 50

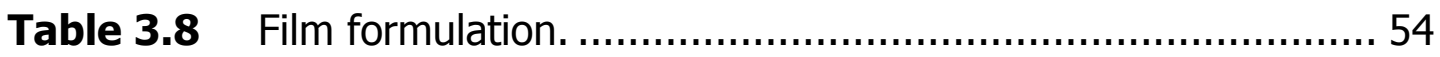

Table 4.1 Preliminary experiments on surfactant selection. ...................60

Table 4.2 Calculated solubility parameters of monomers and lipophilic

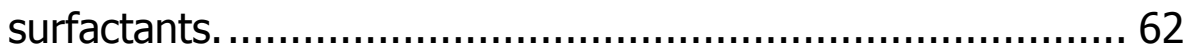

Table 4.3 Compositions of opaque pigments. ................................... 89

Table 4.4 Opacity measurement results of polymer pigments............... 96

Table 4.5 Gloss values of opaque polymer pigments........................... 98

Table 4.6 The color properties of opaque polymer pigments compared to $\mathrm{TiO}_{2}$ 99 


\section{LIST OF FIGURES}

\section{FIGURES}

Figure 1.1 Single hollow opaque pigment.

Figure 1.2 Illustration of multihollow polymer pigment and the mechanism of the improvement of hiding efficiency. ................................ 3

Figure 2.1 Steps of osmotic swelling method...................................... 9

Figure 2.2 Steps of non-solvent encapsulation method. ........................ 10

Figure 2.3 Schematic representation of membrane emulsification methods [58]. 17

Figure 2.4 Instability mechanisms..................................................... 19

Figure 2.5 Micelle (a) and reverse micelle (b)................................. 25

Figure 2.6 Complex formation of Span 80 an Tween 40 surfactants at the water-oil interface [19] ................................................ 30

Figure 2.7 Effects of HLB number on particle size and PDI [17]............ 31

Figure 2.8 Two-step procedure of W/O/W emulsification........................ 32

Figure 2.9 Possible destabilization mechanisms for W/O/W emulsion. .... 35 Figure 2.10 Hollow polymer particles produced in the study of Lee et al. [108]. 37

Figure 2.11 Optical microscope images of multihollow PMMA microcapsules

(a) $10 \% w / w$ EGDMA and (b) $50 \% w / w$ EGDMA [109]........ 38

Figure 3.1 Structural formula of MMA.............................................. 40

Figure 3.2 Structural formula of EGDMA.............................................. 41

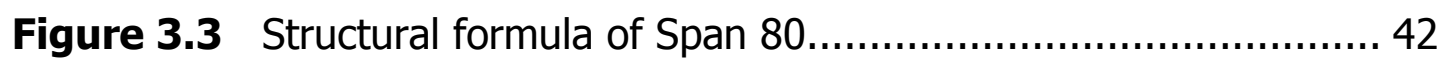

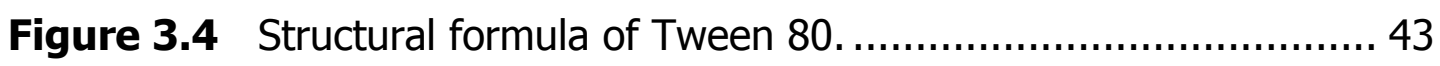

Figure 3.5 Chemical structure of Triton X-405............................... 44 


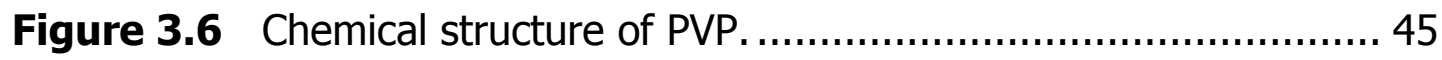

Figure 3.7 Chemical structure of AIBN. ............................................. 45

Figure 3.8 General flow diagram of experimental procedure.................. 46

Figure 3.9 Flow diagram of W/O emulsion preparation step. ................. 48

Figure 3.10 Experimental setup of W/O emulsion preparation step.......... 48

Figure 3.11 Flow diagram and illustration of $\mathrm{W} / \mathrm{O} / \mathrm{W}$ emulsion preparation

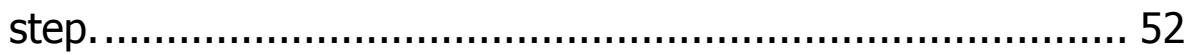

Figure 3.12 Flow diagram and illustration of W/O/W emulsion stabilization

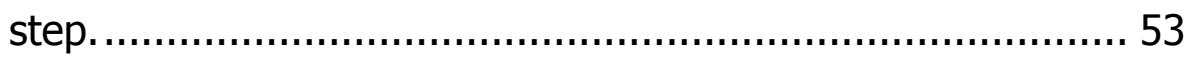

Figure 3.13 Experimental setup for polymerization reaction. ................... 54

Figure 4.1 Influence of surfactant mixture HLB value on the size of water

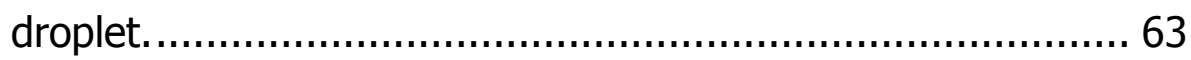

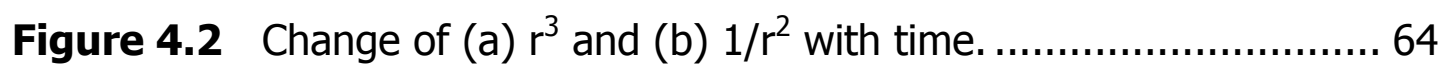

Figure 4.3 Change of viscosity with HLB value..................................... 65

Figure 4.4 Phase diagram for monomer/surfactant/water system. ......... 67

Figure 4.5 Phase diagram for monomer/surfactant/water system. ......... 69

Figure 4.6 Size distribution of Span 80-Tween 80 surfactant mixture in MMA:EGDMA (1:1) (a) before, and (b) after filtration. .......... 70

Figure 4.7 Images of $\mathrm{W} / \mathrm{O}$ emulsions with various amount of water....... 71

Figure 4.8 Images of $\mathrm{W} / \mathrm{O}$ emulsion with $\mathrm{w} / \mathrm{m}$ of 0.05 , at $\mathrm{t}: 0$ and $\mathrm{t}: 24$ hours after ultrasonication.

Figure 4.9 Effect of ultrasonication power on W/O emulsion droplet size.73

Figure 4.10 Effect of time of ultrasonication on W/O emulsion droplet size.

Figure 4.11 Temperature rise due to the ultrasonication....................... 75

Figure 4.12 The calculated scattering efficiency profiles of hollows with different diameters and at varying incident radiations........... 76

Figure 4.13 Relative spectral power distribution of D65 [123] ................ 78 
Figure 4.14 Droplet size distribuiton of W/O emulsion (M/S/W: 75.5/9.4/15.1), 80 W, 30 seconds.

Figure 4.15 The effect of surfactant concentration on $\mathrm{W} / \mathrm{O} / \mathrm{W}$ emulsion droplet size. (wow: droplet size of the W/O/W emulsion, suspwow: the size of suspended and stabilized droplets of W/O/W emulsion) 80

Figure 4.16 Optical microscopy images for (a) $2 \% \mathrm{w} / \mathrm{w}$, (b) $3.5 \% \mathrm{w} / \mathrm{w}$, and (c) $5 \% \mathrm{w} / \mathrm{w}$ Triton X-405, (x400).

Figure 4.17 Effect of mixing speed on W/O/W emulsion monomer droplet size. 83

Figure 4.18 Optical microscopy image of W/O/W emulsions mixed at (a) $1000 \mathrm{rpm}$, (b) $1250 \mathrm{rpm}$, and (c) $1500 \mathrm{rpm}$. (x400). 84

Figure 4.19 Effect of mixing time on W/O/W emulsion droplet size. 85

Figure 4.20 SEM micrographs of polymer particles, $(a 1, a 2)$; with BPO, and (b) with AIBN. 87

Figure 4.21 FTIR spectrum of the synthesized polymer pigment. 88

Figure 4.23 SEM micrographs of (a) OP1, (b) OP2, and (c) OP3 ............. 90

Figure 4.23 An OP2 particle. 91

Figure 4.24 TEM micrographs of (a) OP1 (w/m:0.1), (b) OP2 (w/m:0.2), and (c) OP3 (w/m:0.3). 92

Figure 4.25 TEM micrographs of (a) OP4 (s/m:0.125) and (b) OP5 ( $\mathrm{s} / \mathrm{m}: 0.175)$. 93

Figure 4.26 Effect of PS concentration on MMA:EGDMA (1:1) mixture. .... 94 Figure 4.27 TEM micrographs of (a) OP6 $(0.25 \% \mathrm{w} / \mathrm{w})$, (b) OP7 (0.5 $\% w / w)$, (c) OP8 (1\%w/w), and (d) OP9 (1.5\%w/w). 95 


\section{LIST OF SYMBOLS AND ABBREVIATIONS}

$\begin{array}{ll}\text { AIBN } & \text { Azobisisobutyronitrile } \\ \text { DLS } & \text { Dynamic Light Scattering } \\ \text { EGDMA } & \text { Ethylene Glycol Dimethacrylate } \\ \text { HLB } & \text { Hydrophilic Lipophilic Balance } \\ \text { METU } & \text { Middle East Technical University } \\ \text { M/S/W } & \text { Monomer/Surfactant/Water weight ratio } \\ \text { OP } & \text { Opaque Polymer } \\ \text { rpm } & \text { Revolution Per Minute } \\ \text { PDI } & \text { Polydispersity Index } \\ \text { PS } & \text { Polystyrene } \\ \text { PMMA } & \text { Polymetyl Methacrylate } \\ \text { PVP } & \text { Polyvinylpyroldinone } \\ \text { SEM } & \text { Scanning Electron Microscopy } \\ \text { S/m } & \text { Weight ratio of Surfactant to Monomer } \\ \text { Span } 80 & \text { Sorbitan Monooleate } \\ \text { TEM } & \text { Transmission Electron Microscopy } \\ \text { TiO } 2 & \text { Titanium Dioxide } \\ \text { Tween } 80 & \text { Polyoxyethylene (20) sorbitan monooleate } \\ \text { UNAM } & \text { Bilkent University } \\ & \text { National Nanotechnology Research Center } \\ & \\ \text { Xix }\end{array}$


Watt

$\mathrm{w} / \mathrm{m} \quad$ Weight ratio of Water to Monomer

W/O Water-in-Oil Emulsion

W/O/W Water-in-Oil-in-Water Emulsion

$\delta$

Solubility Parameter 


\section{CHAPTER 1}

\section{INTRODUCTION}

Pigments are used as colorants and fillers in many materials such as paints, cosmetics, and polymers. Most of the white pigments used in paint industry are inorganic substances like titanium dioxide, calcite, zinc sulfide, and zinc oxide. The physico-chemical incompatibility between inorganic pigments and organic resins cause severe paint defects and results in phase separation, agglomeration, and settling. The high density difference between organic vehicle and inorganic pigments is another source of such defects. In paint industry pigments are mainly of inorganic nature whereas organic pigments are used at very low percentages (1-3\%) as coloring agents.

Recently, opaque polymer pigments have received significant attention with their lower density and high compatibility with organic paint resins, and so become better options to traditional white pigments. Opaque polymers have hollow structure with thin polymeric shell and a single void inside (Figure 1.1). They provide white appearance and opacity because of scattering of light randomly at all angles. When an incident beam of electromagnetic radiation within the visible region interacts with a particle having diameter close to the wavelength of radiations, that particle scatters radiations nonselectively. The mathematical explanation of light scattering from small particles for a real case was first described by Gustav Mie [1-3] and after 
him, Bohren and Huffman [4] revised the Mie scattering for spherical particles.

The Mie scattering efficiency is dependent on the shape and size of particle, the refractive index difference between medium and particle, the wavelength of light, and the number of particles which act as scattering centers $[4,5]$. In contrast to traditional pigments, the scattering centers in opaque polymer pigments are the voids instead of the particles itself.

Commercialized polymer pigments are mainly produced by osmotic swelling. In this method, carboxylic acid group containing low molecular weight oligomers are encapsulated by shell polymers. With alkali addition acid groups neutralize and polyelectrolytes form. The increased inner osmotic pressure due to electrolytes leads to the absorption of water which in turn causes swelling $[6,7]$.

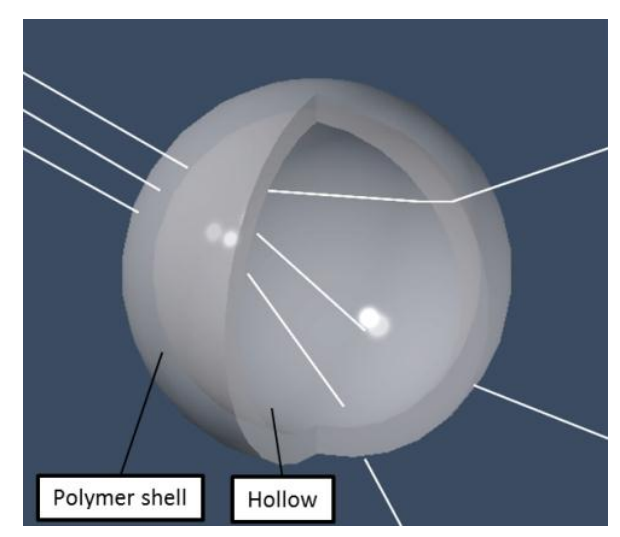

Figure 1.1 Single hollow opaque pigment

The purpose of this study is to produce a new generation opaque polymer pigment with multihollow structure. The increase in the number of hollows 
inside polymer particle can enhance the scattering efficiency and thus may impart higher opacity and hiding power. The illustration of the intended structure to be made is given in Figure 1.2.
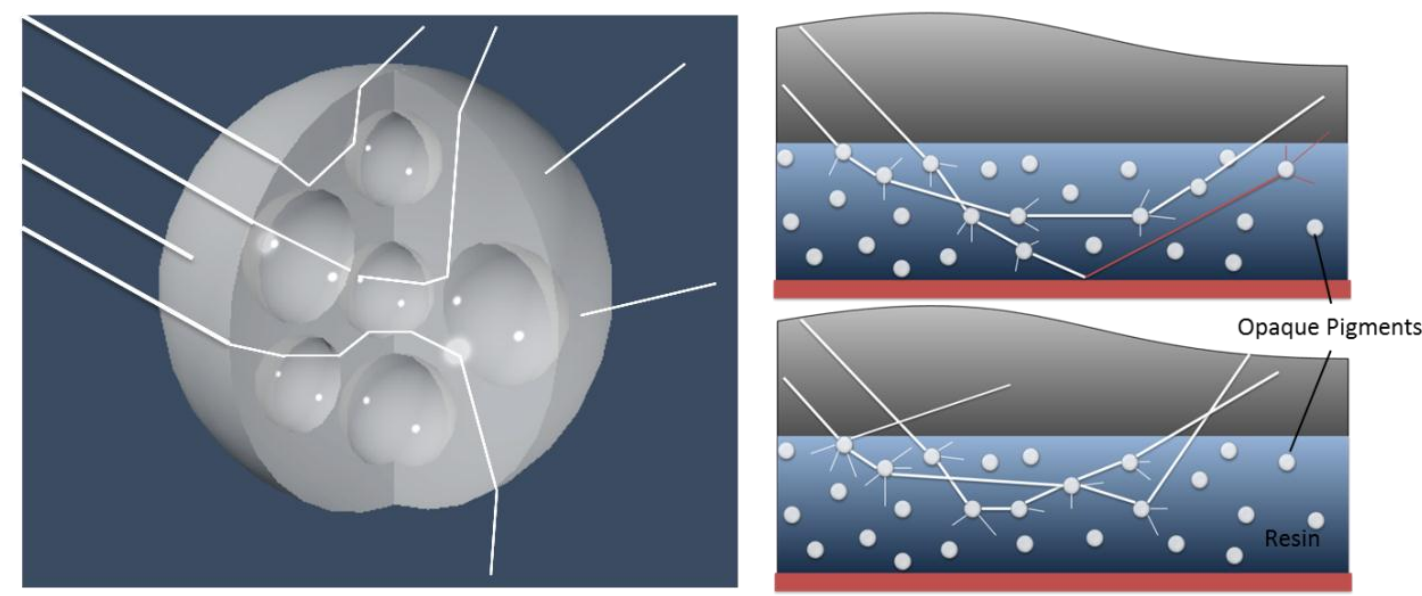

Figure 1.2 Illustration of multihollow polymer pigment and the mechanism of the improvement of hiding efficiency.

In this work, multihollow structured polymer particles were produced by suspension polymerization of "Water-in-Oil-in-Water (W/O/W) emulsion" system. "Oil" means "monomer" throughout the text. The W/O/W emulsions are generated by dispersion of "Water-in-Oil" (W/O) emulsions in continuous water phase which contain hydrophilic surfactant. In W/O emulsions, water droplets are dispersed in monomer phase inside the spherical micelles by using a hydrophobic surfactant. High speed mixing and ultrasonication are needed to make W/O emulsions. The size of hollows inside particles are theoretically equivalent to the size of water droplets formed in W/O emulsification step. W/O/W emulsions are mainly used in controlled drug delivery systems, food industry, and cosmetics [8-10]. 
Emulsion stability is a key factor for producing multihollow structured particles by $\mathrm{W} / \mathrm{O} / \mathrm{W}$ emulsion polymerization. Nature of monomer phase, diameter of water droplets, type and structure of surfactants, viscosity of monomer, and density difference between water and monomer directly affect the stability [11-14]. Creaming, sedimentation, flocculation, coalescence, phase inversion and Oswald ripening are the mechanisms of emulsion destabilization. Sedimentation occurs when the monomer density is lower than water density and creaming occurs in reverse [15]. Coalescence and flocculation are caused by droplet aggregation and migration [15, 16]. Phase inversion is the change of W/O emulsion to O/W emulsion, and vice versa, with the change of temperature of the medium, or with the increase of dispersed phase volume, here water, beyond a critical value [15]. Small droplets have higher "Laplace Pressure" due to high curvature. The Oswald ripening is the fusion of smaller droplets into bigger droplets because of their Laplace pressures difference $[15,17]$. It is stated in many studies that using a co-surfactant in W/O emulsion enhanced the stability [16-19]. The required ratio of surfactants can be predicted from "Hydrophilic-Lipophilic Balance" (HLB) value. The HLB value is a scale which relates the percentage of hydrophilic to lipophilic groups in the surfactant(s) $[20,21]$.

In this current work, W/O emulsions were prepared by using Span 80-Tween 80 surfactant mixtures through utrasonication. The effect of HLB number and sonication parameters on emulsion stability and size were investigated. The stable region for W/O emulsion was determined on a ternary phase diagram. The size of water droplet needed to achieve maximum scattering efficiency was predicted by a mathematical model of the Mie scattering by using the Bohren and Huffman's formulation. The effect of mechanical mixing and hydrophilic surfactant concentration on the sizes of W/O/W emulsion droplets 
were examined, and the obtained emulsions were visually observed by optical microscopy. The W/O/W emulsions were then polymerized after stabilizing them in aqueous polyvinylpyrrolidone (PVP) aqueous solution. The morphological structure of the synthesized opaque polymer pigments were studied by using scanning electron microscopy (SEM) and transmission electron microscopy (TEM). The opacity, the gloss, and the color properties of polymer pigments on styrene-acrylic water based clear resin were investigated. 


\section{CHAPTER 2}

\section{LITERATURE REVIEW}

In this chapter, opaque polymer pigments, their synthesis methods and the light scattering phenomena which are responsible for white appearance and opacity are briefly described. Steps used to produce multihollow structured polymer particles; water-in-oil and water-in-oil-in-water emulsions, their preparation procedures, instability causing phenomena and proposed methods for enhancing the emulsion stability were discussed.

\subsection{Opaque Polymer Pigments}

Opaque pigments are used mainly in plastic, fabric and paints to provide opacity, white appearance, and hiding power. Hiding power is related to the ability of a pigmented coating to obscure a background of contrasting color. The phenomena of white appearance in opaque pigment is different from color pigments. While color pigments provide color by frequency-selective absorption, opaque pigments generate white appearance by scattering the incident light [22-24]. Incident electromagnetic radiation within the range of visible spectrum is scattered when it interacts with a small particle. If the diameter of that particle is close to the wavelength of visible spectrum, scattering generates opacity and white appearance. 
The widely used commercial white pigments in paint industry are titanium dioxide $\left(\mathrm{TiO}_{2}\right)$, zinc sulfide $(\mathrm{ZnS})$, zinc oxide $(\mathrm{ZnO})$, barium sulfate $\left(\mathrm{BaSO}_{4}\right)$, and calcite $\left(\mathrm{CaCO}_{3}\right)$. The mostly preferred one is $\mathrm{TiO}_{2}$ in crystalline form of rutile due to its higher refractive index [25]. Although $\mathrm{TiO}_{2}$ has higher opacity performance, it has poor UV-radiation stability and it easily degrades [25]. These white pigments are inorganic substances and have relatively higher densities compared to polymers. The refractive indices and densities of some white pigments are given in Table 2.1.

Table 2.1 Refractive index and density of some white pigments.

\begin{tabular}{lcc}
\hline White Pigments & Density $\left(\mathbf{g} / \mathbf{c m}^{\mathbf{3}}\right)$ & Refractive Index \\
\hline Titanium dioxide (Rutile) $\left(\mathrm{TiO}_{2}\right)$ & 4.23 & 2.70 \\
\hline Zinc oxide ( $\mathrm{ZnO})$ & 5.60 & 2.00 \\
Zinc sulfide ( $\mathrm{ZnS})$ & 4.09 & 2.40 \\
\hline Barium sulfate $\left(\mathrm{BaSO}_{4}\right)$ & 4.50 & 1.64 \\
Calcite $\left(\mathrm{CaCO}_{3}\right)$ & 2.71 & $1.49-1.66$ \\
\hline
\end{tabular}

Incompatible nature of inorganic opaque pigments results in weaker interaction between them and the organic resins and polymers they are embedded in. This situation causes inorganic pigments to have a tendency of agglomeration among themselves and thereby phase separate from the organic medium. In addition, higher densities of inorganic pigments cause them to sediment due to gravitational effect. 
In order to increase compatibility of inorganic pigments and overcome dispersion problems some methods were proposed in literature. One is reducing the size of pigments where decreased dimensions reduce the surface tension, prevent flocculation and provide higher dispersibility. In addition, according to Stokes-Einstein equation, sedimentation rate of pigments decrease dramatically with reduction in size. However, decreasing the size has unfavorable effect on scattering efficiency where white appearance shifts to blue color according to Rayleigh scattering and with even further reduction pigments become transparent. The optimum size of commercial $\mathrm{TiO}_{2}$ is in between 0.25 and $0.45 \mu \mathrm{m}$ [23]. Another method is modifying the surfaces of inorganic pigments by encapsulating them with polymers in a core shell structure [26-28]. Encapsulation yields compatibility with resin however it is not a solution to high density problem.

The most promising alternative to inorganic pigments is polymeric pigments which have a spherical structure with polymeric shell and a single hollow inside in it $[7,29]$. With the refractive index difference created by airpolymer interface and a diameter near the visible spectrum wavelength, hollow acts as scattering center [7]. This scattering is responsible for opacity and white appearance. Void structured spherical polymer particles were first produced by Kowalski and Vogel and patented in 1984 [30, 31]. After that, studies focused on optimizing these particles to use them as opacifying agent and it was first commercialized by Rohm \& Haas Company. Opaque polymer pigments have lower density, perfect compatibility and strong interaction with resin molecules. However, their scattering efficiencies are not as high as that of $\mathrm{TiO}_{2}$ because of relatively lower refractive index difference in polymer-air interface than in $\mathrm{TiO}_{2}$-polymer interface. Hence, opaque polymer 
pigments have been used together with $\mathrm{TiO}_{2}$ in order to reduce $\mathrm{TiO}_{2}$ content in paint.

There are various methods for the production of single hollow polymeric pigments. The two methods commonly used are (i) osmotic swelling and (ii) non-solvent encapsulation. In osmotic swelling method a low molecular weight carboxylic acid group containing core polymer is synthesized inside micelles with Oil-in-Water (O/W) emulsion polymerization. After addition of monomer and polymerization, the core is encapsulated with shell polymer. With alkali addition, the carboxyl groups of core are neutralized and thus formed polyelectrolytes increase the osmotic pressure inside shell polymer. Due to osmotic pressure core absorbs water and swells the shell [6]. Commercialized opaque polymer pigments are produced by osmotic swelling method. Steps of this method are illustrated in Figure 2.1.

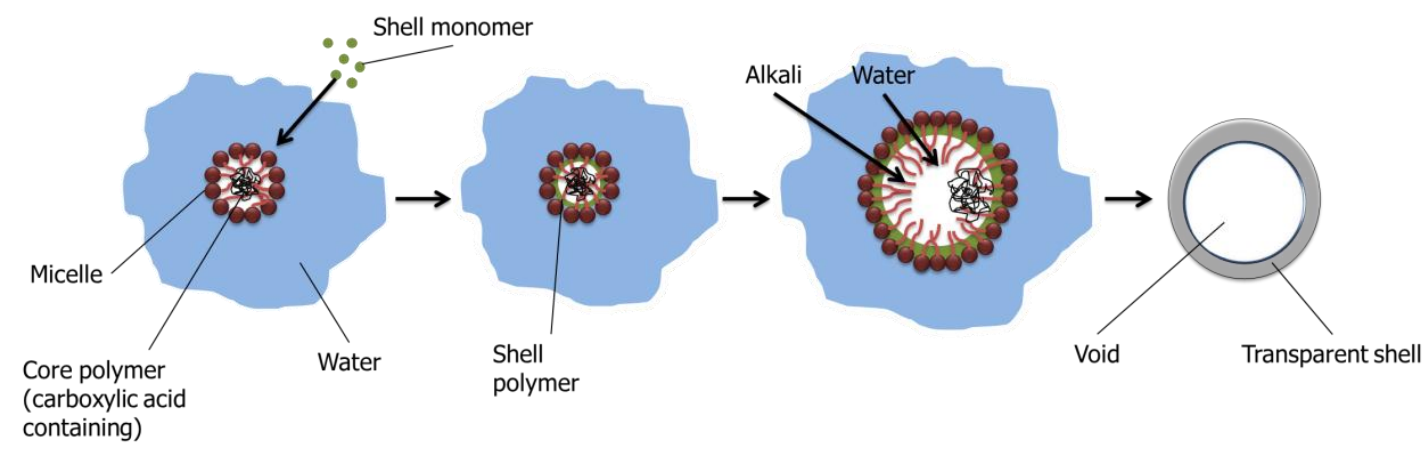

Figure 2.1 Steps of osmotic swelling method.

Khan et al. [32] synthesized single hollow polymer particles by using osmotic swelling method with butyl acrylate-methacrylic acid as core monomers and 
styrene-acrylonitrile as shell monomers. Core polymer was neutralized with ammonia. It was shown that up to $15 \% \mathrm{w} / \mathrm{w}$ of $\mathrm{TiO}_{2}$ can be replaced with polymeric pigment without any loss of opacity performance.

In non-solvent encapsulation method low molecular weight polymers are swollen with a hydrocarbon. Shell monomer should be soluble in that hydrocarbon however its polymer should be incompatible with it. After swelling of micelle with non-solvent, shell monomer is added and polymerized. With polymerization, phase separation occurs and shell polymer moves to hydrocarbon micelle interface. After stabilization of structure with crosslinking and removal of non-solvent, single hollow polymer particle is obtained [33]. Steps of this method are illustrated in Figure 2.2.

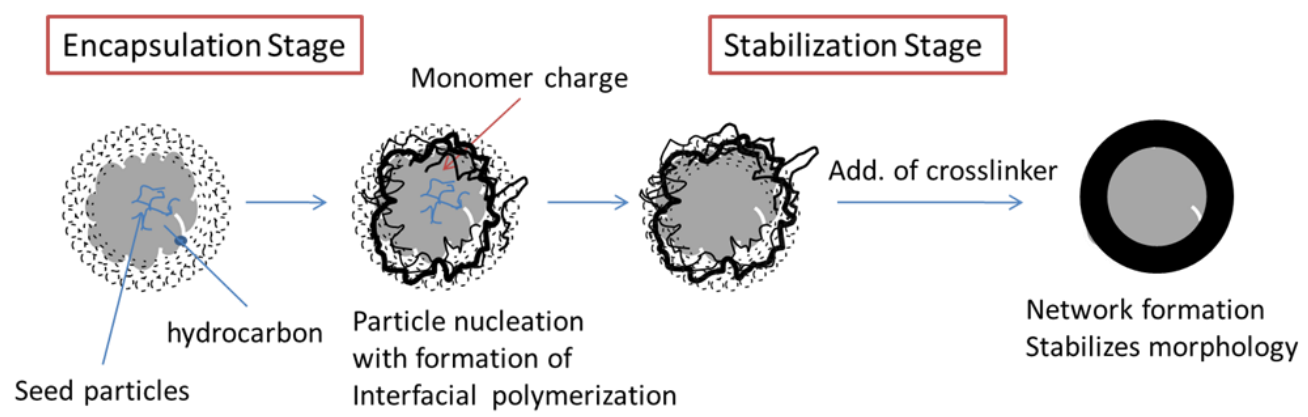

Figure 2.2 Steps of non-solvent encapsulation method.

\subsection{Light Scattering}

An electromagnetic radiation is combination of oscillating electric and magnetic fields which are perpendicular to each other. When an incident radiation interacts with a particle, electrons of that particle are perturbed 
periodically by electric field of incident radiation with a same frequency. The oscillating disturbance of electrons causes an induced dipole moment and which results molecule to emit its own electromagnetic radiation. The emitted radiation by molecule of particle is at identical frequency of incident radiation and this process named as elastic scattering. Due to the contribution of incident and emitted radiations, travelling light slow down and its direction is bended [34, 35]. Opacity and white appearance of pigments are a consequence of scattering phenomena.

When the electromagnetic radiations of visible spectrum interact with opaque pigment, which has a diameter near the visible radiations wavelength, they are scattered around non-selectively. Opacity is a result of that light scattering and white appearance caused by the interference of scattered radiations. The driving effect on light scattering is the refractive index difference between medium and pigment. Refractive index can be thought as the degree of light-matter interaction.

Mathematical expression of light scattering was described by Gustav Mie in the beginning of $20^{\text {th }}$ century for small spherical particles. He treated the interaction of gold colloids with light in point of scattering, absorption, polarization and color phenomena. It was the first solution on a real case $[1$, 3].

Bohren and Huffman [4] modified the solution of Mie scattering for spherical particles having diameter near visible spectrum wavelength. Their formulation is given in below. 


$$
\begin{aligned}
& \sigma_{\text {ext }}=\frac{2 \pi}{\mathrm{k}^{2}} \sum_{\mathrm{n}=1}^{\infty}(2 \mathrm{n}+1) \operatorname{Re}\left(\mathrm{a}_{\mathrm{n}}+\mathrm{b}_{\mathrm{n}}\right) \\
& \sigma_{\text {scat }}=\frac{2 \pi}{\mathrm{k}^{2}} \sum_{\mathrm{n}=1}^{\infty}(2 \mathrm{n}+1)\left(\left|\mathrm{a}_{\mathrm{n}}+\mathrm{b}_{\mathrm{n}}\right|\right) \\
& \sigma_{\text {ext }}=\sigma_{\text {scat }}+\sigma_{\text {abs }} \\
& \mathrm{x}=\mathrm{ka}=\frac{2 \pi \mathrm{n}_{\text {med }} \mathrm{a}}{\lambda}, \quad \mathrm{n}_{\text {max }}=\mathrm{x}+4 \mathrm{x}^{1 / 3}+2
\end{aligned}
$$

where; $\sigma_{\text {ext }}$ is extinction cross section, $\sigma_{\text {scat }}$ scattering cross section, and $\sigma_{\text {abs }}$ is absorption cross section. $\mathrm{x}$ is the size parameter, $\mathrm{a}$ is the radius of scattering center, and $\lambda$ is wavelength of incident radiation in vacuum. In addition;

$$
\begin{aligned}
& a_{n}=\frac{\mu m^{2} j_{n}(m x)\left[x j_{n}(x)\right]^{\prime}-\mu_{1} j_{n}(x)\left[m x j_{n}(m x)\right]^{\prime}}{\mu m^{2} j_{n}(m x)\left[x h_{n}^{(1)}(x)\right]^{\prime}-\mu_{1} h_{n}^{(1)}(x)\left[m x j_{n}(m x)\right]^{\prime}} \\
& b_{n}=\frac{\mu_{1} j_{n}(m x)\left[x j_{n}(x)\right]^{\prime}-\mu j_{n}(x)\left[m x j_{n}(m x)\right]^{\prime}}{\mu_{1} j_{n}(m x)\left[x h_{n}^{(1)}(x)\right]^{\prime}-\mu h_{n}^{(1)}(x)\left[m x j_{n}(m x)\right]^{\prime}} \\
& {\left[m x j_{n}(m x)\right]^{\prime}=m x j_{n-1}(m x)-n j_{n}(m x)} \\
& {\left[x j_{n}(x)\right]^{\prime}=x j_{n-1}(x)-n j_{n}(x)} \\
& {\left[x h_{n}^{(1)}(x)\right]^{\prime}=x h_{n-1}^{(1)}(x)-n h_{n}^{(1)}(x)} \\
& j_{n}(m x)=\sqrt{\frac{\pi}{2 m x}} J_{n+0.5}(m x), y_{n}(m x)=\sqrt{\frac{\pi}{2 m x}} Y_{n+0.5}(m x) \\
& j_{n}(x)=\sqrt{\frac{\pi}{2 x}} J_{n+0.5}(x), \quad y_{n}(x)=\sqrt{\frac{\pi}{2 x}} Y_{n+0.5}(x)
\end{aligned}
$$




$$
\begin{aligned}
& \mathrm{j}_{0}(m x)=\sin m x / m x, y_{0}(m x)=-\cos m x / m x \\
& j_{0}(x)=\sin x / x, y_{0}(x)=-\cos x / x \\
& j_{1}(m x)=\sin m x /(m x)^{2}-\cos m x / m x, y_{1}(m x)=-\cos m x /(m x)^{2}-\sin m x / m x \\
& j_{1}(x)=\sin x /(x)^{2}-\cos x / x, y_{1}(x)=-\cos x /(x)^{2}-\sin x / x \\
& h_{n}^{(1)}(x)=j_{n}(x)+\operatorname{iy}_{n}(x)
\end{aligned}
$$

where; $a_{n}$ and $b_{n}$ are the scattering coefficients. $m$ is the complex refractive index of the particle relative to that of medium. $\mu$ and $\mu_{1}$ are permeability of particle and medium, respectively. $j_{n}()$ and $h_{n}$ are spherical Bessel and spherical Henkel functions of order $n$, respectively. $h_{n}{ }^{(1)}$ is the derivative term and $h_{n}{ }^{(1)}=j_{n}()+i y_{n}() . J_{n}()$ and $Y_{n}()$ are Bessel functions. Scattering efficiencies were described as the ratio of scattering coefficients to $\pi \mathrm{a}^{2}$ [36]. The solution of Mie is valid for single, perfect spherical and optically isotropic particles [1, 4].

Further researches were done by several workers and with the increase of the ability of computers better mathematical definitions were derived for both spherical and non-spherical particles. Matzler [36] wrote computer programs in order to calculate scattering coefficients and efficiency in MATLAB based on numerical computation.

Scattering efficiency, as a result opacity mainly depends on the shape and size of particle, refractive index difference between medium and particle, wavelength of light, and the number of particles which are acting as scattering centers $[4,5]$. 


\subsection{Emulsions}

Emulsion is a dispersion of liquid droplets (dispersed phase) inside another liquid phase (continuous phase). These two liquids are immiscible in fact, however with the presence of a third component, which is named as emulsifier or surface active agent, it becomes possible to produce stable dispersions. Emulsions have great importance both scientifically and commercially. Some of the industrial applications of emulsions can be listed as; detergents and cleaners, such as soap and dry cleaners; cosmetics and personal care products, such as lotions, creams and hair-sprays; textile dying and at the production steps of fibers; metal processing; production and recycling of paper; ore flotation in mining; foods, such as mayonnaise, chocolate, margarines and their packaging; pharmaceuticals and also especially paints and pigments [8-10, 13, 37-41].

Emulsions can be classified according to the size of dispersed droplets. These are; (i) macroemulsions, (ii) microemulsions, and (iii) nanoemulsions. Macroemulsions are milky white-opaque emulsions with droplet diameter higher than $400 \mathrm{~nm}$. They can be observed by optical microscopy if the refractive indices of liquids are different. The phase having higher refractive index, appear brighter under microscope [11,12]. Microemulsion is the class in which the emulsions have droplet size smaller than $100 \mathrm{~nm}$. With this size microemulsions are transparent dispersions. The third class of emulsions is miniemulsion (nanoemulsion) which has droplet size between macroemulsion and microemulsion (100-400 nm). These emulsions have appearance of white-blue color $[11,12,17,42-44]$. Macroemulsions and miniemulsions are thermodynamically unstable but can be kinetically stable which means that under a certain condition of pressure and temperature their stability is dependent on time. Unlike macroemulsions and miniemulsions, 
microemulsions are thermodynamically stable and this stability is independent of time [45]. On the other hand, the total surface area of dispersed droplets are much higher in microemulsions, hence the amount of required surfactant molecules is much higher.

Emulsions can be also classified according to the nature of dispersed and continuous phase such as; (i) Water-in-Oil (W/O) emulsion, (ii) Oil-in-Water $(\mathrm{O} / \mathrm{W})$, multiple Water-in-Oil-in-Water (W/O/W) emulsion, and Oil-in-Waterin-Oil (O/W/O) emulsion [15]. The type of emulsion also depends on the nature of surfactant whether it is hydrophilic or lipophilic, mass fraction of phases and the preparation method [11].

In this study, $\mathrm{W} / \mathrm{O}$ and $\mathrm{W} / \mathrm{O} / \mathrm{W}$ emulsions were prepared since they facilitate production of multihollow opaque polymer pigments. Therefore, in this section it is dwelled on these emulsions.

\subsubsection{Water-in-Oil (W/O) Emulsion}

In W/O emulsion, water is the inner phase and oil is the continuous (outer) phase. "Oil" term is given for any organic liquid which is water immiscible. In this study, oil phase was the monomer mixture. W/O emulsions are prepared by using surface active agents which are more oil soluble and on the contrary $\mathrm{O} / \mathrm{W}$ emulsions are prepared by water soluble ones. This principle is known as Bancroft rule [46, 47]. In conventional method, as first step, surfactant oil solution is prepared. Then, water is added to oil phase and dispersed with an appropriate mixing method like mechanical mixing or ultrasonic homogenization. There are some other methods reported in 
literature, such as (i) Low-energy emulsification, (ii) High internal phase emulsification (HIPE), (iii) Microchannel emulsification.

Low-energy emulsification method consists of; "Phase inversion temperature (PIT)" and "Catastrophic inversion" methods. In phase inversion temperature method, at an appropriate temperature, the hydrophilic-lipophilic nature of surfactant system changes and this effect results $\mathrm{O} / \mathrm{W}$ emulsion to turn W/O emulsion [13, 17, 48, 49]. Catastrophic inversion method implies the excessive increase of the volume fraction of dispersed phase. Inside a surfactant-monomer system, water is gradually added. After a critical volume fraction is reached, O/W emulsion turns to W/O emulsion [14, 50, 51].

In high internal phase emulsification (HIPE), the volume fraction of dispersed phase is much more than W/O emulsions which are produced by the previously given methods (higher than 0.74 ). With this amount of water the shape of droplets are deformed and separated from each other with a film of continuous phase. HIPE method is widely used for the production of open cellular polymer foams [52-55].

Another emulsification method is membrane emulsification. In this method, dispersed phase is passed through a membrane material. The droplets are formed at the interface of the porous membrane and the continuous phase. Schematic representation of method is given in Figure 2.3. Size and distribution of droplets in W/O emulsions are controlled by the pore size of the membranes. For this purpose metallic, ceramic, glass or polymeric membranes and microchannel devices have been used in literature [56-59]. 


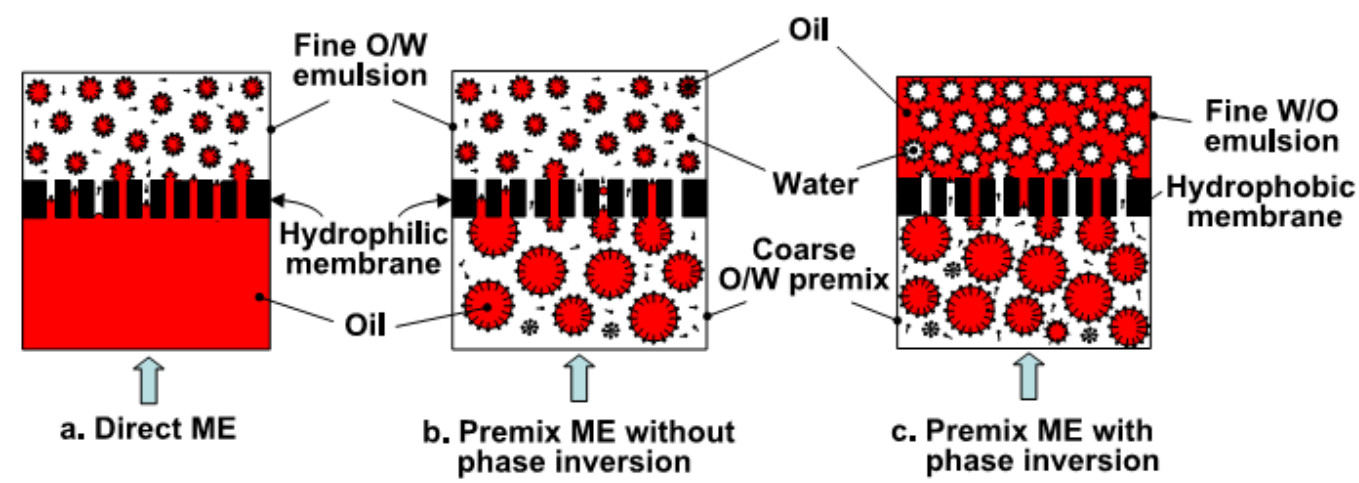

Figure 2.3 Schematic representation of membrane emulsification methods [58].

\subsubsection{Stability of W/O Emulsion}

Stability is a fundamental parameter for an emulsion and can be described as the ability to resist breakdown of the dispersed phase droplets or phase separation. Stability of an emulsion is mainly dependent on; (i) nature of surface active agents, (ii) existence of a steric or electric barrier, (iii) viscosity of the dispersed phase, (iv) viscosity of the continuous phase, (v) size distribution of droplets, (vi) dispersed phase volume fraction, (vii) temperature $[11,12]$, and finally (viii) the density difference of phases $[13$, 14].

Size of droplets in an emulsion directly affects the stability. In thermodynamics, free energy of formation of emulsion is defined by the equation below.

$$
\Delta G_{m}=\Delta A \gamma-T \Delta S^{\text {config. }}
$$


where; $\Delta \mathrm{A}$ is the change in surface area of dispersed phase from one droplet at the beginning to the total area of smaller droplets after emulsification started. $\gamma$ is the $W / O$ interfacial tension. In hear, $\Delta A \gamma$ is the change of surface energy term which is always positive. $T \Delta S^{\text {config. }}$ is the configurational entropy change term and it is also positive since the production of large number of droplets with emulsification. Generally, surface energy term is higher than entropy term ( $\left.\Delta A \gamma>>-T \Delta S^{\text {config. }}\right)$ and it causes $\Delta G_{m}$ to be positive. It means that, the formation of W/O emulsion is nonspontaneous and thermodynamically unfavorable. When the droplet size of an emulsion is reduced to less than approximately $100 \mathrm{~nm}$ the surface energy change term decreases with the dramatic decrease in surface tension and so the surface energy change term becomes lower than the entropy change term. This is the reason why microemulsions are thermodynamically stable [14].

Viscosity of continuous phase is another parameter that affects the stability of W/O emulsion. As the viscosity is increased, the diffusion constant of droplets decrease. This effect causes a reduction in the frequency of collisions $[11,60]$. The relation between viscosity and diffusion for spherical droplets is given by Stokes-Einstein equation (Equation 1.4) [61].

$$
D=\frac{k T}{6 \pi \eta r}
$$

where; $\mathrm{k}$ is the Boltzmann constant, $\mathrm{T}$ is absolute temperature, $\mathrm{r}$ is the radius of droplets, $\eta$ is the viscosity of continuous phase, and $D$ is the diffusion constant. 
In literature, several emulsion breakdown processes have been described. These are; (i) sedimentation or creaming, (ii) Ostwald ripening, (iii) coalescence, (iv) flocculation, and (v) phase inversion. The illustration of instability mechanisms are given in Figure 2.4.

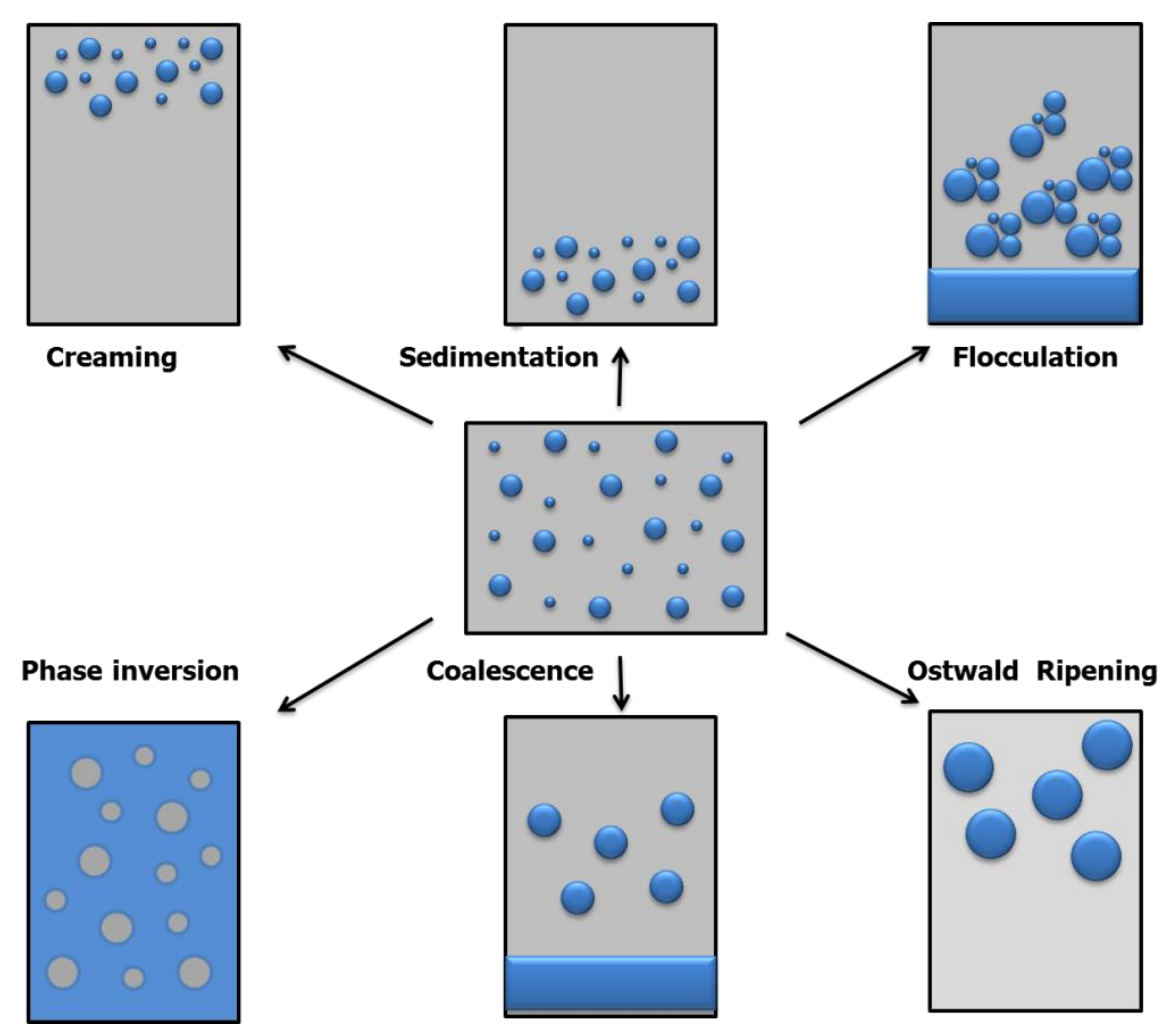

Figure 2.4 Instability mechanisms.

\section{(i) Sedimentation or Creaming}

Sedimentation or creaming occurs when the densities of dispersed droplets and the continuous phase are different. The driving force for sedimentation and creaming is the gravity. When the density of water is higher than oil 
phase (in W/O emulsion) then sedimentation occurs and droplets settle down. Creaming occurs in reverse conditions and water droplets migrate to the top of continuous phase. In literature, rate of sedimentation or creaming is defined by Stokes equation (Equation 2.3) $[13,62,63]$.

$$
\mathrm{v}_{0}=\frac{2 \Delta \rho \mathrm{gr}^{2}}{9 \eta}
$$

where; $\Delta \rho$ is the density difference of water and continuous phase, $r$ is the water droplet radius, $g$ is acceleration due to gravity, and $\eta$ is the viscosity of continuous phase. According to the Stokes equation size of droplet is more important than the other parameters. Rate of sedimentation (or creaming) can be reduced by decreasing size and density difference or increasing the viscosity of continuous phase.

\section{(ii) Ostwald Ripening}

Smaller droplets have higher solubility than larger droplets due to their curvature effect and Laplace pressures. Due to this effect, smaller droplets tend to fuse with larger droplets (molecules of smaller droplets diffuse to larger droplets) and size distribution of droplets shifts to larger ones. Pressure for spherical droplets was first defined by Laplace [64] and Young $[65,66]$. Young-Laplace equation for spherical droplets is given in Equation 2.4 .

$$
\Delta \mathrm{P}=\frac{2 \gamma}{\mathrm{r}}
$$


where; $\Delta \mathrm{P}$ is Laplace pressure, $\gamma$ is the surface tension, and $\mathrm{r}$ is the radius of sphere. According to this equation, pressure difference of droplets is higher if their size difference among them is high. Ostwald ripening occurs in the emulsions which have high polydispersity in size. In addition, Ostwald ripening rate was defined by Lifshitz-Slezov and Wagner (LSW) theory which is given in Equation $2.5[67,68]$.

$$
\omega=\frac{d r^{3}}{d t}=\frac{8 C_{(\infty)} \gamma V_{m} D}{9 p R T}
$$

where; $\omega$ is the frequency of rupture per unit surface of the film, $r$ is the droplet radius after time $t, D$ is the diffusion coefficient of dispersed phase to continuous phase, $\mathrm{C}_{(\infty)}$ is the bulk solubility, $\mathrm{R}$ is the gas constant, $\mathrm{V}_{\mathrm{m}}$ is the molar volume of dispersed phase, $\rho$ is the density of dispersed phase, and $T$ is the temperature.

\section{(iii) Coalescence}

When two emulsion droplets come too close to each other the liquid film between droplets may thin and be disrupted due to the strong van der Waals attraction. In this case, these two droplets fuse and one bigger droplet is formed. Deryaguin and Scherbaker introduced a concept for film stability as disjoining pressure $(\pi)[69]$.

$$
\pi=\pi_{\text {waals }}+\pi_{\text {Elect }}+\pi_{\text {steric }}
$$


Where the three contributions are: Van der Waals; $\pi_{\text {waals }}$, electrostatic repulsion; $\pi_{\text {Elect }}$, and steric repulsion; $\pi_{\text {steric }}$. In order to prevent coalescence electrostatic and steric repulsion of film should be higher than van der Waals attraction $[13,14]$.

In literature, rate of coalescence for an emulsion was expressed by Davies and Rideal [70] based on Smoluchowski theory [11, 71].

$$
\frac{d \bar{V}}{d t}=\frac{4}{3} \frac{V k T}{\eta} e^{-E / k T}
$$

where; $\bar{V}$ is the mean volume of droplet, $\mathrm{V}$ is volume fraction of dispersed phase, $\mathrm{k}$ is the Boltzmann constant, $\mathrm{T}$ is temperature, $\eta$ is viscosity, $E$ is the energy barrier term which includes the effect of electrostatic and steric repulsion effect. As shown in equation; temperature, volume fraction, viscosity and the surfactant directly affect the coalescence instability of W/O emulsion.

\section{(iv) Flocculation}

Flocculation occurs when dispersed droplets aggregate due to lack of sufficient repulsive forces. Flocculation ends up with two possible results, one is the phase separation and the other is creaming or sedimentation $[12,13]$. 


\section{(v) Phase Inversion}

Phase inversion is the change of $\mathrm{W} / \mathrm{O}$ emulsion to $\mathrm{O} / \mathrm{W}$ emulsion and vice versa. There are two mechanisms for phase inversion mentioned in literature. (i) Transitional phase inversion results due to change in conditions such as temperature which affects the solubility of surfactant chains. When the conditions change, the hydrophilic-lipophilic nature of surfactant may also be changed, and more oil soluble surfactant may become more water soluble. The other mechanism is (ii) Catastrophic phase inversion. When the volume fraction of dispersed phase exceeds a critical value, dispersed phase may be inverted to continuous phase.

In literature there are several studies, proposing methods to evaluate the stability of a W/O emulsions and investigating effects of parameters on that stability.

Porras et al. investigated the stability properties of surfactant/decane/water emulsions which were prepared by various combinations of span-tween surfactants. Emulsion droplet size was measured by dynamic light scattering and stability analyzed by back light scattering data variations where stable emulsions did not give back scattering data. Stable nanoemulsions against phase separation were obtained with span-tween combination and ratio of Span 80-Tween 80 (51:49), and Span 20-Tween 80 (62:38). On the contrary, Span 20-Tween 20 (60:40) surfactant systems resulted in quick phase separation. It is shown that obtained nanoemulsions had long term stability for weeks however droplet size was increased with time. It was concluded that dominant mechanisms for size increase are Ostwald ripening and coalescence [16]. 
Peng et al. [17] prepared polyoxyethylene 2-laury ether $\left(\mathrm{C}_{12} \mathrm{E}_{2}, \mathrm{HLB}: 6.0\right)$ and polyoxyethylene 4-lauryl ether $\left(\mathrm{C}_{12} \mathrm{E}_{4}, \mathrm{HLB}\right.$ : 9.7)/isohexadecane/water nanoemulsions by low-energy emulsification method (phase inversion temperature) at mixing temperature of $70{ }^{\circ} \mathrm{C}$. Size of droplets and polydispersity index were measured by dynamic light scattering. Stability was analyzed by looking into change in droplet size with time and polydispersity index. Unstable emulsions had higher polydispersity variation with time. The most stable emulsions were obtained with $\mathrm{C}_{12} \mathrm{E}_{2}: \mathrm{C}_{12} \mathrm{E}_{4}$ ratio of $6: 4$. In addition, the effect of water concentration on size and stability was investigated. As the amount of water was increased from $10 \%$ to $50 \%$, size and the instability of emulsion increased due to the decrease in interfacial film. It was shown that increase in size caused to the increase in Ostwald ripening rate.

Ghannam et al. [72] investigated stability based on the separated amount of water from the emulsion with time. Water-in-diesel fuel emulsions were prepared by using nonionic Triton X-100 (iso-octylphenoxypolyethoxy ethanol) surfactant and high speed mixing method at $15000 \mathrm{rpm}$ for 2 minutes. W/O emulsion with the water content of $10 \%$ had 4 weeks, and $20 \%$ had 10 days stability without water separation. However, as the amounts exceeded $20 \%$, stability was limited to 5 hours. Increase in water concentration caused an increase in the percentage of water separation.

\section{Surfactants}

Surface active agents are amphiphilic molecules that consist of both hydrophilic (polar) and lipophilic (non-polar) groups. The lipophilic portion, 
which is attached with hydrophilic part, is generally a straight or branched hydrocarbon. When surfactant molecules are dissolved in a solvent, after a certain concentration is exceeded molecules tend to aggregate and form oriented structure. That structure is called as "micelle" and minimum required concentration to form micelle is called as "critical micelle concentration". In case when the solvent is water the hydrophilic head of surfactant interact with water via hydrogen or dipole interaction and due to their insoluble nature and van der Waals attraction between each other lipophilic tails aggregate and repelled from aqueous phase in order to minimize free energy. In case when the solvent is oil, reverse micelle formed with repelled hydrophilic head and attracted lipophilic portion. Depending on the structure of lipophilic tail different micelle structures can be formed (Spherical, wormlike and large lamellar). The structure of spherical micelle and reverse micelles are given in Figure 2.5 .

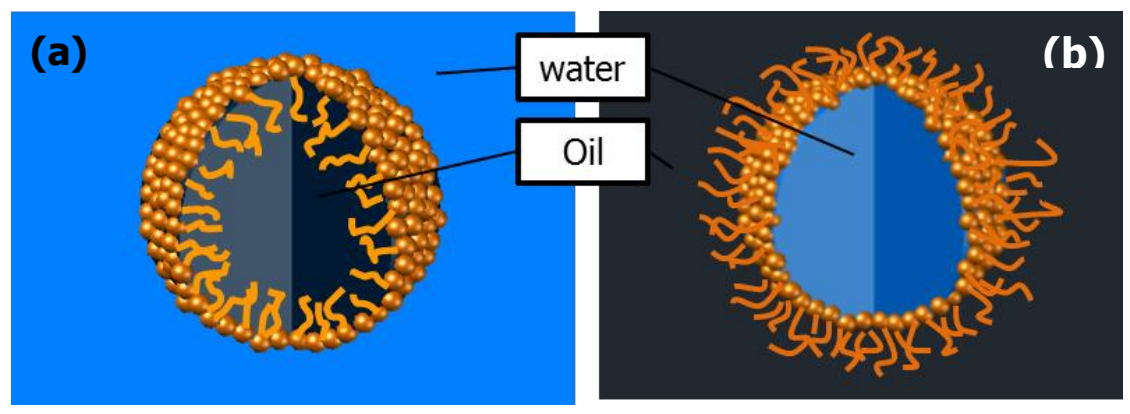

Figure 2.5 Micelle (a) and reverse micelle (b).

Surfactants can be classified according to the nature of hydrophilic portion as; (i) nonionic, (ii) anionic, (or cationic), and (iii) amphoteric surfactants. Anionic surfactants contain negatively charged hydrophilic groups such as; 
carboxyl, sulfonate, phosphate or sulfate. In cationic surfactants, hydrophilic group is a cation such as; amine oxides and quaternary ammonium halides. Amphoteric surfactants contain both negatively and positively charged groups. Nonionic surfactants do not have any charged groups. They provide the required solubility with their content of highly polar groups such as polyoxyethylene $[11,73]$.

The main role of surfactant is to reduce the interfacial free energy by reducing the surface tension of water/oil boundary. Adsorption of surfactant molecules at the interface of two immiscible liquids lower the surface tension and make one phase dispersible in the other phase. Higher the amount of adsorbed surfactant causes a larger the reduction in surface tension. The degree of surfactant adsorption depends on the structure of surfactant molecules and the nature of liquid phases [11, 14, 74]. Foyeke et al. [75] investigated the interfacial properties of lipophilic nonionic surfactants of Span 20, Span 80, Span 83, and Span 85 in mineral oil/water emulsion system. The results showed that increase of bulk concentration of surfactants reduced the interfacial tension.

The amount of surfactant directly influences the dispersed droplet size and W/O emulsion stability. In the literature, most studies concluded that increasing the amount of surfactant reduces the droplet size and increase the emulsion stability $[17,18,76]$.

\section{Hydrophilic-Lipophilic Balance (HLB) concept}

Surfactant selection is significant in order to produce desired type of emulsion whether it is $\mathrm{W} / \mathrm{O}$ or $\mathrm{O} / \mathrm{W}$. According to Bancroft rule it is needed to 
use lipophilic surfactant (more oil soluble) for W/O emulsification and hydrophilic (more water soluble) for O/W. Griffin et al. [20] proposed a semiempirical scale for the selection of appropriate surfactant called "HydrophilicLipophilic Balance (HLB)" number. HLB number is the scale which relates the percentage of hydrophilic to lipophilic groups in the surfactant structure. The required HLB range for particular applications and emulsion types are given in Table 2.2.

Table 2.2 Ranges of HLB and corresponding emulsion and application $[14,77]$.

\begin{tabular}{cc}
\hline HLB Range & Application \\
\hline $1.5-3$ & Anti-foaming agents \\
$3-6$ & Water-in-Oil (W/O) Emulsion \\
$7-9$ & Wetting Agent \\
$8-18$ & Oil-in-Water (O/W) Emulsion \\
$13-15$ & Detergent \\
$15-18$ & Solubilizer \\
\hline
\end{tabular}

The HLB values in Table 2.2 are not certain and may change according to the nature of oil, viscosity, and oil/water ratio [11,49]. Kloet et al. [78] showed that an O/W emulsion formed with kerosene/water ratio of 50:50 and Span 80/Tween surfactant mixture HLB value of 13.9. On the other hand, when kerosene/water ratio was changed to 20:80 with same HLB value this time formed emulsion was W/O. Despite few exceptions HLB value concept is a successful method for surfactant prediction. 
Davies et al. [70] devised a method for calculation of the HLB value of particular surfactants based on the contribution of structural groups. Formula for HLB calculation and the group numbers of used in formula is given in Equation 2.8 and Table 2.3.

HLB $=7+\sum$ (Hydrophilic group numbers) $-\sum$ (Lipophilic group numbers) $(2.8)$

Table 2.3 HLB group numbers [14].

\begin{tabular}{lc}
\hline Surfactant type/group & Group number \\
\hline Hydrophilic & \\
$-\mathrm{COONa}$ & 19.1 \\
$-\mathrm{COO}^{-}$ & 21.2 \\
$-\mathrm{SO}_{4} \mathrm{Na}^{+}$ & 38.7 \\
$\mathrm{~N}$ (tertiary amine) & 9.4 \\
\hline Ester (sorbitan ring) & 6.8 \\
\hline$-\mathrm{O}-$ & 1.3 \\
\hline $\mathrm{CH}-($ sorbitan ring) & 0.5 \\
\hline Lipophilic & \\
\hline$\left(-\mathrm{CH}_{-}\right),\left(-\mathrm{CH}_{2}-\right), \mathrm{CH}_{3}$ & 0.475 \\
\hline Derived & \\
\hline$-\mathrm{CH}_{2}-\mathrm{CH}_{2}-\mathrm{O}$ & 0.33 \\
\hline$-\mathrm{CH}_{2}-\mathrm{CH}_{2}-\mathrm{CH}_{2}-\mathrm{O}-$ & -0.15 \\
\hline
\end{tabular}

HLB number of surfactants has significant effect of both emulsion stability and dispersed droplet size. Al-Sabagh [79] examined the effect of HLB number on the asphalt emulsions by using different surfactants with various 
HLB numbers. Stability of emulsions was defined by batch settling time (time required to $50 \%$ of aqueous phase separation) and coalescence rate. The maximum stability of W/O emulsion was obtained at HLB values of 4-5, and $\mathrm{O} / \mathrm{W}$ emulsion at HLB values of $10-13$ with $8 \%$ of surfactant concentration. For W/O emulsions, as HLB increased from the value of 4.7 to 6.7 , stability decreased and coalescence rate increased.

In literature, many studies concluded that using surfactant mixtures can yield higher emulsion stability performance. Boyd et al. [19] stated that there is a synergetic effect between span 80 and tween 40 surfactant when used as a blend. The lipophilic hydrocarbon chains of Tween 40 which is located in oil phase penetrate with the hydrocarbon chains of Span 80, so that they interact strongly. The illustration of this complex formation is given in Figure 2.6 in the next page.

Song et al. [18] investigated the stability of W/O emulsion by using the change of turbidity ratio data with time. It was stated that the slope of turbidity change with time has direct relation with polydispersity index and higher slope yields less stability. Stability investigation with turbidity was confirmed by percentage phase separation. As surfactant system of Span 80Tween 80 mixture, and as oil phase diesel was used. Experiments showed that surfactant mixtures had higher stability than only Span 80 . The most stable emulsion was obtained with surfactant mixture at HLB value of 6 . Minimum phase separation occurred with the amount of $2.5 \% \mathrm{w} / \mathrm{w}$ surfactant and $10 \% \mathrm{w} / \mathrm{w}$ water. 


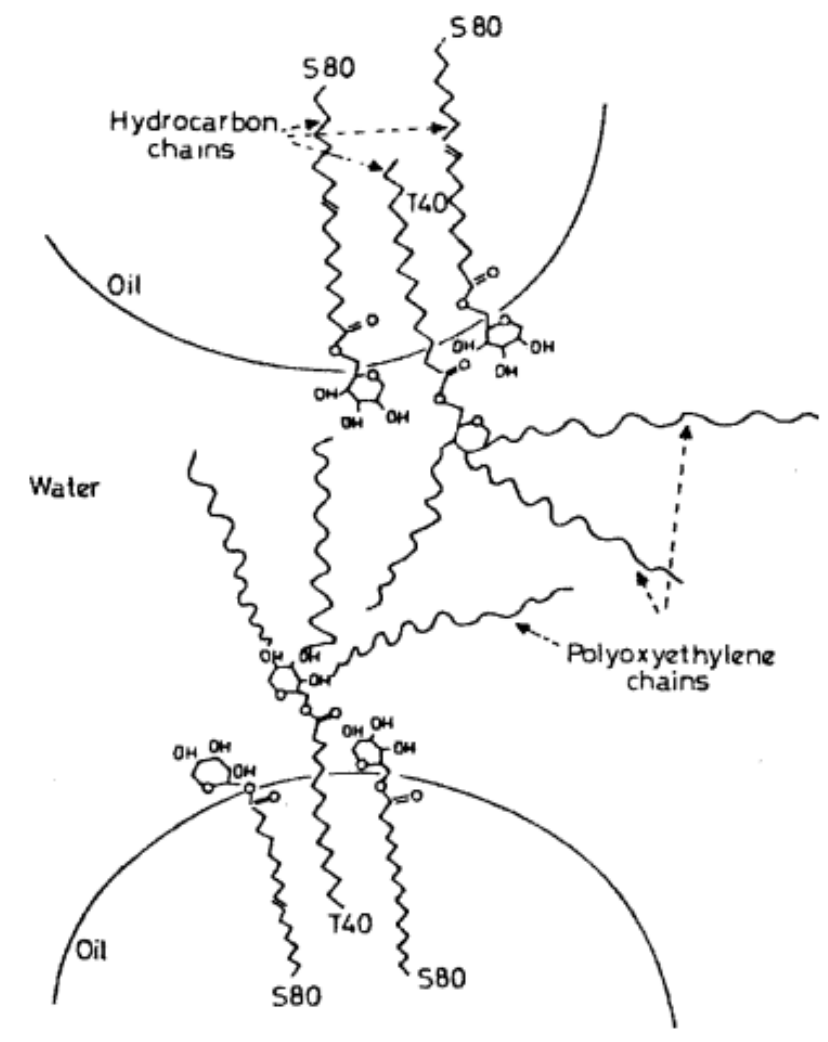

Figure 2.6 Complex formation of Span 80 an Tween 40 surfactants at the water-oil interface [19].

One other effect of HLB value on surfactant blend is the size and polydispersity index (PDI) of dispersed droplets. Peng et al. [17] investigated the change of size and PDI with HLB value. The influence of HLB number of polyoxyethylene 2-laury ether $\left(\mathrm{C}_{12} \mathrm{E}_{2}, \mathrm{HLB}\right.$ : 6.0) and polyoxyethylene 4-lauryl ether $\left(C_{12} E_{4}\right.$, HLB: 9.7) ratios of isohexadecane/water emulsions is shown in Figure 2.7. 


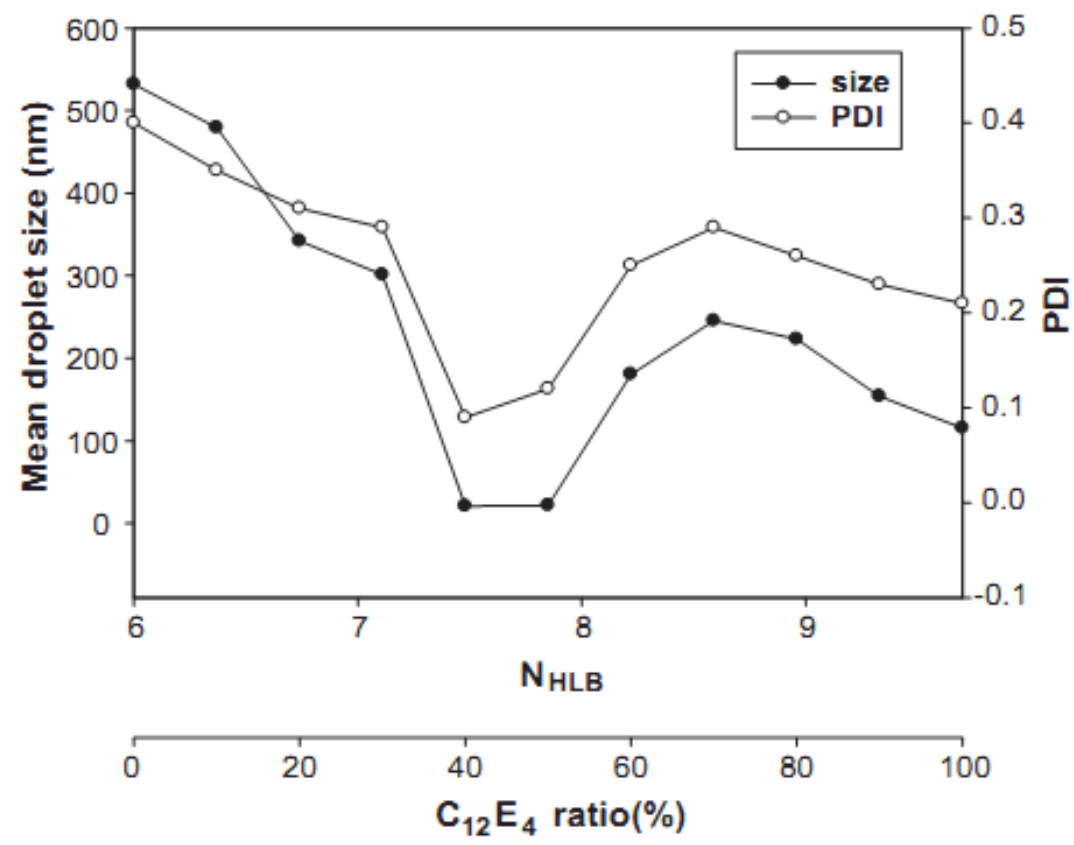

Figure 2.7 Effects of HLB number on particle size and PDI [17].

As shown in Figure 2.7, increase of HLB number up to 7 had a reducing effect on both size and PDI.

\subsubsection{Water-in-Oil-in-Water (W/O/W) Emulsion}

Water-in-Oil-in-Water $(\mathrm{W} / \mathrm{O} / \mathrm{W})$ emulsions are multiple emulsions that combine both W/O and O/W emulsions. W/O/W emulsions are the dispersion of oil globules, which contain relatively smaller water droplets, inside in an aqueous continuous phase. There are two main methods reported in literature for W/O/W emulsification. First is the (i) two-step procedure and the other is (ii) one-step procedure. In both one and two-step processes of 
W/O/W emulsification, nonionic surfactants of Spans and Tweens were widely used [80-82].

In two-step procedure, firstly W/O emulsion is prepared with a low HLB value surfactant(s) by high energy mixing or homogenization and then this emulsion is dispersed in an aqueous phase containing high HLB value surfactant but this time with relatively low energy mixing [83-85]. Dispersions of two-step procedure are given in Figure 2.8.

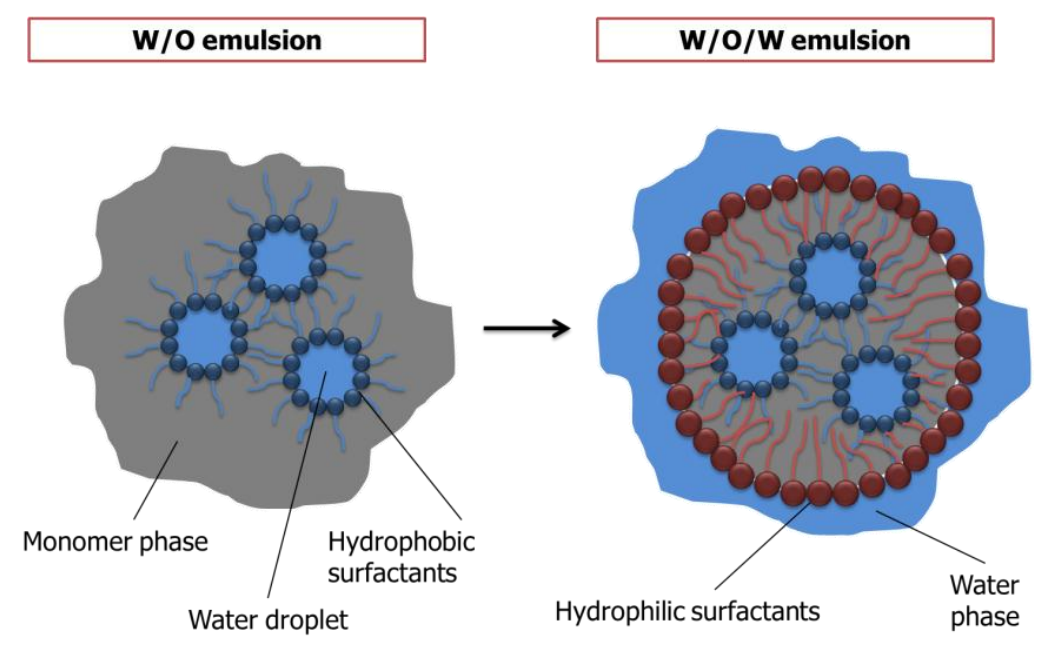

Figure 2.8 Two-step procedure of W/O/W emulsification.

Galam et al. prepared W/O/W emulsions first dispersing water inside oily phase containing dissolved lipophilic Span 80 surfactant by homogenizer at a speed of $35000 \mathrm{rpm}$. Then the prepared primary W/O emulsion was poured slowly into aqueous phase containing Tween 80 , at low speed of mixing. 
One-step W/O/W emulsification method base on the phase inversion phenomena which is a consequence of changing the surfactant affinity by temperature increase. Morais et al. [86] prepared W/O/W emulsions with one-step emulsification process. Oil phase containing lipophilic Span 80, hydrophilic PEG40 hydrogenated castor oil surfactants (HLB value of 9.3 in the mixture) and aqueous phase were heated separately to $85^{\circ} \mathrm{C}$. After that, continuous aqueous phase was slowly added to oil phase with mechanical stirring at $400 \mathrm{rpm}$. In literature, one-step emulsification is generally not preferred because of poor reproducibility and limited instability $[49,86,87]$.

\subsubsection{Stability of Water-in-Oil-in-Water (W/O/W) Emulsion}

W/O/W double emulsions are less stable than single W/O or O/W emulsions due to the existence of nested phases and increased interfaces. Stability of W/O/W emulsion depends on numerous parameters such as; surfactant type and concentration, HLB number, nature of oil, preparation method and conditions, viscosity, and the phase volume ratios [81, 86, 88-94].

Schmidts et al. [95] prepared double emulsions by using Span 80 as lipophilic surfactant and different type of hydrophilic surfactants with various HLB values. The influence of HLB number and hydrophilic surfactant nature on stability of $\mathrm{W} / \mathrm{O} / \mathrm{W}$ emulsion was investigated. It is shown that not only the HLB value but also the chemical structure of surfactant influences the stability of W/O/W emulsions. Jiao et al. [82] investigated the effect of lipophilic and hydrophilic surfactant concentration on oil and external water phase, respectively. Stability was enhanced with increased amount of surfactants up to $20 \%$ for lipophilic Span 83 and $0.1 \%$ Tween 80 . However, 
further increase of concentration had destructive effect on shape of droplets and stability.

There are several pathways described in literature for double emulsion breakdown. One of the possible mechanisms is the coalescence of primary emulsion droplets in case of the lack of the sufficient repulsive forces provided by interfacial film. In this case, dispersed primary droplets combine and bigger droplets are generated. Like internal droplets, oil droplets may also fuse through coalescence $[95,96]$.

The other destabilization mechanisms are related to the migration of internal aqueous phase to external aqueous phase or vice versa. Osmotic pressure gradient between internal and external phases is the driving effect which results in phase transportation. When osmotic pressure is higher in internal phase than in external phase, water droplets migrate through continuous aqueous phase and result to empty oil droplets. In reverse case, when osmotic pressure is lower in internal phase, water passes through inner droplets and causes to swell droplets. Extreme swelling ends up with burst and release of internal phase $[49,96]$.

Laplace pressure effect is the other reason for $\mathrm{W} / \mathrm{O} / \mathrm{W}$ emulsion destruction. As a consequence of curvature effect smaller droplets have higher pressures than larger ones and the continuous aqueous phase. If the interfacial film strength is not sufficient and size difference in inner droplets is large, smaller droplets tent to join to form bigger ones and number of inner droplets decrease. A second possibility is the loss of internal phase due to the Laplace pressure gradient between inner droplets and external aqueous phase. Pressure difference causes the water from the inner droplets to diffuse to 
outer phase. Water transportation from inner to outer phase turns the double W/O/W emulsion to regular O/W emulsion [49, 96]. Some possible destabilization mechanisms for W/O/W emulsion are given in Figure 2.9.

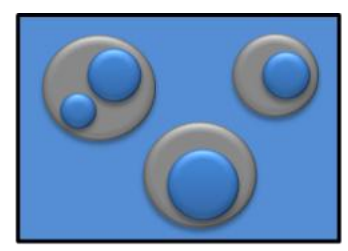

Coalescence, Ostwald ripening of water droplets

Coalescence of oil droplets

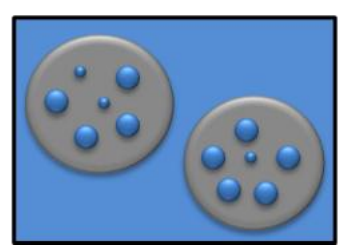

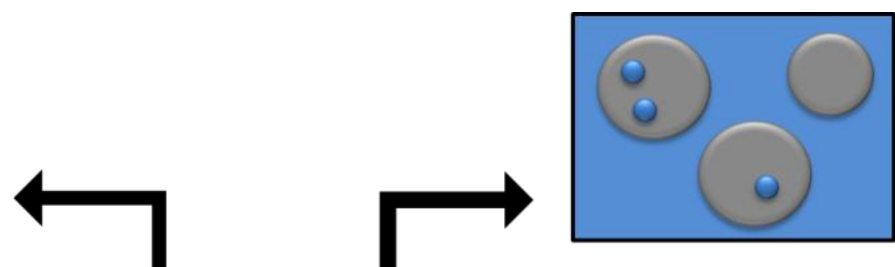

Water migration from inner to outer phase

Water migration from outer to inner phase
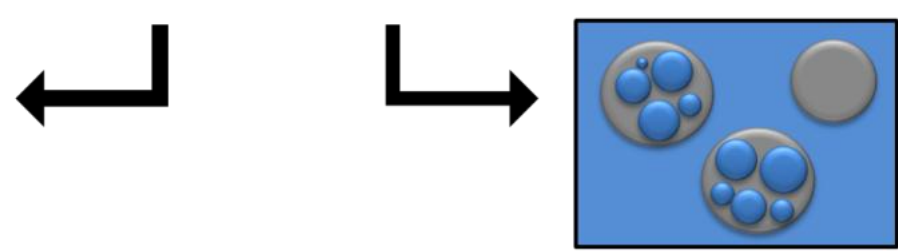

Figure 2.9 Possible destabilization mechanisms for W/O/W emulsion.

Several approaches have been proposed in literature to overcome W/O/W emulsion instability. Studies have been mainly focused on modifying the nature of phases by increasing viscosity in order to prevent water diffusion, enhancement of the stability of primary or double emulsion interface, and regulating osmotic pressure of inner water phase by using additives to balance Laplace pressure effect [89]. 
The influence of electrolytes such as $\mathrm{NaCl}, \mathrm{MgSO}_{4}$ and other additives such as sugars and proteins was investigated in several studies due to osmotic pressure effect on emulsion stability [97-100]. Increase in osmotic active agent concentration increased the osmotic pressure of internal droplets and have provided enhanced stability. However, with further increase in concentration, osmotic pressure effect became dominant and emulsion was destabilized by swelling droplets [82]. Another alternative to improve emulsion stability is using amphiphilic polymeric surfactants. Coverage of droplet interface by polymeric surfactants enhances the stability due to their strong steric stabilization capacities. In addition they provide elasticity to interfacial film and prevent droplet coalescence [101-103]. Another way to increase stability is increasing external phase viscosity by using thickeners $[97,104-106]$.

\subsection{Polymerization of W/O/W Emulsion}

Polymerization of $\mathrm{W} / \mathrm{O} / \mathrm{W}$ emulsions is widely used to produce hollow structured particles. These particles have numerous application areas such as; drug delivery systems [8], foods [9], cosmetics [10], and microcapsules [107]. In literature, polymerization was preformed usually by free radical polymerization method. Lee et al. [108] produced multihollow structured poly(methyl methacrylate) microcapsules with suspension polymerization by using thermal initiator. Instead of hydrophilic surfactant W/O/W emulsion was formed with hydrophilic polyvinyl alcohol polymer. SEM micrographs of produced multihollow polymer particles are given in Figure 2.10. 


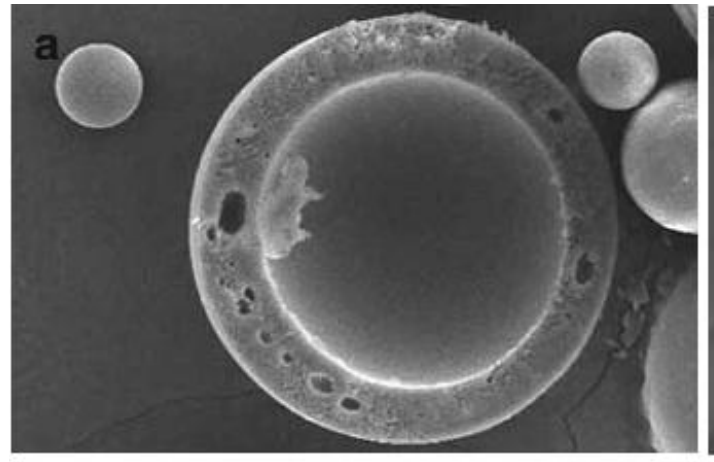

$30 \mu \mathrm{m}$

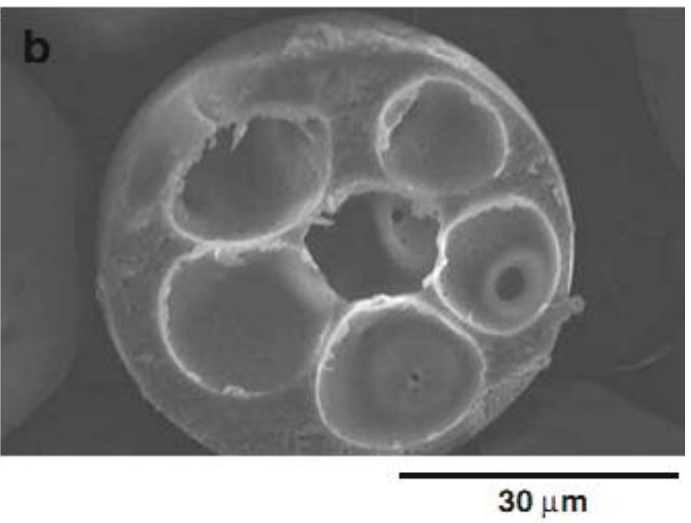

$30 \mu \mathrm{m}$

Figure 2.10 Hollow polymer particles produced in the study of Lee et al. [108].

Kim et al. [106] studied the influence of thickener on the hollow structure. Urethane acrylate (UA) was used as thickener and dissolved in monomer phase in order to increase oil viscosity. They concluded that as the UA concentration was increased, number of hollows obtained after polymerization increased. Higher viscosity enhanced W/O/W emulsion stability and avoided water move from inner to outer phase.

Studies showed that degree of crosslinking has a considerable effect on stability during polymerization. Kim et al. [109] produced ethylene glycol dimethacrylate crosslinked multihollow polymethyl methacrylate polymer particles. It was reported that as the degree of crosslinking was increased the ability of water (and water soluble ingredients) entrapment increased due to the quick formation of polymer network in initial stage. In Figure 2.11, optical microscope images of hollow particles with different crosslinker concentrations are given. 

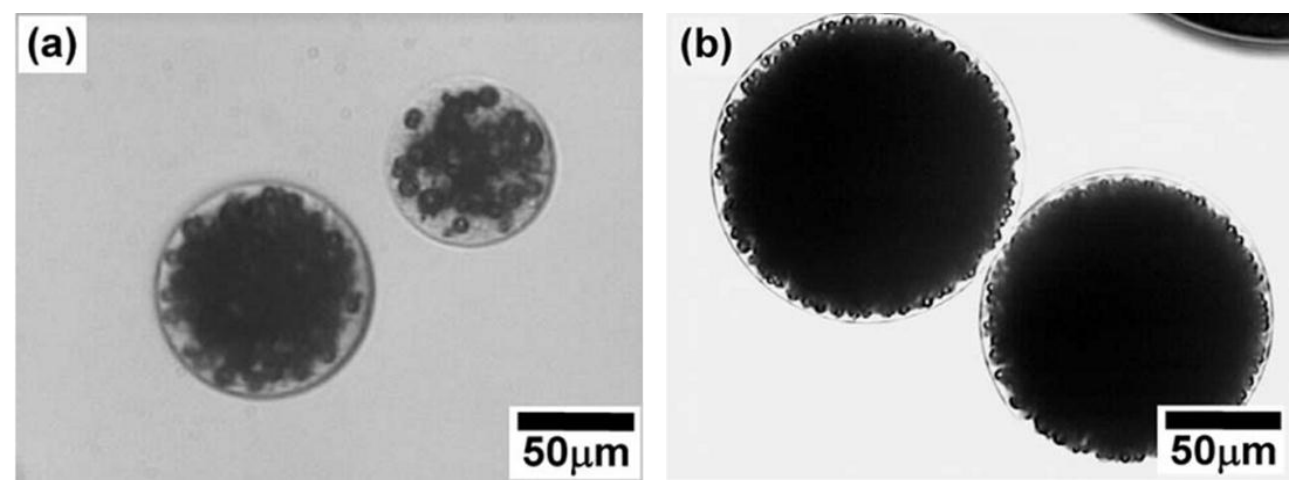

Figure 2.11 Optical microscope images of multihollow PMMA microcapsules (a) $10 \% \mathrm{w} / \mathrm{w}$ EGDMA and (b) $50 \% \mathrm{w} / \mathrm{w}$ EGDMA [109]. 


\section{CHAPTER 3}

\section{EXPERIMENTAL}

In this chapter, the materials used in experiments are described. Furthermore, the steps of the procedure for producing of opaque polymer pigment are explained in detail. The characterization methods used are also given.

\subsection{Materials}

- Methyl methacrylate (MMA)

- Ethylene glycol dimethacrylate (EGDMA)

- Sorbitan monooleate (Span 80)

- Polyoxyethylene (20) sorbitan monooleate (Tween 80)

- Polyoxyethylene (40) isooctylphenyl ether (Triton X-405)

- Polyvinylpyrrolidone (PVP)

- 2,2'azobisisobutyronitrile (AIBN)

- Poylstyrene (PS)

\subsubsection{Monomers}

Methyl methacrylate (MMA) was used as the main monomer for synthesizing the polymer backbone. MMA was selected because of better optical properties of poly(methyl methacrylate) (PMMA). High light transmittance, 
high light deterioration resistance, high Abbe number (lower wavelength dependence of refractive index) and lower birefringence (uniformity of refractive index due to the isotropic structure) can be listed as optical characteristics of PMMA $[110,111]$. Besides these properties, PMMA has high chemical resistance and weathering corrosion resistance $[112,113]$. Due to these characteristics PMMA is widely used in optical devices and coatings. MMA is a colorless and transparent liquid with sharp distinctive odor. Properties and structural formula of MMA (Merck) are given in Table 3.1 and Figure 3.1 , respectively.

Table 3.1 Properties of MMA used in this study.

\begin{tabular}{|l|l|}
\hline Chemical formula & $\mathrm{CH}_{2}=\mathrm{C}\left(\mathrm{CH}_{3}\right) \mathrm{COOCH}_{3}$ \\
\hline Molecular weight (g/mole) & 100.12 \\
\hline Density $\left(\mathbf{g} / \mathbf{c m}^{\mathbf{3}}\right)\left(\mathbf{2 5}^{\circ} \mathbf{C}\right)$ & 0.94 \\
\hline Refractive index & 1.4118 \\
\hline Viscosity $\left(\mathbf{2 0}^{\circ} \mathbf{C}\right)$ & $0.6 \mathrm{mPa} . \mathrm{s}$ \\
\hline
\end{tabular}<smiles>C=C(C)C(=O)OC</smiles>

Figure 3.1 Structural formula of MMA. 
Ethylene glycol dimethacrylate (EGDMA) was used as crosslinking agent for the synthesis of polymer particles. EGDMA is widely used as the crosslinker of PMMA. EGDMA (Merck) is a transparent liquid. Properties and structural formula of EGDMA used in this study are given in Table 3.2 and Figure 3.2, respectively.

Table 3.2 Properties of EGDMA used in this study.

\begin{tabular}{|l|l|}
\hline Chemical formula & $\mathrm{CH}_{2}=\mathrm{C}\left(\mathrm{CH}_{3}\right) \mathrm{COOCH}_{2} \mathrm{CH}_{2} \mathrm{OCOC}\left(\mathrm{CH}_{3}\right)=\mathrm{CH}_{2}$ \\
\hline Molecular weight (g/mole) & 198.22 \\
\hline Density $\left(\mathbf{g} / \mathbf{c m}^{\mathbf{3}}\right)\left(\mathbf{2 5}{ }^{\circ} \mathbf{C}\right)$ & 1.051 \\
\hline Refractive index & 1.454 \\
\hline Viscosity $\left(\mathbf{2 5}^{\circ} \mathbf{C}\right)$ & 3.45 \\
\hline
\end{tabular}<smiles>C=C(C)C(=O)OCCOC(=O)C(=C)C</smiles>

Figure 3.2 Structural formula of EGDMA.

\subsubsection{Surfactants}

Surfactants were used to form micelles in the emulsion preparation steps. Sorbitan monooleate (Span 80) was used as primary surfactant in preparation of "Water-in-Oil" (W/O) emulsion. Span 80, fatty acid ester of 
sorbitan, is a brown viscous liquid. Span 80 is a monomer soluble surfactant with hydrophobic character and it has "Hydrophilic-Lipophilic Balance Value" (HLB) of 4.3. Properties and structural formula of Span 80 (Sigma Aldrich) are given in Table 3.3 and Figure 3.3, respectively.

Table 3.3 Properties of Span 80 used in this study.

\begin{tabular}{|l|l|}
\hline Chemical formula & $\mathrm{C}_{24} \mathrm{H}_{44} \mathrm{O}_{6}$ \\
\hline Molecular weight (g/mole) & 428.61 \\
\hline Density $\left(\mathbf{g} / \mathbf{c m}^{\mathbf{3}}\right)\left(\mathbf{2 5}^{\circ} \mathbf{C}\right)$ & 0.994 \\
\hline Refractive index & 1.48 \\
\hline Viscosity $\left(\mathbf{2 5}^{\circ} \mathbf{C}\right)$ & $1200-2000 \mathrm{mPa} . \mathrm{s}$ \\
\hline
\end{tabular}

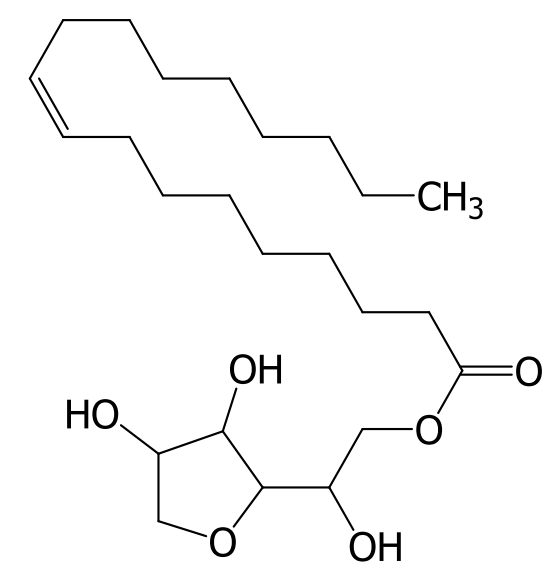

Figure 3.3 Structural formula of Span 80 .

Polyoxyethylene (20) sorbitan monooleate (Tween 80) was used as cosurfactant for preparation of W/O emulsion with Span 80 . Tween 80 is a polyethylene sorbitol ester and a nonionic surfactant like Span 80 . Tween 80 
is a hydrophilic surfactant with a HLB value of 15 . It is a viscous liquid with a color of clear yellow. Properties and structural formula of Tween 80 (Sigma Aldrich) used in this study are given in Table 3.4 and Figure 3.4, respectively.

Table 3.4 Properties of Tween 80 used in this study.

\begin{tabular}{|l|l|}
\hline Chemical formula & $\mathrm{C}_{64} \mathrm{H}_{124} \mathrm{O}_{26}$ \\
\hline Molecular weight (g/mole) & 1310 \\
\hline Density $\left(\mathbf{g} / \mathbf{c m}^{3}\right)\left(\mathbf{2 5}^{\circ} \mathbf{C}\right)$ & 1.07 \\
\hline Refractive index & 1.473 \\
\hline Viscosity $\left(\mathbf{2 5}^{\circ} \mathbf{C}\right)$ & $400-620 \mathrm{mPa} . \mathrm{s}$ \\
\hline
\end{tabular}

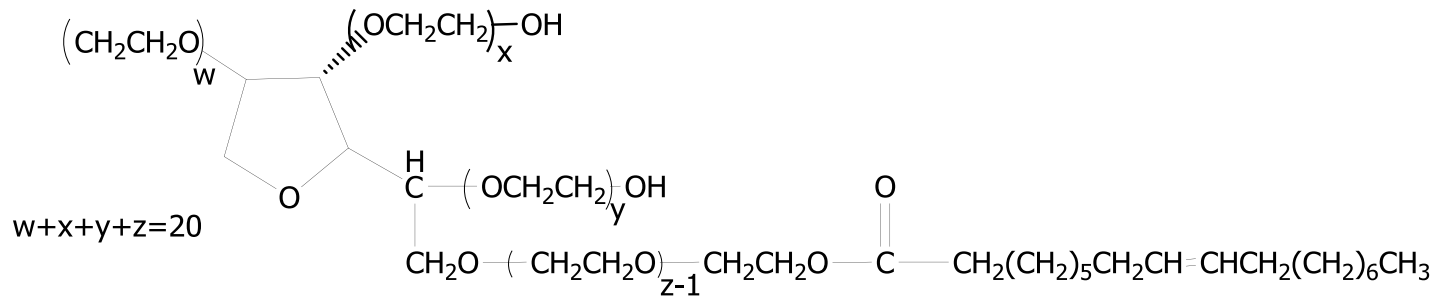

Figure 3.4 Structural formula of Tween 80 .

With regard to its similar chemical structure, Tween 80 is often used in combination with Span 80 . Span 80 and Tween 80 are widely used in food, cosmetics and pharmaceutical applications.

One of the other surfactant used in this study is Polyoxyethylene (40) isooctylphenyl ether (Triton X-405). It is used in the preparation step of "Water-in-Oil-in-Water" (W/O/W) emulsion. Triton X-405 is obtained by the 
reaction of octylphenol with ethylene oxide. It is a nonionic hydrophilic surfactant with an HLB value of 17.6. Properties and structural formula of Triton X-405 (Sigma Aldrich - 70\% in $\mathrm{H}_{2} \mathrm{O}$ ) are given in Table 3.5 and Figure 3.5 , respectively.

Table 3.5 Properties of Triton X-405 used in this study.

\begin{tabular}{|l|l|}
\hline Chemical formula & $\mathrm{C}_{33} \mathrm{H}_{60} \mathrm{O}_{10.5}$ \\
\hline Molecular weight (g/mole) & 624 \\
\hline Density $\left.\left(\mathbf{g} / \mathbf{c m}^{\mathbf{3}}\right) \mathbf{( 2 5}^{\circ} \mathbf{C}\right)$ & 1.096 \\
\hline Refractive index & 1.49 \\
\hline Viscosity (25 $\left.{ }^{\circ} \mathbf{C}\right)$ & $490 \mathrm{mPa} . \mathrm{s}$ \\
\hline
\end{tabular}

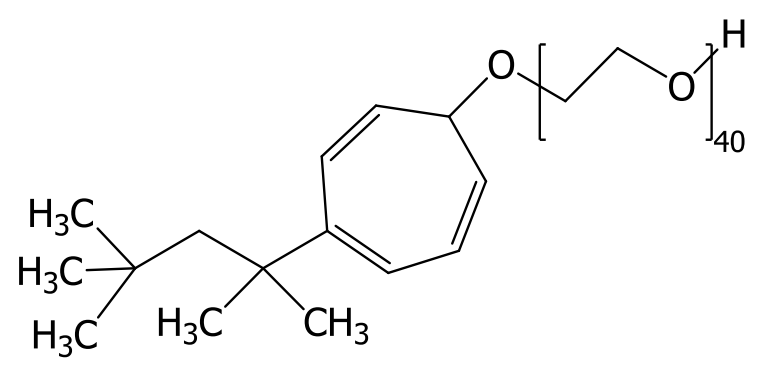

Figure 3.5 Chemical structure of Triton X-405.

\subsubsection{Stabilizer}

Polyvinylpyrrolidone (PVP) is used in study as stabilizer for "Water-in-Oil-inWater" (W/O/W) emulsion. The molecular weight of PVP was 1300000. Chemical structure of PVP is given in Figure 3.6. 


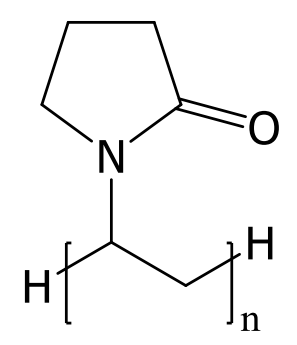

Figure 3.6 Chemical structure of PVP.

\subsubsection{Initiator}

In this study, 2,2'azobisisobutyronitrile (AIBN) was used as free radical thermal initiator for polymerization reactions. AIBN is in the form of crystalline powder with white color. Initiation temperature range of AIBN is 50-70 ${ }^{\circ} \mathrm{C}$. Chemical structure of AIBN is given in Figure 3.7.

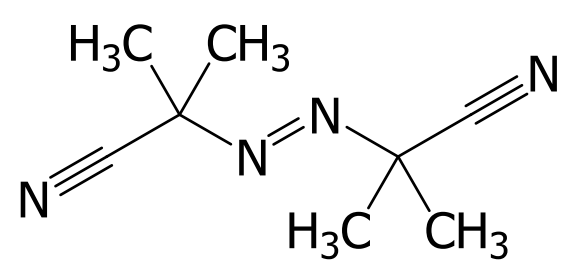

Figure 3.7 Chemical structure of AIBN.

\subsubsection{Thickener}

In this study, $10 \% \mathrm{w} / \mathrm{w}$ MMA solution of polystyrene (PS) was used as thickener to increase the viscosity of monomer solution. 


\subsection{Procedure}

In this study, experiments of opaque polymer synthesis were carried out in four main steps; these are (i) preparation of W/O emulsion, (ii) preparation of W/O/W emulsion, (iii) stabilization of W/O/W emulsion, (iv) polymerization of $\mathrm{W} / \mathrm{O} / \mathrm{W}$ emulsion. Synthesized pigments were then mixed with a water based resin. Detailed descriptions of these steps are given below. In every step of experiments various characterization methods were performed. General flow diagram of procedure is shown in Figure 3.8.

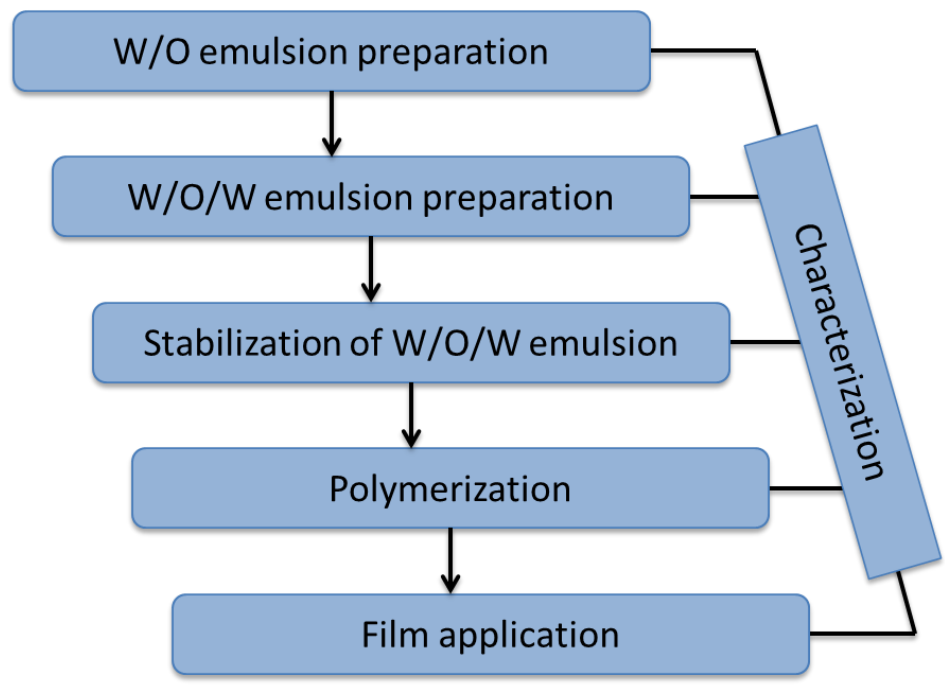

Figure 3.8 General flow diagram of experimental procedure.

\subsubsection{Preparation of Water-in-Oil Emulsion}

W/O/W double emulsions were prepared in two-step procedure. First one was the preparation of $\mathrm{W} / \mathrm{O}$ emulsion. The aim was forming very fine water droplets, which were encapsulated by micelles, inside the monomer phase. After polymerization and drying, these water droplets would form the hollows of opaque pigment. The flow diagram and experimental setup of first step 
are shown in Figure 3.9 and Figure 3.10, respectively. Briefly, monomer mixture of $5 \mathrm{~g}$ MMA and $5 \mathrm{~g}$ EGDMA was prepared first by magnetic stirring at $400 \mathrm{rpm}$ for 15 minutes in a $25 \mathrm{ml}$ erlenmeyer flask. Oil soluble free radical initiator (AIBN) was added to monomer mixture and dissolved with further mixing of 15 minutes. Then, surfactant mixture of Span 80 and Tween 80 were added to prepared monomer mixture and dispersed for 30 minutes at $400 \mathrm{rpm}$ by magnetic stirrer. The ratio of the binary mixture of span 80 and Tween 80 mixture was estimated according to HydrophilicLipophilic Balance value concept. HLB value of surfactant mixture was calculated by using Equation $3.1[20,21]$.

$\mathrm{HLB}_{\text {mix }}=\mathrm{x}_{1} \mathrm{HLB}_{1}+\mathrm{x}_{2} \mathrm{HLB}_{2}$

where; $\quad \mathrm{HLB}_{\text {mix }}$ : HLB value of surfactant mixture.

$\mathrm{x}_{1}$ : weight fraction of surfactant 1 .

$\mathrm{x}_{2}$ : weight fraction of surfactant 2 .

$\mathrm{HLB}_{1}$ : HLB value of surfactant 1.

$\mathrm{HLB}_{2}$ : HLB value of surfactant 2.

The HLB values of surfactant mixture were fixed at 5, 6, 7, 8 and 9. The ratios of binary surfactant mixtures are given in Table 3.6.

Table 3.6 Surfactant ratios at given HLB values.

\begin{tabular}{|c|c|c|c|c|c|}
\hline $\begin{array}{c}\text { Surfactant composition/HLB } \\
\text { value }\end{array}$ & HLB 5 & HLB 6 & HLB 7 & HLB 8 & HLB 9 \\
\hline Span $80:$ Tween $80(\% \mathrm{w} / \mathrm{w})$ & $93: 7$ & $84: 16$ & $75: 25$ & $65: 35$ & $56: 44$ \\
\hline
\end{tabular}




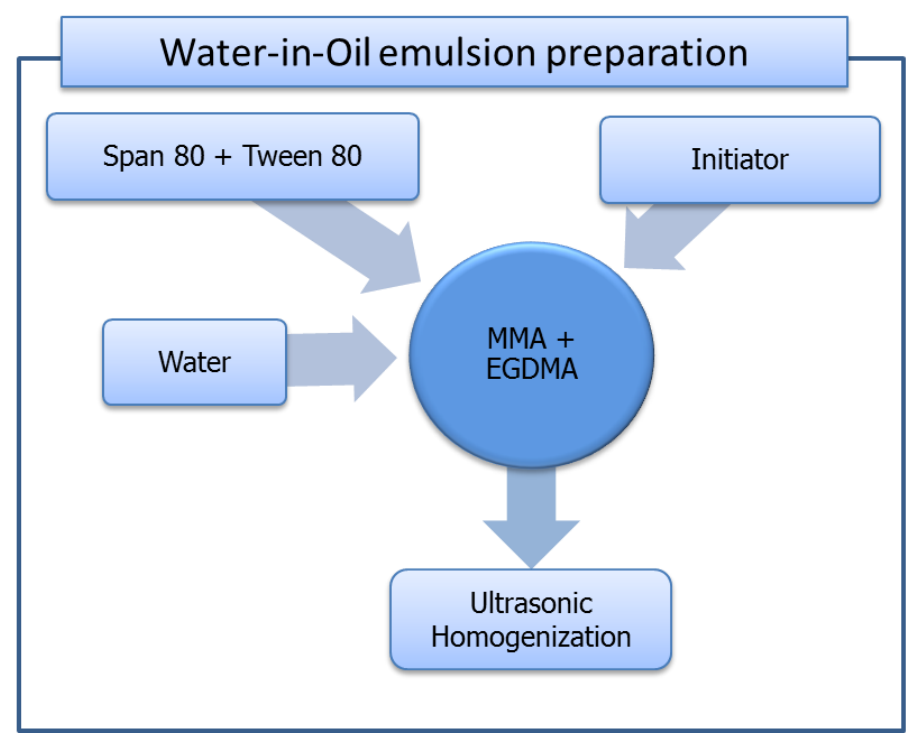

Figure 3.9 Flow diagram of W/O emulsion preparation step.

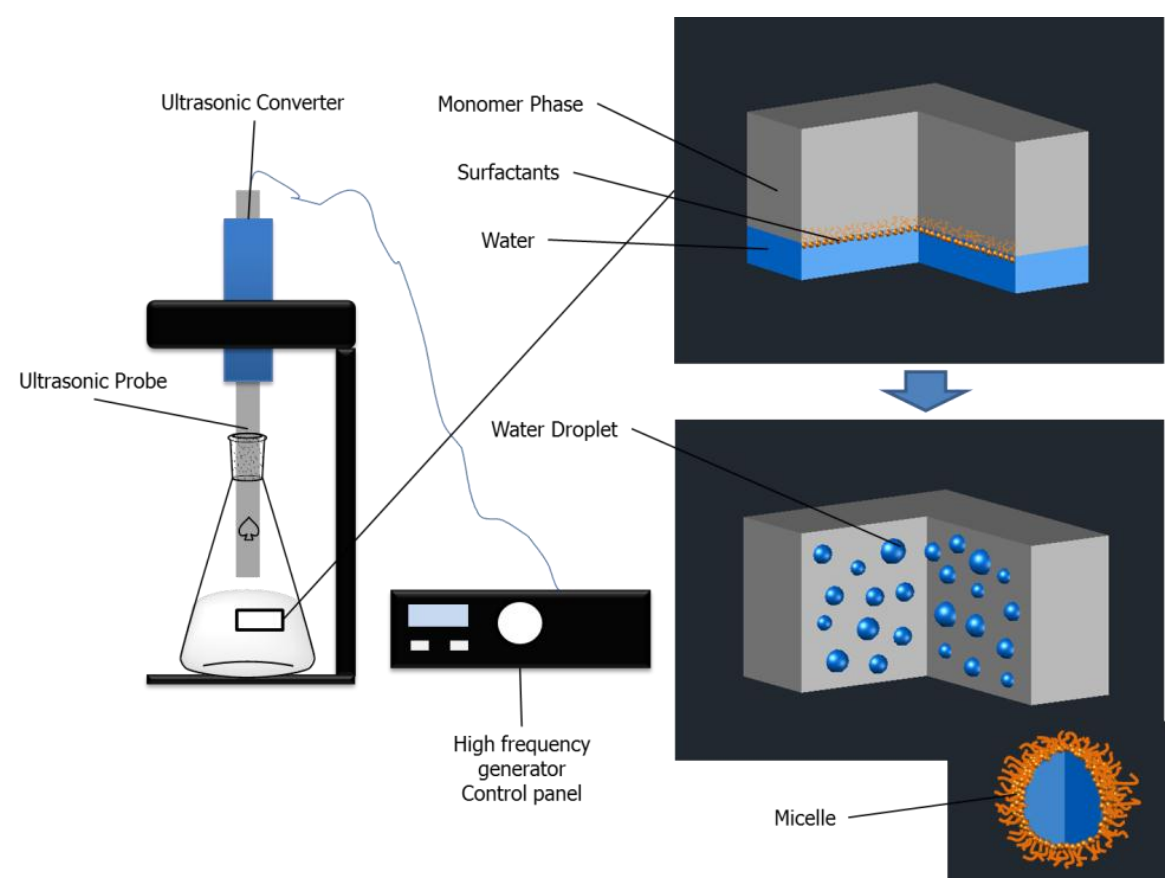

Figure 3.10 Experimental setup of W/O emulsion preparation step. 
After preparation of monomer phase, distilled deionized water was added to mixture drop by drop by using a syringe. The amount of surfactant mixture and water used in experiments was varied to investigate the stability and size characteristics of W/O emulsions. For this aim, ternary phase diagrams were prepared to visualize the stable region for monomer, surfactant and water (M/S/W) composition. Phase diagrams were generated by preparing W/O emulsions with different ratios of $\mathrm{M} / \mathrm{S} / \mathrm{W}$. The compositions of $\mathrm{W} / \mathrm{O}$ emulsions are given in Table 3.7.

After addition of water to monomer phase, the mixture was ultrasonically (US) homogenized (Bandalin Sonopuls HD 2200, with maximum power of $200 \mathrm{~W}$ ). In order to investigate the effect of US mixing parameters on water droplet size of W/O emulsions, sonication was done with various power and time. During sonication, energy input into the mixture caused the temperature of medium to increase dramatically. Temperature increase has negative effects on W/O emulsions such as monomer loss due to evaporation and degradation of thermal initiator before polymerization step. For these reasons, sonication of mixtures was done with cold water bath to avoid sudden temperature increase. After sonication, milky white appeared W/O emulsions were obtained. 
Table 3.7 Composition of prepared W/O emulsions.

\begin{tabular}{|c|c|c|c|c|c|c|c|c|c|c|}
\hline \multirow{2}{*}{$\begin{array}{l}\text { MMA } \\
(\mathrm{g})\end{array}$} & \multirow{2}{*}{$\begin{array}{c}\text { EGDMA } \\
(\mathbf{g})\end{array}$} & \multirow{2}{*}{$\begin{array}{l}580 \\
(g)\end{array}$} & \multirow{2}{*}{$\begin{array}{l}\text { T80 } \\
\text { (g) }\end{array}$} & \multirow{2}{*}{$\begin{array}{c}\text { Water } \\
(\mathrm{g})\end{array}$} & \multicolumn{3}{|c|}{$\%$ ratio of } & \multirow{2}{*}{$\mathbf{s} / \mathbf{w}^{*}$} & \multirow{2}{*}{$\mathbf{w} / \mathbf{m} * *$} & \multirow{2}{*}{ 呈 } \\
\hline & & & & & $\mathbf{s}$ & $\mathbf{m}$ & $\mathbf{w}$ & & & \\
\hline 5.0 & 5.0 & 0.82 & 0.43 & 4.0 & 8.2 & 65.6 & 26.2 & 0.125 & 0.40 & 8 \\
\hline 5.0 & 5.0 & 0.82 & 0.43 & 3.5 & 8.5 & 67.8 & 23.7 & 0.125 & 0.35 & 8 \\
\hline 5.0 & 5.0 & 0.82 & 0.43 & 3.0 & 8.8 & 70.1 & 21.1 & 0.126 & 0.30 & 8 \\
\hline 5.0 & 5.0 & 0.82 & 0.43 & 2.5 & 9.1 & 72.7 & 18.2 & 0.125 & 0.25 & 8 \\
\hline 5.0 & 5.0 & 0.82 & 0.43 & 2.0 & 9.4 & 75.5 & 15.1 & 0.125 & 0.20 & 8 \\
\hline 5.0 & 5.0 & 0.82 & 0.43 & 1.5 & 9.8 & 78.4 & 11.8 & 0.125 & 0.15 & 8 \\
\hline 5.0 & 5.0 & 0.82 & 0.43 & 1.0 & 10.2 & 81.6 & 8.2 & 0.125 & 0.10 & 8 \\
\hline 5.0 & 5.0 & 0.82 & 0.43 & 0.5 & 10.6 & 85.1 & 4.3 & 0.125 & 0.05 & 8 \\
\hline 5.0 & 5.0 & 0.98 & 0.52 & 2.0 & 11.1 & 74.0 & 14.9 & 0.150 & 0.20 & 8 \\
\hline 5.0 & 5.0 & 0.82 & 0.43 & 2.0 & 9.4 & 75.5 & 15.1 & 0.125 & 0.20 & 8 \\
\hline 5.0 & 5.0 & 0.65 & 0.35 & 2.0 & 7.7 & 76.9 & 15.4 & 0.100 & 0.20 & 8 \\
\hline 5.0 & 5.0 & 0.98 & 0.52 & 2.5 & 10.7 & 71.4 & 17.9 & 0.150 & 0.25 & 8 \\
\hline 5.0 & 5.0 & 0.82 & 0.43 & 2.5 & 9.1 & 72.7 & 18.2 & 0.125 & 0.25 & 8 \\
\hline 5.0 & 5.0 & 0.65 & 0.35 & 2.5 & 7.4 & 74.1 & 18.5 & 0.100 & 0.25 & 8 \\
\hline 5.0 & 5.0 & 2.09 & 1.11 & 2.2 & 21.0 & 65.0 & 14.0 & 0.32 & 0.22 & 5 \\
\hline 5.0 & 5.0 & 2.09 & 1.11 & 2.2 & 21.0 & 65.0 & 14.0 & 0.32 & 0.22 & 6 \\
\hline 5.0 & 5.0 & 2.09 & 1.11 & 2.2 & 21.0 & 65.0 & 14.0 & 0.32 & 0.22 & 7 \\
\hline 5.0 & 5.0 & 2.09 & 1.11 & 2.2 & 21.0 & 65.0 & 14.0 & 0.32 & 0.22 & 8 \\
\hline 5.0 & 5.0 & 2.09 & 1.11 & 2.2 & 21.0 & 65.0 & 14.0 & 0.32 & 0,22 & 9 \\
\hline
\end{tabular}

*s/w: Surfactant to monomer ratio.

$* * \mathbf{w} / \mathbf{m}$ : Water to monomer ratio. 


\subsubsection{Preparation of Water-in-Oil-in-Water Emulsion}

Prepared W/O emulsion in first step was then used to generate Water-in-Oilin-Water emulsion. Aqueous solution of Triton-X 405 was used as continuous phase of W/O/W emulsion. In a beaker, $60 \mathrm{~g}$ of Triton X-405 solution with a concentration of $5 \% \mathrm{w} / \mathrm{w}$ (of total solution) was prepared by magnetic stirring at $400 \mathrm{rpm}$ for 2 hours and at ambient temperature. W/O emulsion (13.25 g) was slowly added to Triton-X 405 solution with mechanical mixing. In order to avoid foaming of solution, W/O emulsion was added while mixing at $600 \mathrm{rpm}$ and the speed was gradually increased up to $1250 \mathrm{rpm}$ in 1 minute. After addition of W/O emulsion, mixing was continued to be stirred for further 4 minutes more. The effect of the concentration of Triton X-405 solution, mixing speed and time were examined. Flow diagram of this step and illustration of W/O/W emulsion are given in Figure 3.11.

The aim in this step was forming monomer droplets which were containing smaller water droplets inside it. Surfactant was used to generate spherical micelles and monomer droplets were encapsulated by these micelles. After W/O/W emulsions were prepared, samples were taken and investigated under optical microscope to prove generation of multiple emulsions. The appearance of $\mathrm{W} / \mathrm{O} / \mathrm{W}$ emulsions was milky white. 


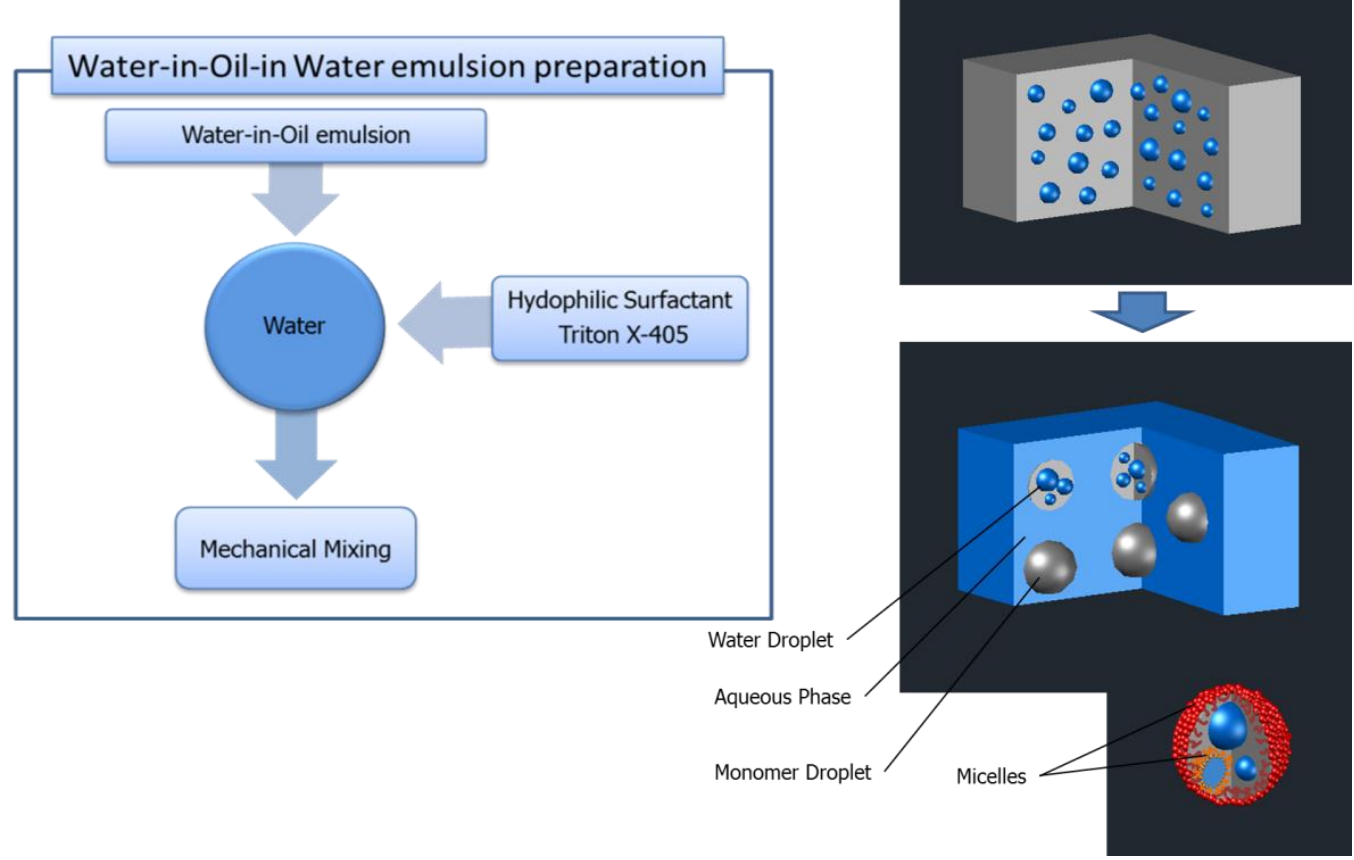

Figure 3.11 Flow diagram and illustration of W/O/W emulsion preparation step.

\subsubsection{Stabilization of Water-in-Oil-in-Water Emulsion}

W/O/W emulsion was stabilized by using a stabilizing agent. $1 \% \mathrm{w} / \mathrm{w}$ aqueous solution of PVP was used for this purpose. W/O/W emulsion was slowly poured in PVP solution (60 g) stepwise while it is mechanically mixed at $500 \mathrm{rpm}$. After all emulsion was poured, mixing was continued for 1 more minute. In this step it is aimed to encapsulate micelles with stabilizing agent to improve the stability of $\mathrm{W} / \mathrm{O} / \mathrm{W}$ emulsion. The reason for mild mixing and short time was preserving the previous size and structure of monomer droplets. It is observed in preliminary experiments that rigorous mixing caused to degradation of multiple-emulsion and turn it to single Oil-in-Water $(\mathrm{O} / \mathrm{W})$ emulsion. Flow diagram of this step and illustration of stabilized W/O/W emulsion are given in Figure 3.12. 


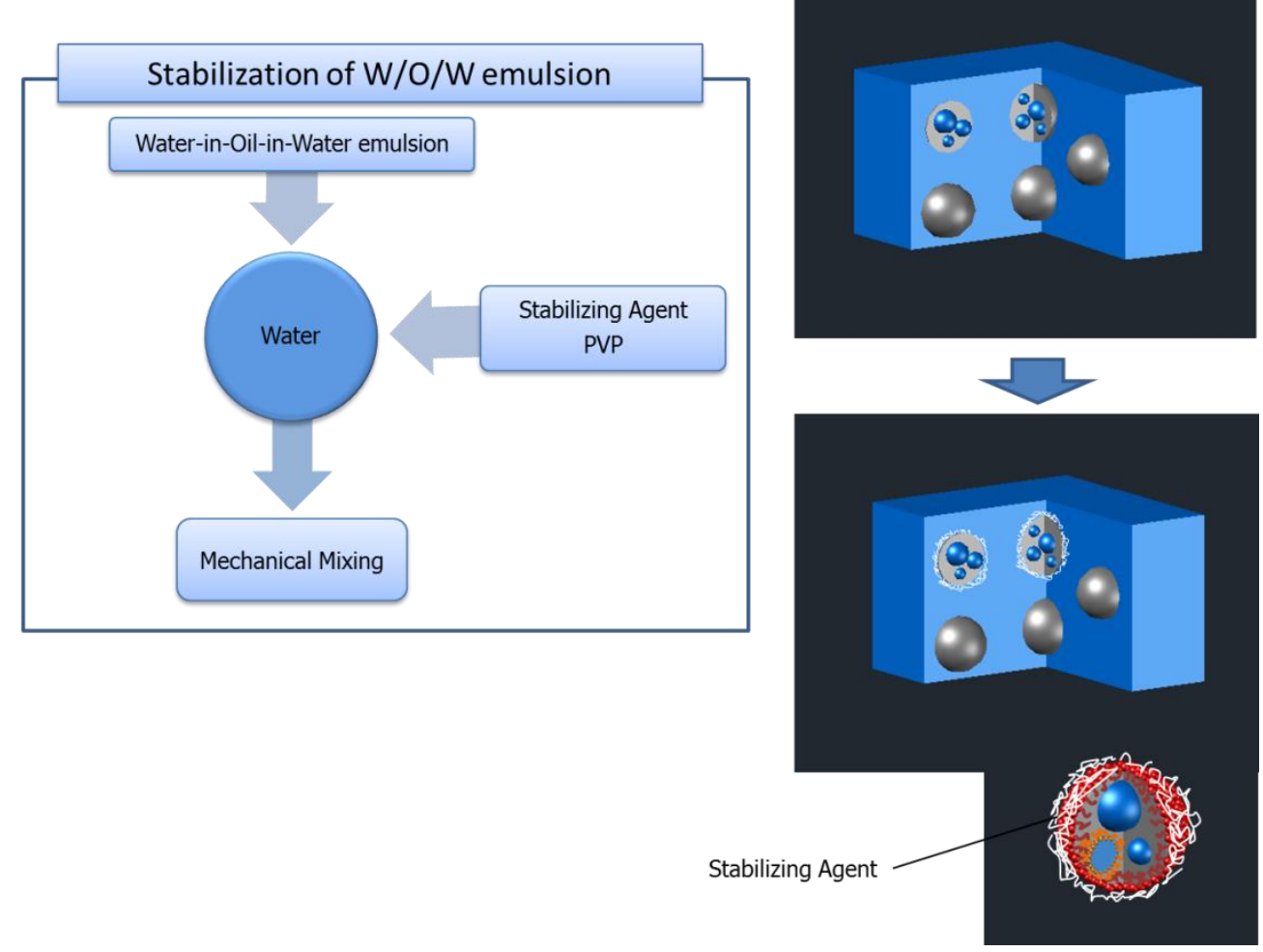

Figure 3.12 Flow diagram and illustration of W/O/W emulsion stabilization step.

\subsubsection{Polymerization}

After the stabilization process, the emulsion was transferred into four necked glass reactor equipped with a condenser and temperature controller. Nitrogen was used as inert gas during polymerization. After the system was deoxygenated, the reaction was carried out at $55{ }^{\circ} \mathrm{C}$ for 20 hours. The reaction medium was mixed at $250 \mathrm{rpm}$ during the entire process. Experimental setup of polymerization is shown in Figure 3.13. 


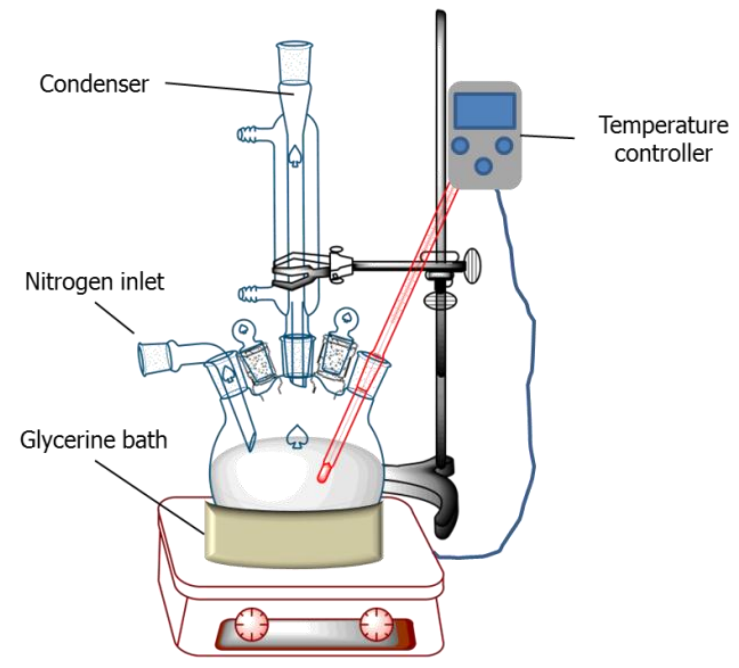

Figure 3.13 Experimental setup for polymerization reaction.

\subsubsection{Film Application}

Produced opaque polymer pigments were mixed with a water based styrene acrylic resin (Betapol SA-5017B, Betek Paint and Chemical Inc.) having 50 $\% \mathrm{w} / \mathrm{w}$ solid content in order to investigate paint properties such as opacity and gloss. Films were applied with wet thickness of $150 \mu \mathrm{m}$ by Apex four sided applicator. The recipe used for preparing films is given in Table 3.8. All films were dried at ambient temperature for 24 hours before measurements.

Table 3.8 Film formulation.

\begin{tabular}{|l|c|}
\hline Component & (\% w/w) \\
\hline Opaque Polymer Pigment & 7.7 \\
\hline Water & 69.2 \\
\hline Styrene-Acrylic Resin (50 \%w/w solid) & 15.4 \\
\hline Hydroxyethyl cellulose (\% 2) & 7.7 \\
\hline
\end{tabular}




\subsection{Characterization Methods}

In this study, various characterization methods were used which are DLS (Dynamic Light Scattering) size measurement, SEM (Scanning Electron Microscopy), TEM (Transmission Electron Microscopy), FTIR (Fourier Transform Infrared) spectroscopy, viscosity measurement, optical microscopy opacity and gloss measurements. Details of these methods and instruments are described below.

\subsubsection{Dynamic Light Scattering (DLS) Size Measurement}

The size of W/O and W/O/W emulsion samples were measured by Malvern Zetasizer Nano ZS (Model no: ZEN3500, $\lambda=633 \mathrm{~nm}$ lazer) instrument which is located in Nuclear Application Laboratory in Chemical Engineering Department (METU). DLS instrument measures the Brownian motion of droplets and interpreting size from velocity of these droplets. Brownian motion is due to the random collision of particles inside a liquid and one of the features of this motion is the slower motion of large particle and faster motion of smaller particles.

In such emulsion systems, droplets with higher volume may be formed in very few numbers even it does not give any peak at number average distribution. This effect causes misunderstanding in average size characteristics. To avoid this effect DLS device gives average size as zaverage diameter which is intensity based. Emulsion samples were rested for 15 minutes and kept inside ultrasonic bath for 5 minutes in order to allow emulsions to come to steady state and for removal of undesired air bubbles. Measurements were carried out by using quartz cells as sample holder. 


\subsubsection{Scanning Electron Microscopy (SEM)}

Size and morphology of opaque polymer pigments were characterized by Scanning Electron Microscopy (SEM) which is located in National Nanotechnology Research Laboratory (UNAM-Bilkent University) (Model: FEI Quanta 200 FEG). SEM samples were prepared by two methods. In first one, polymer suspension was washed and centrifuged two times. As washing solution (1:1) water and ethanol mixture was used. After washing and separation of samples, they were vacuum dried at $70^{\circ} \mathrm{C}$ and under 0.4 bar pressure. SEM sample specimens were coated with gold/palladium before analysis.

\subsubsection{Transmission Emission Microscopy (TEM)}

Hollow structure of opaque polymer particles was investigated by using Transmission Electron Microscopy (TEM) operated at 120 kV (Model: FEI Tecnai G2 Spirit) which is located in METU Central Laboratory.

\subsubsection{Fourier Transform Infrared (FTIR) Spectroscopy}

Molecular structure of opaque polymer particles were analyzed by using Fourier Transform Infrared (FTIR) spectroscopy (Model no: Shimadzu IR Prestige-21).

\subsubsection{Viscosity Measurement}

Viscosity measurements were done by using vibrational viscometer (Model no: AND SV-10, constant frequency of $30 \mathrm{~Hz}$ ) which has two gold plate 
sensors. In principle, vibrational viscometers relate viscosity with the damping force exerted on vibrating sensors by liquid medium. Measurements were done at constant temperature of $19^{\circ} \mathrm{C}$.

\subsubsection{Optical Microscopy}

Visual observation of emulsions was done by optical microscopy (Model: Prior, maximum magnification of 1000X). Image of emulsions was taken by using a digital camera.

\subsubsection{Opacity Measurement}

Opacity measurements were done by color spectrophotometer (Model no: Xrite Color İ5, spectral range: $360-750 \mathrm{~nm}$, light source: CEI standard illuminant D65) which is located in Nuclear Application Laboratory of Chemical Engineering Department (METU). Opacity of polymer pigments was defined as contrast ratio value which is the ratio of lightness against black and white background, respectively.

\subsubsection{Color Measurement}

The color properties of produced opaque polymer pigments were examined by $L^{*} a * b$ value and measured by using color spectrophotometer (Model no: X-rite Color İ5, spectral range: 360-750 nm, light source: CEI standard illuminant D65). The " $L$ " value indicates the lightness of sample where the value is 0 at pure white and 100 at black color. On the other hand "a" value is the measure of color from red to green ( + means shift to red and - means 
shift to green) and " $b$ " from yellow to blue (+ means shift to yellow and means shift to blue).

\subsubsection{Gloss Measurement}

Gloss values of films were measured by using glossmeter at angles of $20^{\circ}$, $60^{\circ}$, and $85^{\circ}$ (Model: Rhopoint, Novo-Gloss). Gloss value of paint can be described as the angle dependent measure of the relative ratio of diffused reflection to specular reflection from the surface. Angle of $20^{\circ}, 60^{\circ}$, and $85^{\circ}$ are used to define high gloss, medium gloss and matt paints, respectively. Where a value lower than 10 indicates matt surface and higher than 70 indicates high gloss. 


\section{CHAPTER 4}

\section{RESULTS AND DISCUSSION}

\subsection{Preliminary Studies on Surfactant Selection}

In order to prepare stable and submicron sized water-in-oil (W/O) emulsion, it is essential to select appropriate surface active agent(s). For this purpose, first non-ionic surfactants Span 80 (sorbitan monooleate, HLB=4.3) and Span 83 (sorbitan sesquioleate, HLB=3.7) both with lipophilic character were separately used, and the stability of prepared W/O emulsions was examined visually and by size measurement. The surfactants were first dissolved in monomer(s) of methyl methacrylate (MMA) and/or ethylene glycol dimethacrylate (EGDMA), and water is then added to the solution. Preliminary experiments showed that Span 80-only and Span 83-only were not adequate to obtain homogeneous emulsions. After ultrasonic emulsification, very quick sedimentation and following phase separation was observed.

To create synergetic effect and to increase the interfacial film strength, the surfactant mixtures of Span 80-AOT (dioctyl sodium sulfosuccinate, $H L B=32$ ), Span 80-Brij 97 (polyoxyethylene 10 oleoyl ether, HLB=12) , Span 80-SDBS (Sodium dodecylbenzenesulfonate, HLB=11.7), Span 80-SLS (Sodium Lauryl Sulfate, HLB=40), Span 83-Tween 80 (Polyoxyethylene (20) sorbitan monooleate, $\mathrm{HLB}=15$ ), and Span 80 -Tween 80 were prepared and used for W/O emulsification. SDBS, AOT and SLS are anionic, and Brij 97 and Tween 80 are non-ionic hydrophilic surfactants. The surfactant, monomer, 
and water weight ratio, The HLB number of surfactant mixtures, and the observed emulsion stability properties are given in Table 4.1.

Table 4.1 Preliminary experiments on surfactant selection.

\begin{tabular}{|l|c|c|c|c|c|c|}
\hline \multirow{2}{*}{$\begin{array}{c}\text { Surfactant } \\
\text { system }\end{array}$} & \multirow{2}{*}{$\begin{array}{c}\text { Monomer } \\
\text { system }\end{array}$} & \multirow{2}{*}{ HLB } & \multicolumn{2}{c|}{$\begin{array}{c}\text { Ratio of emulsion } \\
\text { components }\end{array}$} & \multirow{2}{*}{$\begin{array}{c}\text { Stability } \\
\text { observation }\end{array}$} \\
\cline { 5 - 6 } Span80 & MMA:EGDMA(1:1) & 4.3 & 6.2 & 73.7 & 20.1 & Phase separation \\
\hline Span80 & MMA:EGDMA(1:1) & 4.3 & 9.6 & 80.0 & 10.4 & sedimentation \\
\hline Span80 & MMA & 4.3 & 10.0 & 80.0 & 10.0 & Sedimentation \\
\hline Span83 & MMA:EGDMA(1:1) & 3.7 & 10.0 & 80.0 & 10.0 & Sedimentation \\
\hline Span83 & MMA:EGDMA(1:1) & 3.7 & 6.9 & 80 & 13.1 & Phase separation \\
\hline Span80-AOT & MMA:EGDMA(1:1) & 7 & 10.0 & 80.0 & 10.0 & Phase separation \\
\hline Span80-AOT & MMA:EGDMA(1:1) & 7 & 9.6 & 76.9 & 13.5 & Phase separation \\
\hline Span80-Brij97 & MMA & 7 & 10.0 & 80.0 & 10.0 & Sedimentation \\
\hline Span80-Brij97 & MMA & 7 & 9.8 & 78.4 & 11.8 & Sedimentation \\
\hline Span80-SDBS & MMA & 5 & 10.0 & 80.0 & 10.0 & Sedimentation \\
\hline Span80-SDBS & MMA & 5 & 9.7 & 77.4 & 12.9 & Sedimentation \\
\hline Span80-SLS & MMA:EGDMA(1:1) & 7 & 11.8 & 78.4 & 9.8 & Sedimentation \\
\hline Span80-SLS & MMA:EGDMA(1:1) & 9 & 15.1 & 75.5 & 9.4 & Sedimentation \\
\hline Span83-Tween80 & MMA:EGDMA(1:1) & 8 & 10.0 & 80.0 & 10.0 & Sedimentation \\
\hline Span83-Tween80 & MMA:EGDMA(1:1) & 8 & 10.0 & 76.0 & 14.0 & Phase separation \\
\hline Span80-Tween80 & MMA:EGDMA(1:1) & 8 & 10.0 & 80.0 & 10.0 & Stable \\
\hline Span80-Tween80 & MMA:EGDMA(1:1) & 8 & 9.8 & 78.4 & 11.8 & Stable \\
\hline
\end{tabular}

The emulsions which were homogenous and did not undergo phase separation or sedimentation for a few hours were assumed to be stable. The only successful surfactant mixture for preparation of W/O emulsion was Span 80 -Tween 80 system. The reason was their similar chemical structures which enhanced the interaction of surfactant molecules. The lipophilic portion of 
Tween 80 can easy interact with hydrocarbon tail of Span 80 , and forms stronger interfacial film.

One of the factors affecting the surfactant efficiency is the adsorption ability of surfactant molecules at the monomer-water interface. In case of lipophilic surfactants, this is directly related to the solubility of surfactants in monomer phase. The solubilities of Span 80 and Span 83 in monomer mixture of MMA and EGDMA can be compared by their Hildebrand solubility $(\delta)$ parameters. The lower the difference in the value of $\delta$ means the higher the miscibility. The solubility parameters were calculated by the formula below introduced by Hildebrand and Scot [114].

$$
\delta=\sqrt{\frac{\Delta \mathrm{H}_{\text {vap }}-\mathrm{RT}}{\mathrm{V}_{\mathrm{m}}}}
$$

where; $\Delta H_{\text {vap }}\left(\mathrm{J}\right.$ mole $\left.^{-1}\right)$ is the enthalpy of vaporization, $R\left(\mathrm{~J} \mathrm{~mol}^{-1} \mathrm{~K}^{-1}\right)$ is the gas constant, $T(K)$ is the temperature, and $V_{m}\left(m^{3} m^{-1}\right)$ is the molar volume. The $\Delta \mathrm{H}_{\text {vap }}$ values were estimated by the Hildebrand equation given by $[114,115]$.

$$
\Delta \mathrm{H}_{\text {vap }}=-12.340+99.2\left(\mathrm{~T}_{\mathrm{b}}\right)+0.084\left(\mathrm{~T}_{\mathrm{b}}\right)
$$

where; $\mathrm{T}_{\mathrm{b}}(\mathrm{K})$ is boiling temperature. The calculated $\delta$ values are given in Table 4.2. 
Table 4.2 Calculated solubility parameters of monomers and lipophilic surfactants.

\begin{tabular}{|l|c|c|}
\hline Compound & $\begin{array}{c}\text { Solubility } \\
\text { parameter }(\boldsymbol{\delta})\end{array}$ & $\Delta\left(\boldsymbol{\delta}_{\text {MMA }}-\boldsymbol{\delta}_{\mathbf{2}}\right)$ \\
\hline MMA & 20.9 & - \\
\hline EGDMA & 19.8 & 1.1 \\
\hline Span 80 & 18.2 & 2.7 \\
\hline Span 83 & 14.2 & 6.7 \\
\hline
\end{tabular}

As seen in Table 4.2 MMA and EGDMA have very close solubility parameters which provide that they are compatible and miscible with each other. On the other hand, the $\Delta$ value of Span 80 is lower than that of Span 83. It simply means that it is more compatible with monomers than Span 83.

\subsection{Effect of Hydrophilic-Lipophilic Balance (HLB) Value on Emulsion Stability}

In order to understand the effect of surfactant mixture on W/O emulsion stability and on water droplet size, a set of experiments were performed at different Span 80/Tween 80 ratios. This ratio was arranged in a way to keep the HLB values equal to $5,6,7,8$, and 9. The monomer/surfactant/water (M/S/W) weight ratio was kept constant at 66/20/14 which actually give percentage values and total up 100 . The emulsification was performed by ultrasonication at $60 \mathrm{~W}$ for $6 \mathrm{~min}$.

The size of water droplets was measured at time intervals of $0,6,12,18$ and $24 \mathrm{~h}$, and the change in the size of water droplets with time was taken as a criterion for the stability of W/O emulsions. The results of size measurements were given in Figure 4.1. The increase in the HLB value caused a decrease in 
the diameter of droplets. This must be due to lower stability achieved at high hydrophilic (i.e. high HLB) values. It is seen that emulsions prepared with surfactant mixture with HLB value of 5 and 6 had higher size difference in time.

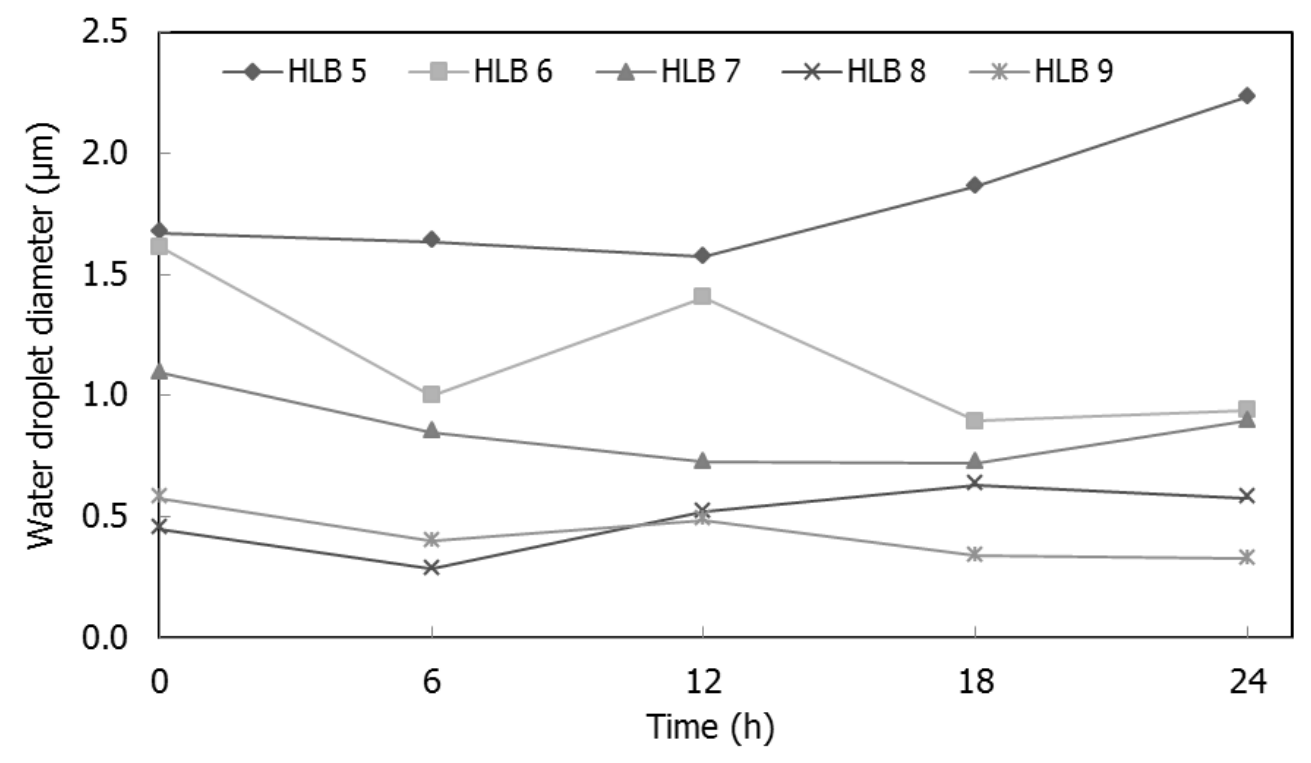

Figure 4.1 Influence of surfactant mixture HLB value on the size of water droplet.

Furthermore, it is possible to relate the change of size in time to stability. The Ostwald ripening and the coalescence grow the droplet size in time and sedimentation of big droplets results in size reduction in the remaining upper portion of emulsion. According to the Lifshitz-Slezov and Wagner (LSW) theory there is a linear relationship between $r^{3}$ (i.e. droplet volume) and time when the dominating breakdown mechanism is Ostwald ripening. If the relation between $1 / r^{2}$ and time also follows a linear behavior then the prominent instability is coalescence. A plot of $1 / r^{2}$ and $r^{3}$ versus time is given in Figure $4.2 a$ and $b$. A linear behavior can be assured by $R^{2}$ values which are given below the symbols in both figures. It is seen that the $\mathrm{R}^{2}$ values are quite low to assure linearity. So it can be said that neither Ostwald ripening 
nor coalescence was the only driving breakdown of emulsions studied. As figured out from the fluctuation of droplet size with time, the Ostwald ripening, the coalescence, and the sedimentation were all competitive in the breakdown of emulsions.

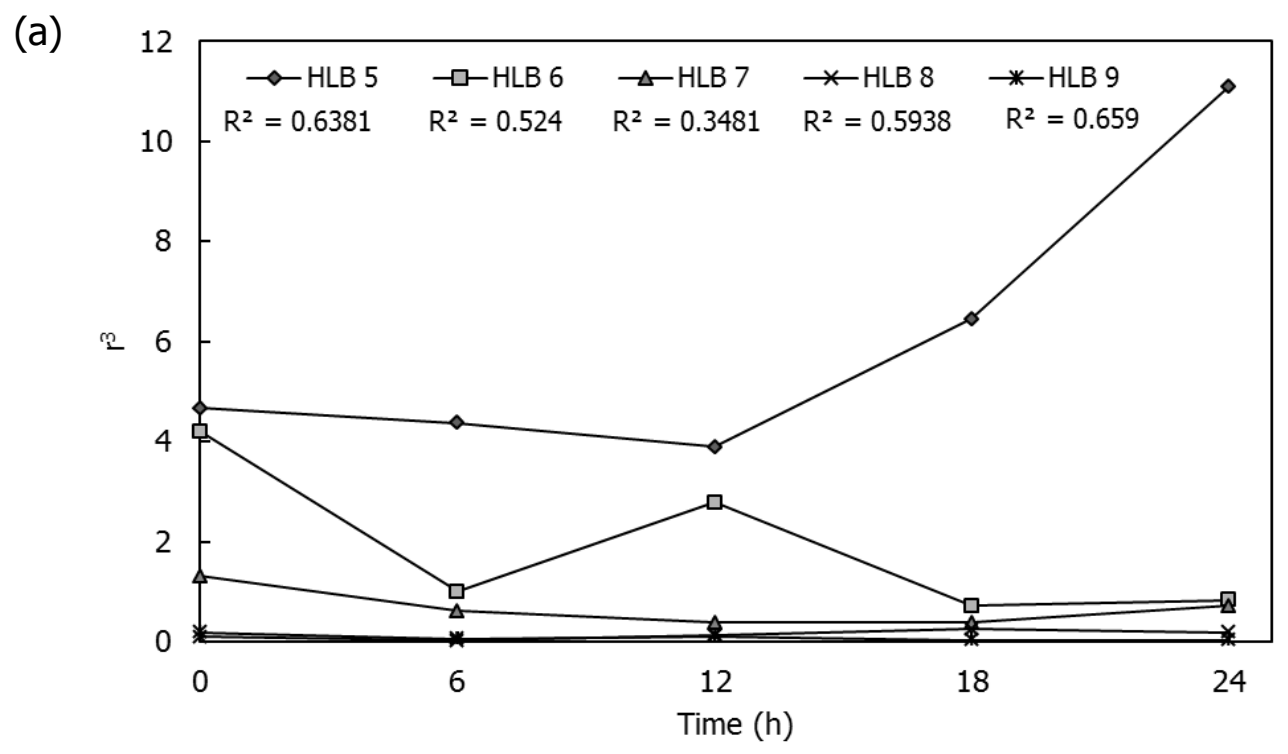

(b)

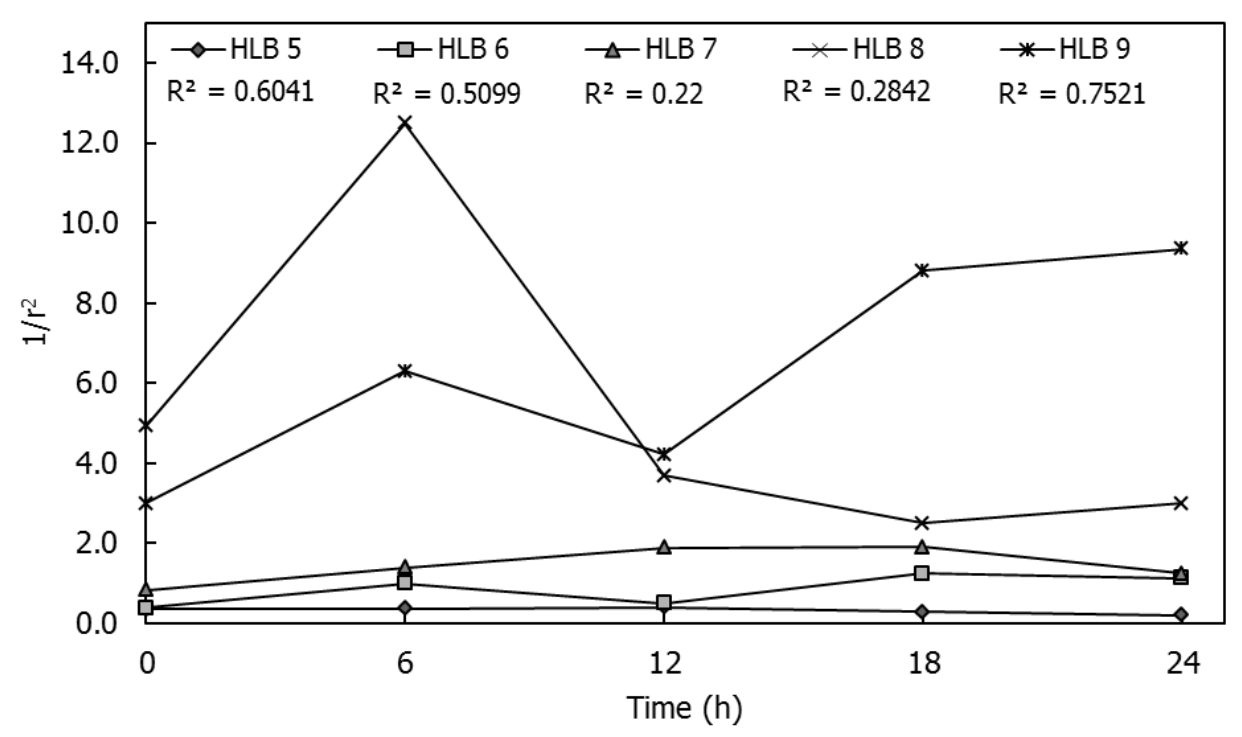

Figure 4.2 Change of (a) $r^{3}$ and (b) $1 / r^{2}$ with time. 
Higher droplet sizes favored the sedimentation as expected. In the case when $\mathrm{HLB}=5$, an increasing trend in size in time was observed which may be caused by higher coalescence or Ostwald ripening rate. On the other hand when $\mathrm{HLB}=6$ the size of droplets reduced in time which may be caused by high sedimentation rate of large droplets. When the HLB value was increased, it was observed that size fluctuation reduced dramatically. It can be concluded that both droplet growth and sedimentation rate decreased and relatively more stable emulsions were obtained.

According to the Stokes-Einstein equation the size reduction and viscosity increase depress sedimentation rate. In this study, the increase of the HLB value not only decreased the size but also slightly increased the oil phase viscosity since Tween 80 has higher viscosity than Span 80 . The variation of viscosity with HLB value is given in Figure 4.3.

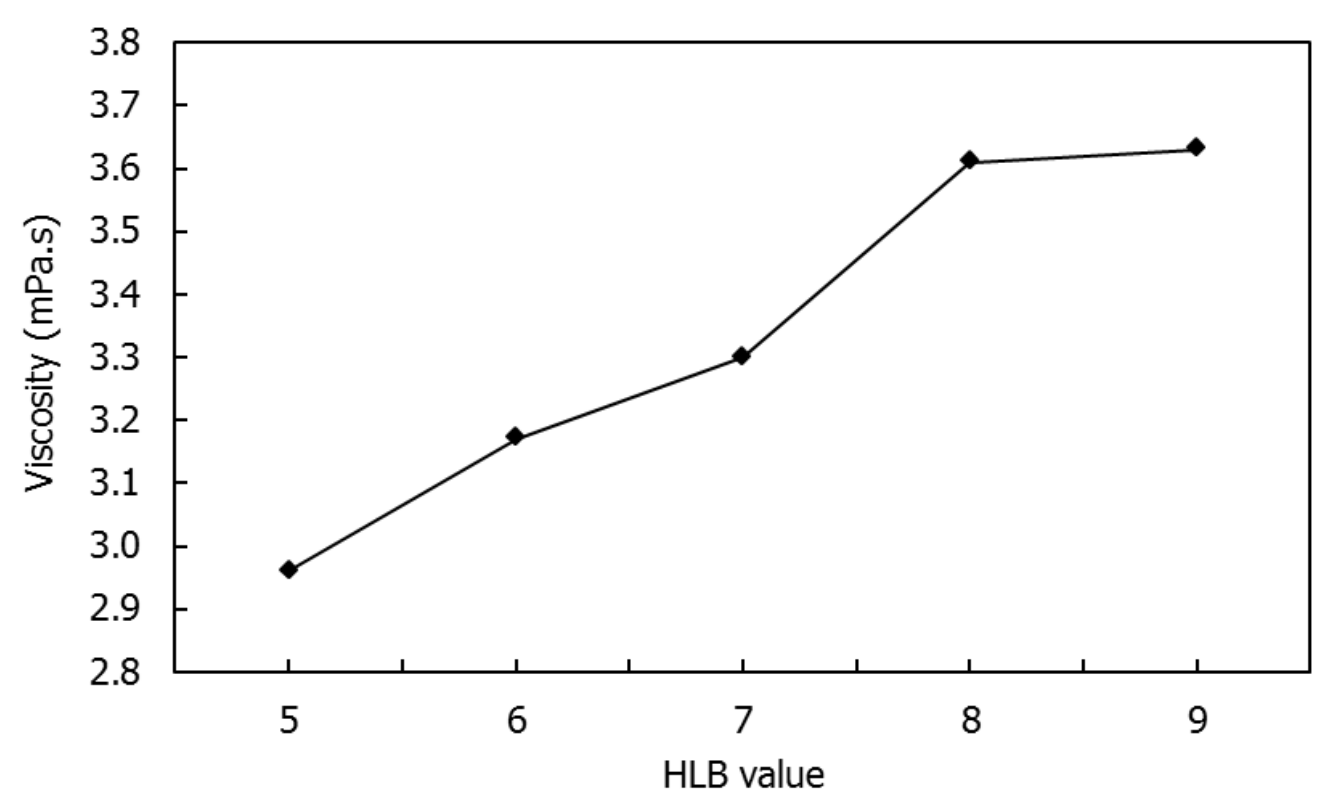

Figure 4.3 Change of viscosity with HLB value. 
In fact, a good emulsion is expected to have long term stability; however, it is out of the scope of this study and a few hours of stability was sufficient to proceed further in this research. The W/O emulsions prepared were soon used for the preparation of multiple water-in-oil-in-water (W/O/W) emulsion system. The W/O/W emulsions were continuously stirred during entire polymerization process which avoids sedimentation. On the other hand, viscosity increase due to polymerization prevents destabilization.

The surfactant mixtures with HLB value of 8 and 9 both yielded better stability and smaller droplet, however for the proceeding experiments the surfactant mixture with a HLB value of 8 was used. The reason was the increase of hydrophilic character with the increase of HLB value, and thus to get closer to the destability edge due to phase inversion of W/O.

\subsection{Phase Stability Diagram for W/O Emulsion}

\subsubsection{Effect of Surfactant}

The amount of the emulsion components; monomer, surfactant, and water have significant influence on stability and size. In these set of experiments, emulsions were prepared with various ratio of monomer, surfactant, and water $(\mathrm{M} / \mathrm{S} / \mathrm{W})$, and the stability region of compositions were investigated. For this purpose ternary phase diagram was prepared to visualize stable region. In this chart every point represents a ternary ratio of $\mathrm{M} / \mathrm{S} / \mathrm{W}$. W/O emulsions were prepared with Span 80 and Span 80-Tween 80 (HLB 8) surfactant(s), and homogenized by ultrasonic mixing. Phase diagram for W/O emulsions for MMA:EGDMA (1:1) monomer mixture is given in Figure 4.4. 


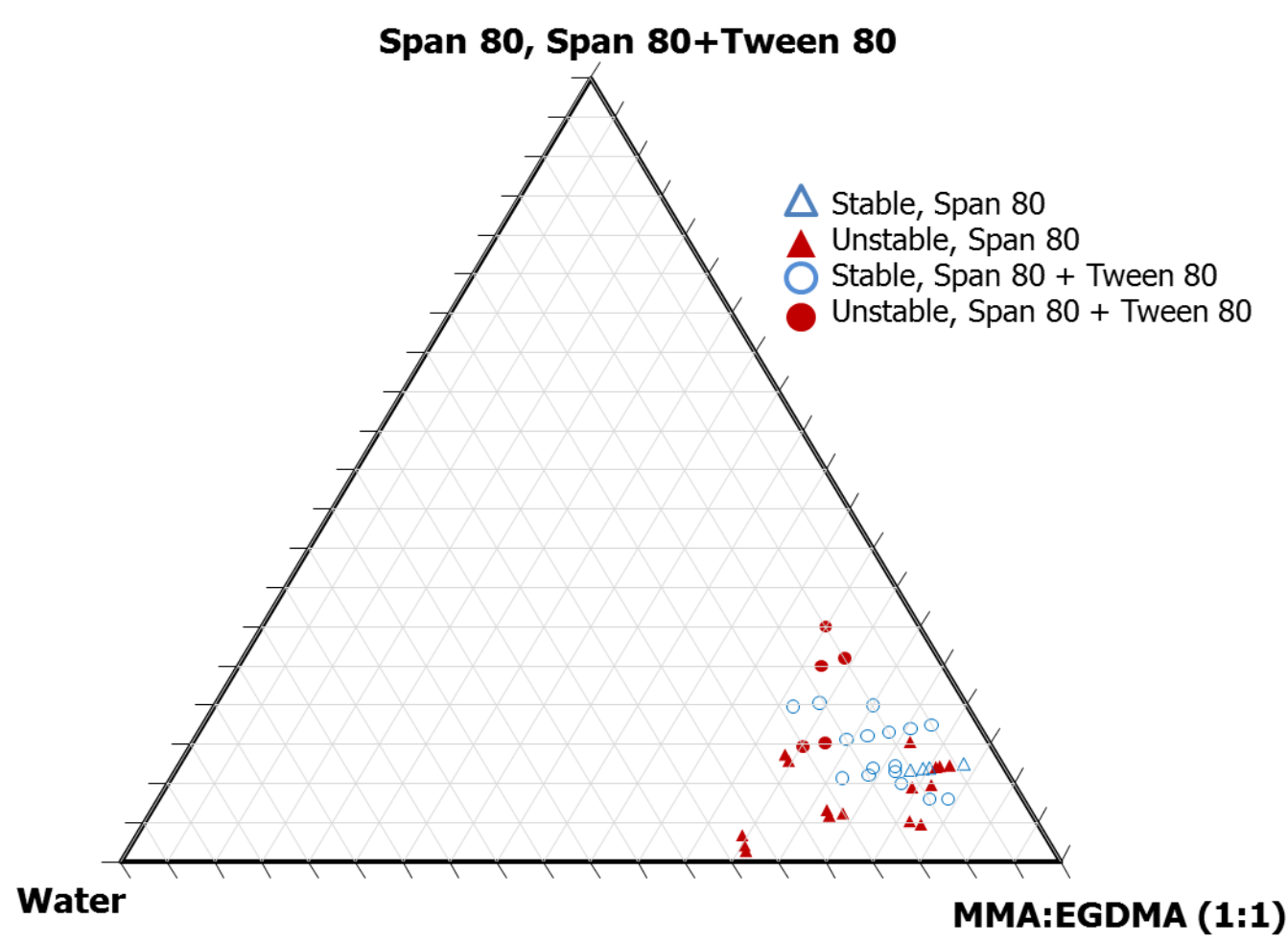

Figure 4.4 Phase diagram for monomer/surfactant/water system.

It is seen from Figure 4.4 that the stability region is very small (open triangles) when Span 80 was used as the only surfactant; but a larger stability region was obtained with Span 80-Tween 80 mixture (open circles). Therefore it is much advantageous to work with Span 80-Tween 80 mixture.

In order to reduce the droplet size it is necessary to increase the amount of surfactant molecules for compensating the increased surface area of droplets. However, it was observed that when surfactant concentration exceeded $20 \% \mathrm{w} / \mathrm{w}$, the emulsions lost their homogeneity and a gel formed. This was a puzzling problem and had to be clarified.

It is highly possible that the surfactant mixture had a limited solubility in monomer mixture and the excess surfactant molecules could result in 
agglomeration. The solubility of surfactant is dependent on the chemical potential, i.e. the chemical composition of monomer mixture. The chemical potential of monomer mixture can be influenced at large extent by introducing methacrylic acid which is highly hydrophilic because of its acidic group. The W/O emulsions were prepared with a monomer composition of MMA:MAA:EGDMA (8:1:1) to investigate if the size of micelles could be further decreased by increasing the amount of surfactant. MAA has similar optical properties with MMA and copolymerizes with the monomers.

The ternary stability diagram in this case is given by Figure 4.5 . It is seen from the comparison of Figure 4.4 and 4.5 that the stability region could be further enlarged by the use of MAA. So the modification of monomer mixture can help to consume more surfactant molecules and improve the stability region.

MAA seemed to be a promising chemical to increase the solubility of surfactant and a potential agent to decrease the size of droplets. However the highly ionic character of carboxylic group of MAA may entirely change the pathway of the scope of the research. So the experiments with MMA were taken as the evidence that agglomeration is caused by the excess surfactant molecules. The next step was therefore focused on the decrease of agglomeration of surfactant molecules by physical means. 


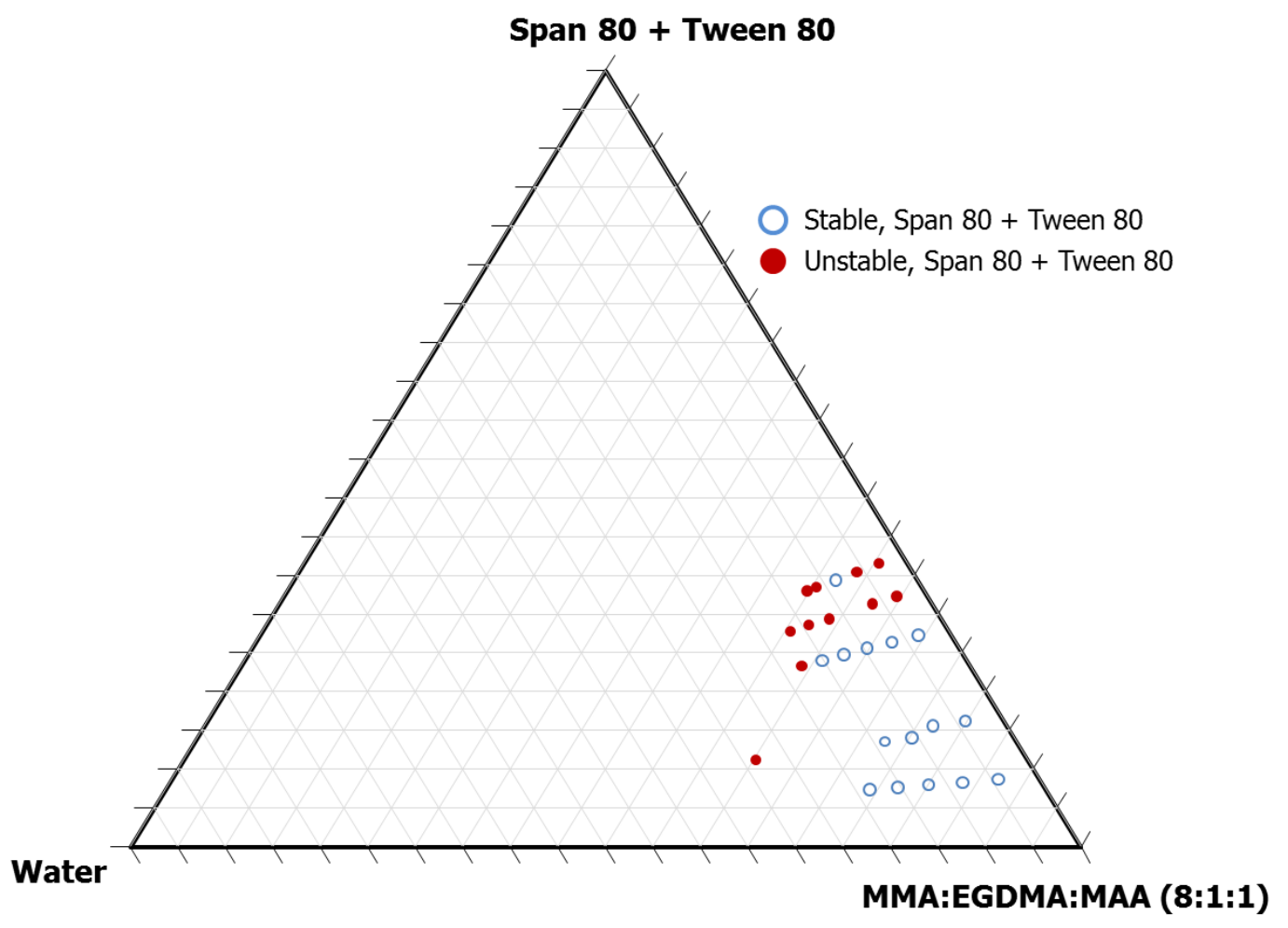

Figure 4.5 Phase diagram for monomer/surfactant/water system.

The particle size of the monomers and surfactant mixture was measured by particle size analyzer and it is shown by second distribution on the right hand side in Figure 4.6. The average particle size is around $1000 \mathrm{~nm}$, and it is clear that such large particles can reveal due to agglomeration.

In order to breakdown agglomeration the surfactant and monomer mixture was filtered out by using a syringe filter made of inert polyvinylidenfluoride (PVDF). The pore size the filter was $450 \mathrm{~nm}$. The particle size of the filtrate was analyzed and the first distribution on the left hand side of Figure 4.6 was obtained. The agglomeration was totally removed and a well dispersed mixture was obtained. In addition, turbid appearance of the monomer and surfactant mixture became quite clear. 

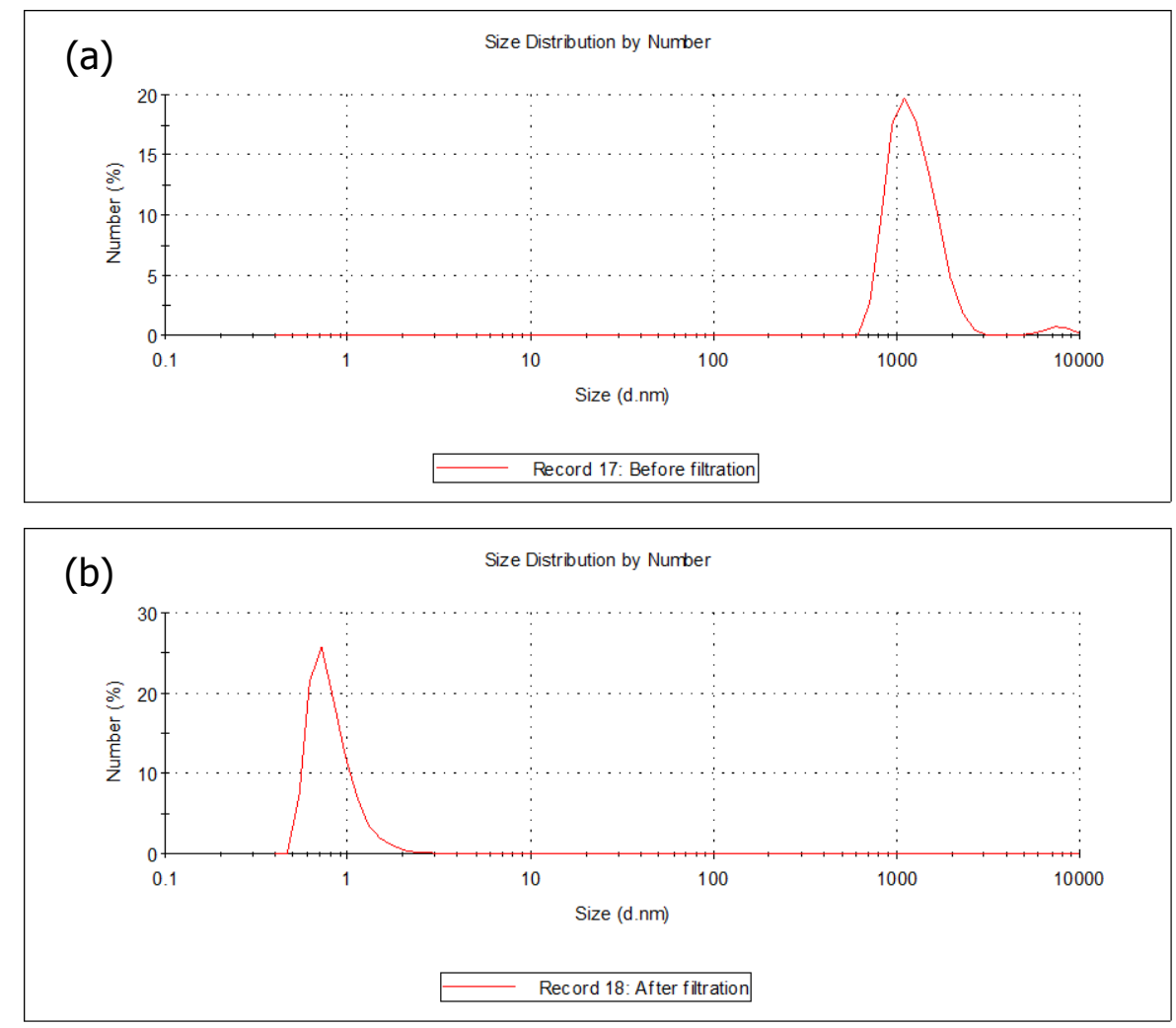

Figure 4.6 Size distribution of Span 80-Tween 80 surfactant mixture in MMA:EGDMA (1:1) (a) before, and (b) after filtration.

The filter was first dried out at $85^{\circ} \mathrm{C}$ for 2 days and then used in filtration. It was dried out again after filtration at same conditions, and the weight difference was calculated. It was found out that the weight increased by 0.05 $\% \mathrm{w} / \mathrm{w}$. This can be either due to some surfactants adsorbed or polymer formed from the adsorbed monomers. This weight is actually insignificant and it can be said that all organic contents passed into filtrate.

\subsubsection{Effect of Water Content}

The amount of water is another parameter that affects emulsion stability. High water concentrations destabilized the W/O emulsions due to 
catastrophic phase inversion which occurs when the amount of water far exceeds the amount of monomer. For instance, when water concentration exceeded $30 \% \mathrm{w} / \mathrm{w}$, the viscosity of W/O emulsion with a surfactant to water weight ratio of 0.125 , increased drastically and turned into a viscous phase.

On the other hand, the number of water droplets dispersed in monomer mixture might be increased as the concentration of water increased. This is a desired situation since the higher number of droplets raises the possibility of the existence of multiple droplets inside the W/O/W emulsion. The increased opacity of emulsions with increased amount of water was an evidence for this effect. The increased number of number of droplets is naturally expected to increase light scattering. The emulsions which were prepared with increased water to monomer $(\mathrm{w} / \mathrm{m})$ ratios (Figure 4.7$)$. The visual appearances of the emulsions $(0.05 \mathrm{w} / \mathrm{m})$ after 24 hours of ultrasonication are given in Figure 4.8 .

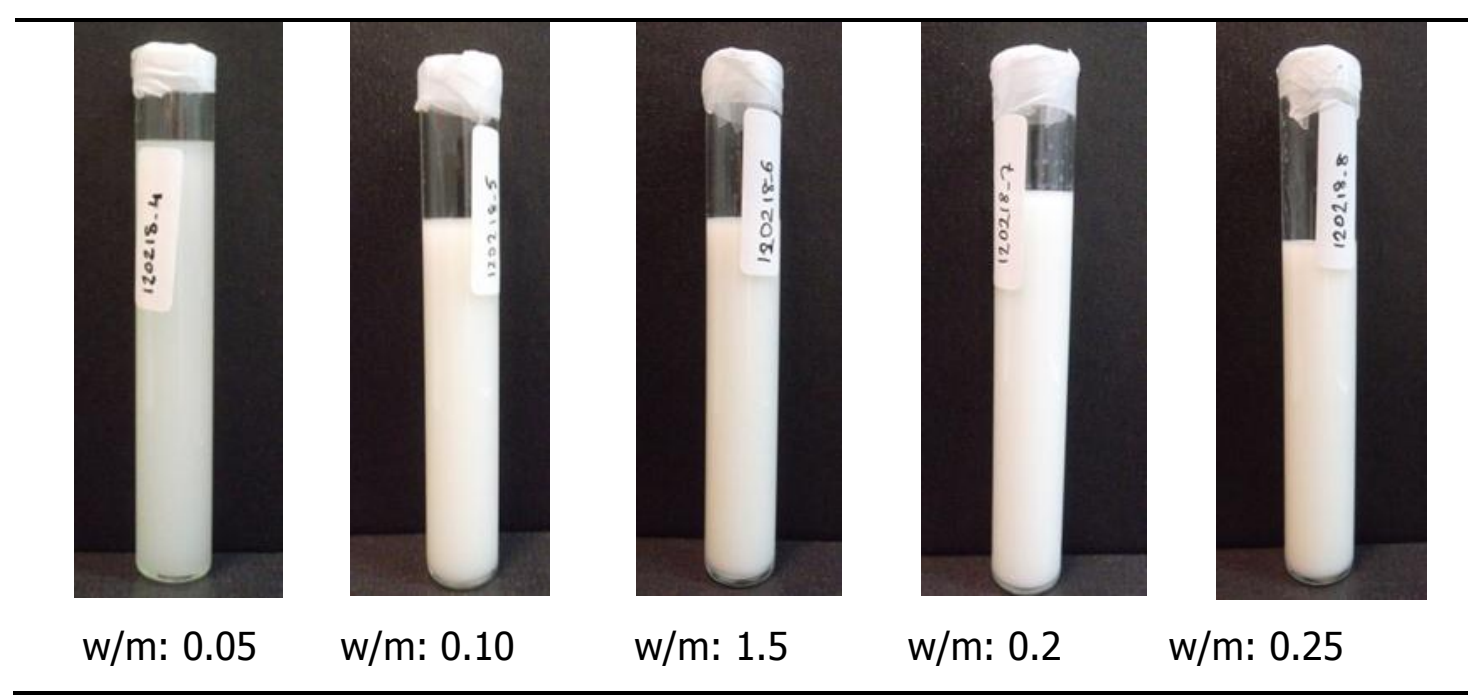

Figure 4.7 Images of W/O emulsions with various amount of water. 


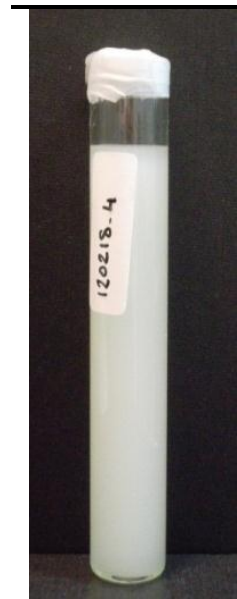

$\mathrm{t}: 0 \mathrm{~h}$

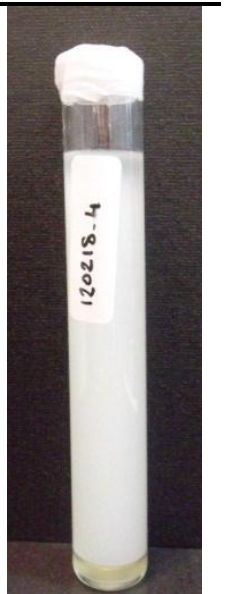

$\mathrm{t}: 24 \mathrm{~h}$

Figure 4.8 Images of $\mathrm{W} / \mathrm{O}$ emulsion with $\mathrm{w} / \mathrm{m}$ of 0.05 , at $\mathrm{t}: 0$ and $\mathrm{t}: 24$ hours after ultrasonication.

\subsection{Effect of Ultrasonication Parameters on W/O Emulsion Droplet Size}

The droplet size is the key factor that determines the diameter of voids inside the hollow polymer particles. Actually water droplets turn into voids at the final step. In order to produce submicron size fine droplets it is necessary to apply sufficiently high force onto monomer-surfactant-water mixture. In literature, it was reported that very fine droplets could be obtained within very short times by ultrasonication [116-118]. The same method was also used in this research.

When an ultrasonic wave which has a frequency higher than $20 \mathrm{kHz}$, is imposed on a liquid medium it creates alternating positive and negative pressures in that liquid. The positive and negative pressures cause the liquid molecules to compress and stretch, respectively. When the negative pressure generated by ultrasonic wave is large enough to alter the molecular interactions of liquid, local break down of liquid occurs and voids are 
generated. These voids are referred as cavitation bubbles. The formation and collapse of those bubbles due to pressure fluctuations generates high energy waves and results a mechanical mixing effect $[116,119,120]$.

\subsubsection{Effect of Ultrasonication Power}

In Figure 4.9, the effect of ultrasonication power on the W/O emulsion droplet size is given. All emulsions were prepared with the same monomer/surfactant/water ratio of 75.5/9.4/15.1, and ultrasonicated for 30 seconds at various mixing powers. It is seen from Figure 4.9 that minimum droplet diameter was achieved at $80 \mathrm{~W}$. Further increase of power increased the size of water droplets. At high powers droplets may gain high kinetic energies, and droplets may hit each other with high velocities. At such powerful collisions the steric repulsion of interfacial films may be overcome and droplets may coalescence yielding larger size droplets.

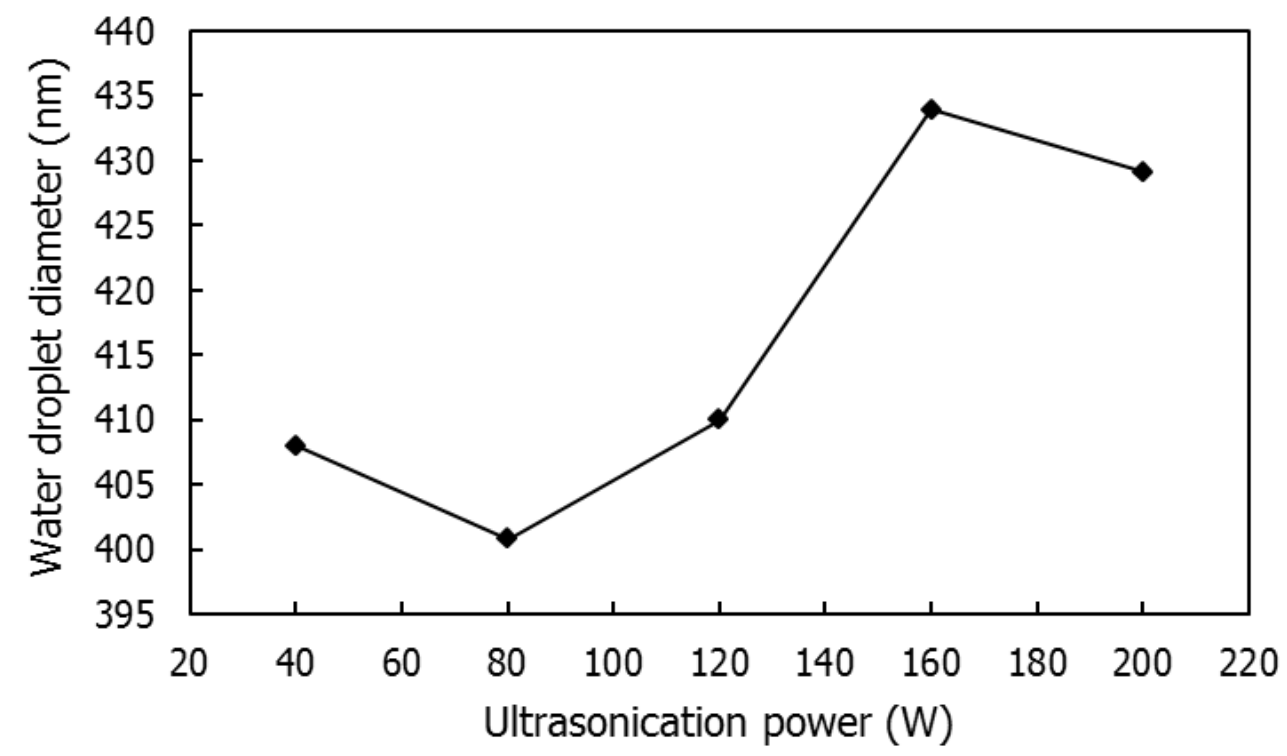

Figure 4.9 Effect of ultrasonication power on W/O emulsion droplet size. 


\subsubsection{Effect of Time of Ultrasonication}

The effect of the time of ultrasonication on W/O emulsion droplet size is shown in Figure 4.10. The emulsions were mixed at $80 \mathrm{~W}$ and various mixing time. The ratio of monomer/surfactant/water was taken to be 75.5/9.4/15.1. A similar trend was also observed for the ultrasonication time studies. Small droplets formed at short times, and they coalesced with each other and yielded large size particles at elongated ultrasonication. The oscillating behavior may be interpreted as the evidence of competition of droplet fragmentation and coalescence.

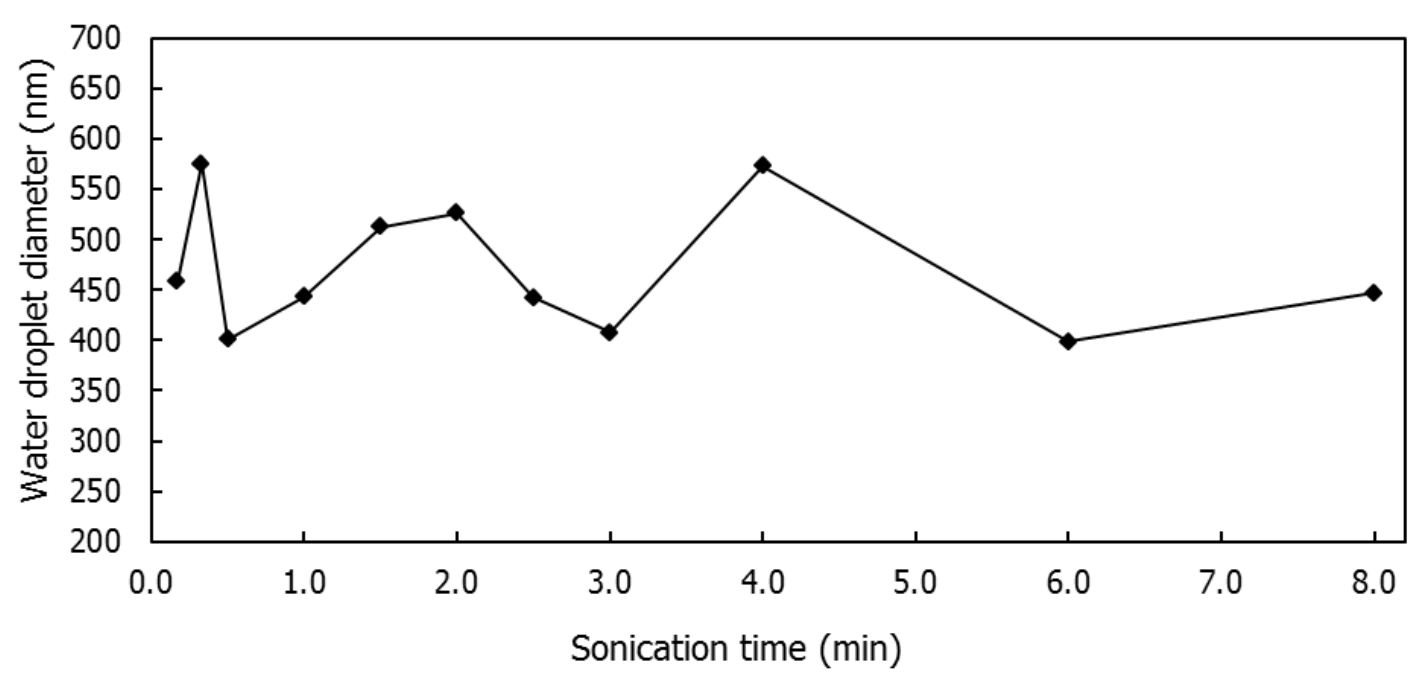

Figure 4.10 Effect of time of ultrasonication on W/O emulsion droplet size.

The energy load during ultrasonication caused to considerably increase in the temperature of emulsion. In order to avoid undesired loss of monomer mass and phase inversion, all the ultrasonic emulsifications were performed in cold water bath. 


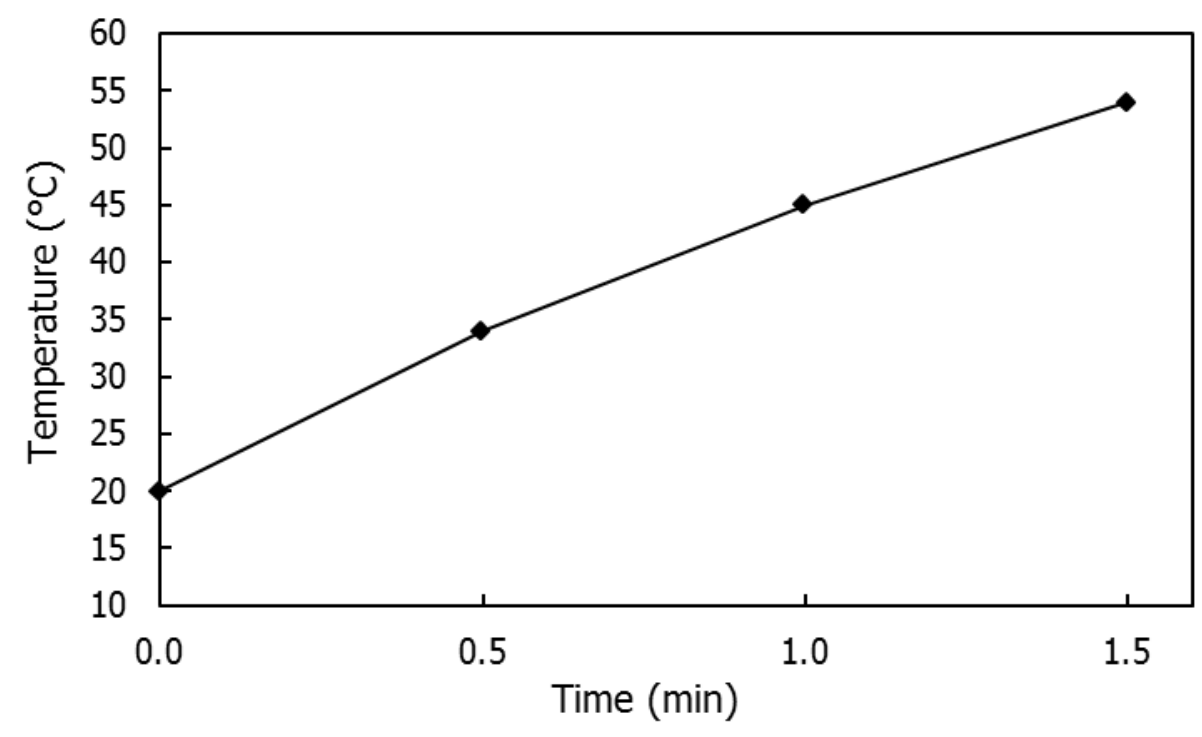

Figure 4.11 Temperature rise due to the ultrasonication.

The temperature rise during ultrasonication at $80 \mathrm{~W}$ was illustrated in Figure 4.11. There is almost a linear dependence of the increase of temperature on the time (or total energy) of ultrasonication.

\subsection{Mathematical Modeling of Scattering Efficiency}

Opacity of a pigment is directly dependent to its scattering ability. In this study, the proper hollow size to achieve better opacity performance was investigated by a mathematical model of Mie scattering efficiency. The extinction efficiencies of hollows for the range of visible incident radiations were calculated by using the formulation of Bohren and Huffman [4]. An efficiency calculation program was written in MATLAB for this aim. The codes are given in Appendix A. 
Bohren and Huffman's scattering efficiency solution is valid for isotropic and spherical single particles where multiple scattering effects are not considered. The calculations were done by assuming that the medium in this study contains voids embedded in polymer matrix. The required complex refractive index of polymer particle was taken as $1.49+0.01 \mathrm{i}$ which is the value for poly(methyl methacrylate) and it is also very close to that of poly(ethylene glycol dimethacrylare) [121]. The refractive index of void was taken as $1.0+0.01 \mathrm{i}$. The coefficient of imaginary part was taken as 0.01 which is commonly used value for all weakly absorbing media [122]. The scattering efficiencies for various radiations and hollows having diameter in the range of 50 to $4000 \mathrm{~nm}$ are visualized in Figure 4.12.

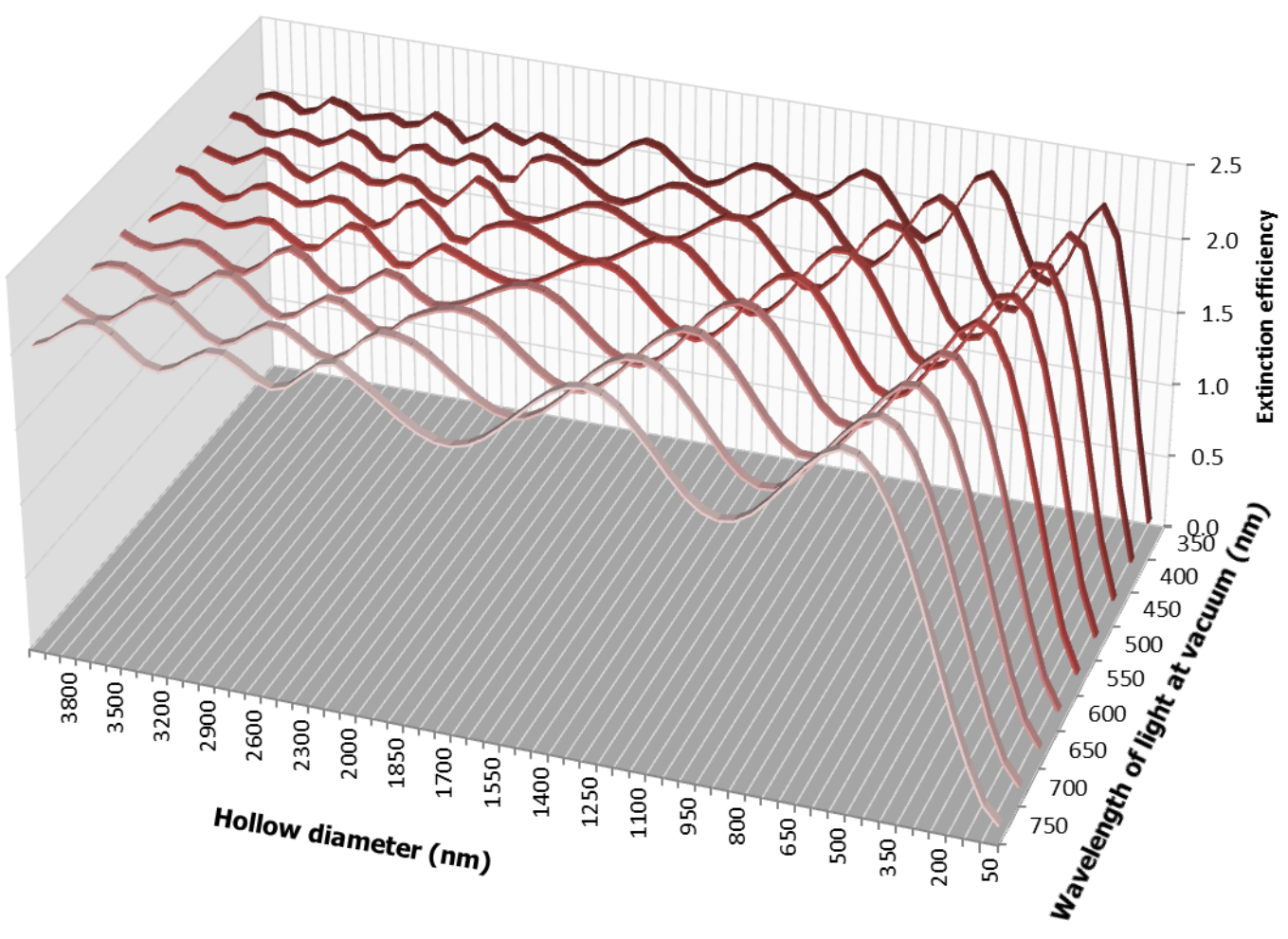

Figure 4.12 The calculated scattering efficiency profiles of hollows with different diameters and at varying incident radiations. 
It seen from Figure 4.12 that scattering efficiency has a decreasing and oscillating behavior as the diameters of hollows increase. On the other hand, as the wavelength of radiation increases the peaks get wider. The scattering efficiency is measured in terms of the amplitudes of peaks. It is seen that the second peak (the starting point is the very right hand side) has the highest amplitude and thus highest scattering efficiency. The first peak comes next, and other peaks starting with the third peak have slightly decreasing scattering efficiencies.

Another observation that can be noticed is that the radiations at different wavelengths have highest efficiency responses at different void sizes. The radiations of visible spectrum with smaller wavelengths are more effectively scattered by relatively smaller voids. Similarly, as the wavelength of radiation increase, the size required for maximum scattering efficiency also increase. This can be easily noticed from the shift of peaks with hollow diameter.

In Figure 4.13, the relative spectral power distribution of illuminant D65 is shown, which is the equivalent of daylight [123]. As seen from the graph, the radiations with wavelengths approximately between 430 and $650 \mathrm{~nm}$ have higher spectral power. On the other hand, the human eye lens has maximum transparency at wavelengths from 550 to $650 \mathrm{~nm}$ which makes eye more sensitive in this region of radiations $[124,125]$. For these reasons, it is beneficial to form hollows which are more effectively scatter the radiations at wavelength of 550 to $600 \mathrm{~nm}$. According to simulation, these hollows should have sizes near 450 and $1050 \mathrm{~nm}$ (see Figure 4.12). 


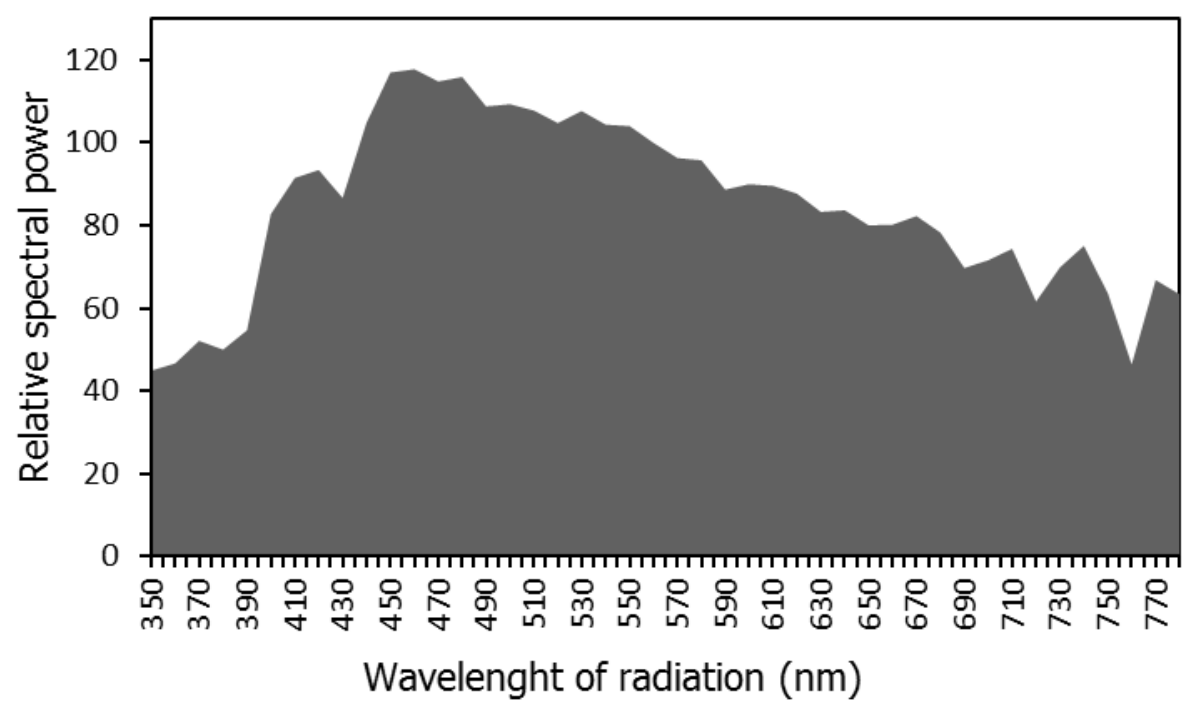

Figure 4.13 Relative spectral power distribution of D65 [123].

Light interacts with matter as a beam of radiations at various wavelengths. Hence, as a consequence of mathematical model, the voids with a size distribution within the range of wavelengths of visible radiation spectrum may yield higher scattering performance than singular sized voids.

\subsection{W/O Emulsion Preparation with Required Droplet Size}

The previous experiments have shown that smaller droplets could be obtained with ultrasonic homogenization at $80 \mathrm{~W}$ for 30 seconds as mentioned above. In order to generate droplets within the size range of visible spectrum radiations, numerous monomer/surfactant/water ratios were tried for the $\mathrm{W} / \mathrm{O}$ emulsification at $80 \mathrm{~W}$ and for 30 seconds. The optimum result was obtained with a monomer/surfactant/water weight ratio of 75.5/9.4/15.1, and with the Span 80-Tween 80 surfactant mixture having an HLB value of 8 . The volume size distribution of this appropriate $W / O$ emulsion is given in Figure 4.14. It exhibited a bimodal size distribution 
which was also observed for all other W/O emulsions with varying compositions.

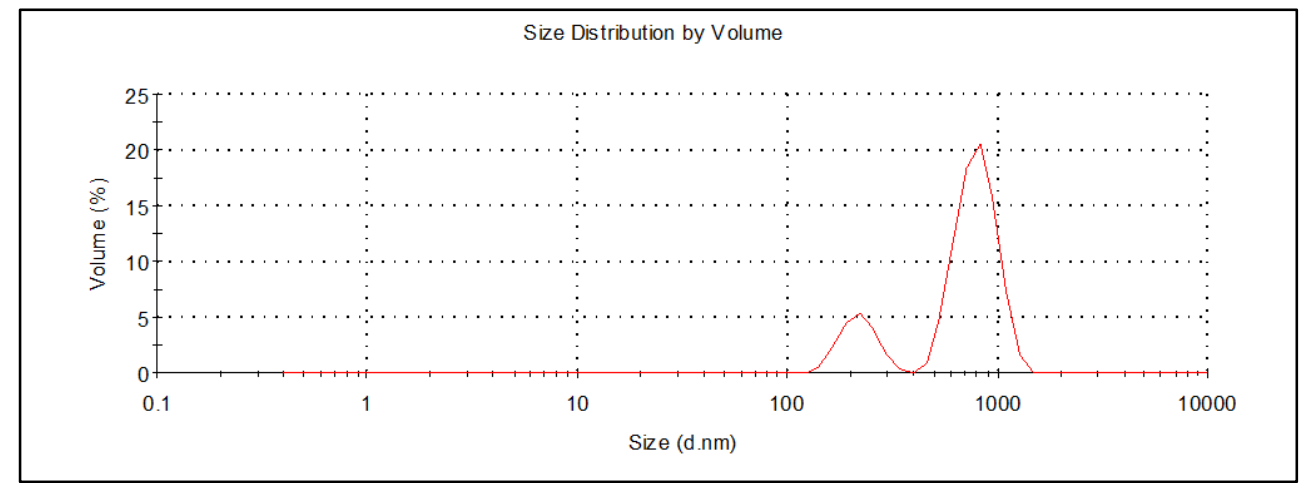

Figure 4.14 Droplet size distribuiton of $\mathrm{W} / \mathrm{O}$ emulsion (M/S/W: 75.5/9.4/15.1), $80 \mathrm{~W}, 30$ seconds.

\subsection{Effect of Hydrophilic Surfactant Concentration on $\mathrm{W} / \mathrm{O} / \mathrm{W}$ Emulsion Droplet Size}

The prepared W/O emulsions were slowly poured into an aqueous solution of hydrophilic Triton X-405 under mechanical mixing at 1000 rpm for 4 minutes. At this step, the monomer phase containing water droplets was encapsulated by micelles and hereby the spherical monomer droplets with multiple water droplets were obtained. In order to investigate the effect of surfactant concentration on monomer droplet size, the W/O/W emulsions were prepared at the surfactant concentrations of 2, 3.5 and $5 \% \mathrm{w} / \mathrm{w}$. As seen from Figure 4.15, the increased surfactant concentration reduced the size of droplets. 


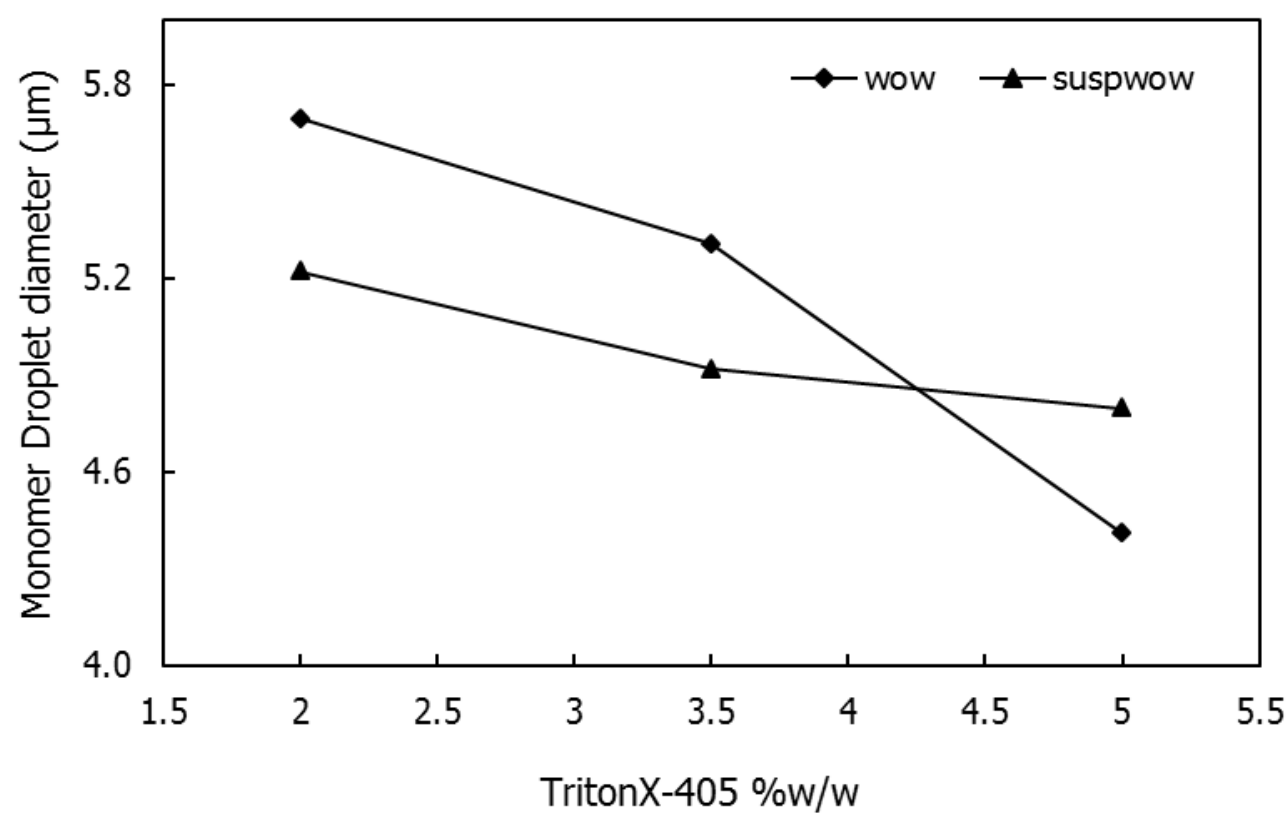

Figure 4.15 The effect of surfactant concentration on $\mathrm{W} / \mathrm{O} / \mathrm{W}$ emulsion droplet size. (wow: droplet size of the W/O/W emulsion, suspwow: the size of suspended and stabilized droplets of W/O/W emulsion)

The prepared multiple emulsions were also observed by optical microscopy and their images are given in Figure 4.16. The images clearly show that the successful preparation of the multiple emulsions with multiple water droplets was accomplished. Nevertheless, there were few W/O/W droplets containing single water droplet inside (see "1"). There are also a few regular oil-inwater (O/W) droplets (see "2"). 

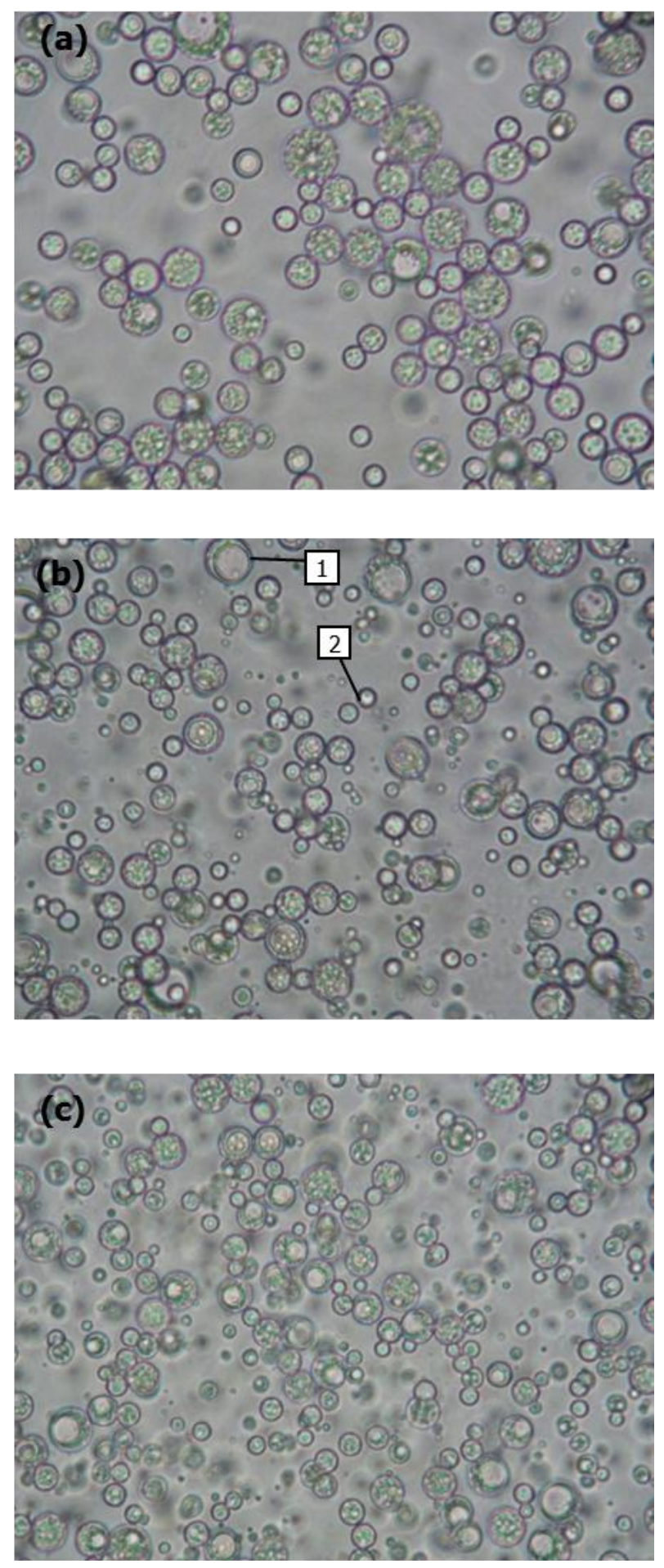

Figure 4.16 Optical microscopy images for (a) $2 \% \mathrm{w} / \mathrm{w}$, (b) $3.5 \% \mathrm{w} / \mathrm{w}$, and (c) $5 \% \mathrm{w} / \mathrm{w}$ Triton X-405, (x400). 
The W/O/W emulsions were then stabilized by an aqueous solution of 1 $\% \mathrm{w} / \mathrm{w}$ polyvinylpyrrolidone. Similar to the previous step, the $\mathrm{W} / \mathrm{O} / \mathrm{W}$ emulsions were slowly poured into the solution under mechanical mixing at $500 \mathrm{rpm}$, and the mixture was stirred for 1 more minute. The mixing has to done at low rpm not to break down the existing morphology of droplets. The comparison of both curves in Figure 4.15 shows that there is not significant size change during stabilization when mixed at $500 \mathrm{rpm}$ for 1 minute. The stabilization was done without significantly disturbing the $\mathrm{W} / \mathrm{O} / \mathrm{W}$ emulsion structure. All the proceeding experiments were also carried by using the aqueous solution of $5 \% \mathrm{w} / \mathrm{w}$ Triton X-405.

\subsection{Effect of Mixing Parameters on W/O/W Emulsion Droplet Size}

Since the opaque polymer pigment particle was obtained by suspension polymerization of $\mathrm{W} / \mathrm{O} / \mathrm{W}$ emulsion, its size was equivalent to the $\mathrm{W} / \mathrm{O} / \mathrm{W}$ emulsion monomer droplets. Hence, adjusting of multiple emulsion droplet size is essential where it should be small enough not to cause problems during film applications and large enough to encapsulate multiple smaller water droplets inside. In this set of experiments the effects of mechanical mixing parameters were examined.

\subsubsection{Effect of Mechanical Mixing Speed}

Figure 4.17 shows the effect of mixing speed on the W/O/W emulsion droplet size. The emulsions were mixed for 4 minutes. As expected, the increase of the mixing speed reduced the diameter. 


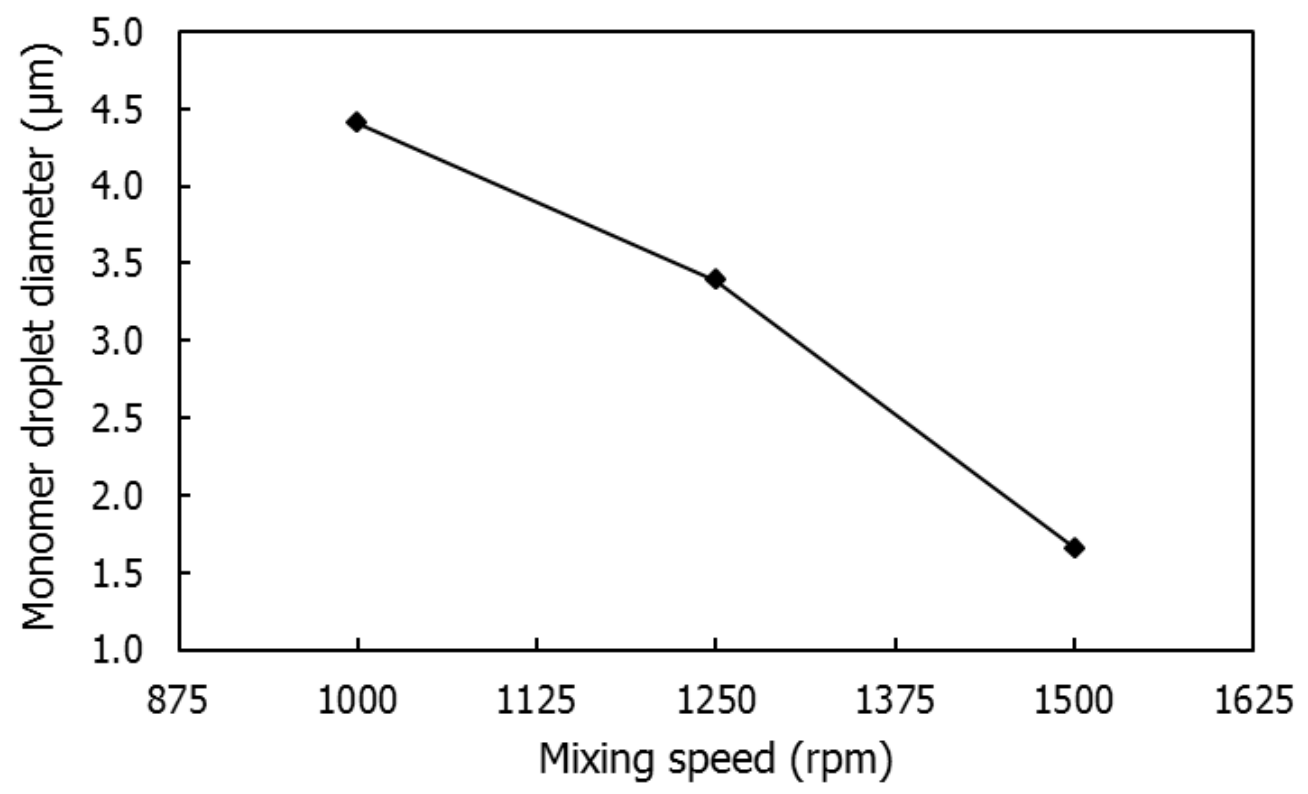

Figure 4.17 Effect of mixing speed on W/O/W emulsion monomer droplet size.

It can be observed that the reduced size of monomer droplets caused a decrease in the number of multiple droplets as expected. It can also be observed that the same behavior prevails for $\mathrm{O} / \mathrm{W}$ emulsions. The minimum monomer droplet size having multiple water droplets were obtained in Figure $4.18 \mathrm{~b}$ where the mixing was carried at $1250 \mathrm{rpm}$. Hence the proceeding experiments were performed at $1250 \mathrm{rpm}$.

Ultrasonication method was also attempted for use in the preparation of multiple emulsions. However, multiple emulsions could never be obtained even at the very low power of $10 \mathrm{~W}$; only O/W emulsion formed always. 

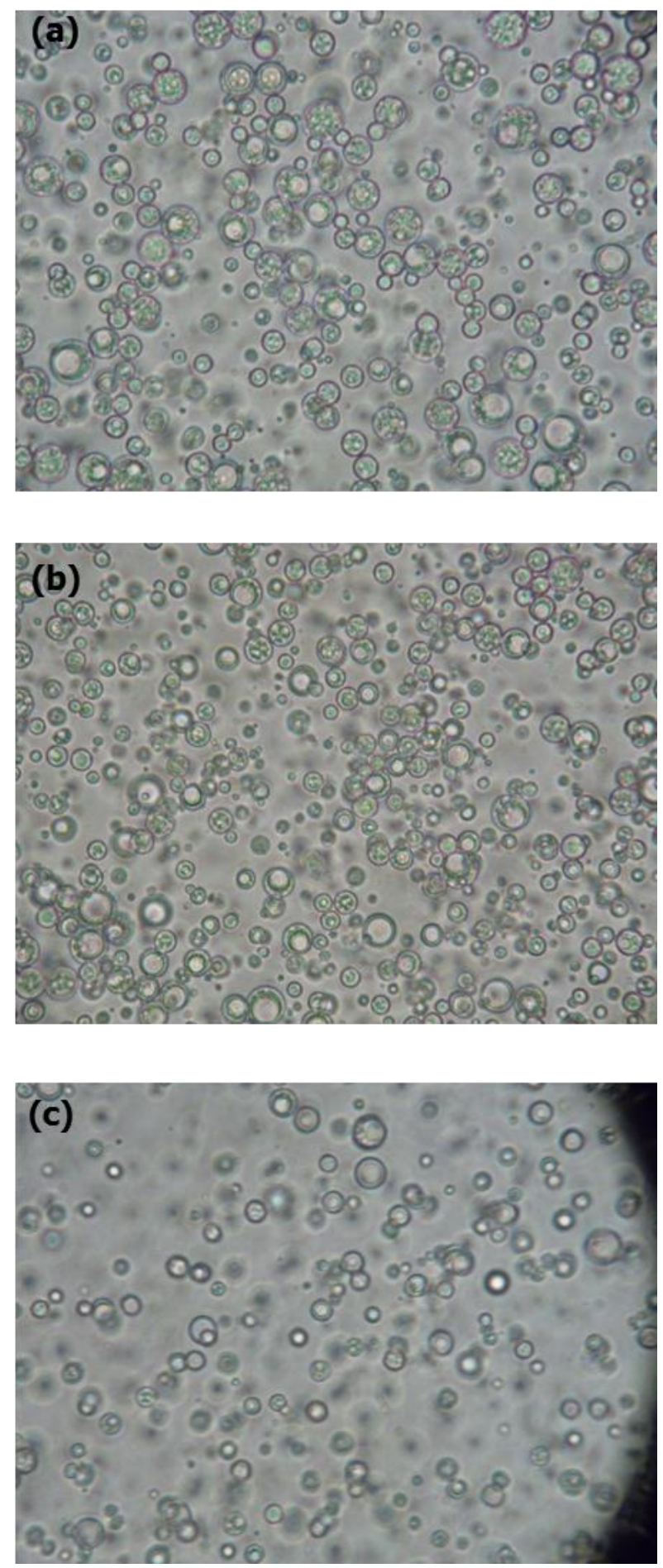

Figure 4.18 Optical microscopy image of W/O/W emulsions mixed at (a) $1000 \mathrm{rpm}$, (b) $1250 \mathrm{rpm}$, and (c) $1500 \mathrm{rpm}$. (x400). 


\subsubsection{Effect of Time of Mechanical Mixing}

The other investigated mixing parameter was the time. The W/O/W emulsion was slowly added to $5 \% \mathrm{w} / \mathrm{w}$ Triton X-405 solution at $1250 \mathrm{rpm}$ and the samples were taken with time intervals of $2,4,6,8$, and 10 minutes. The size measurement results (Figure 4.19) showed that as mixing time increase it is possible to obtain smaller droplets. For the aim of not to lose multiple emulsion structure due to excessive size deduction, the mixing was performed for 4 minutes.

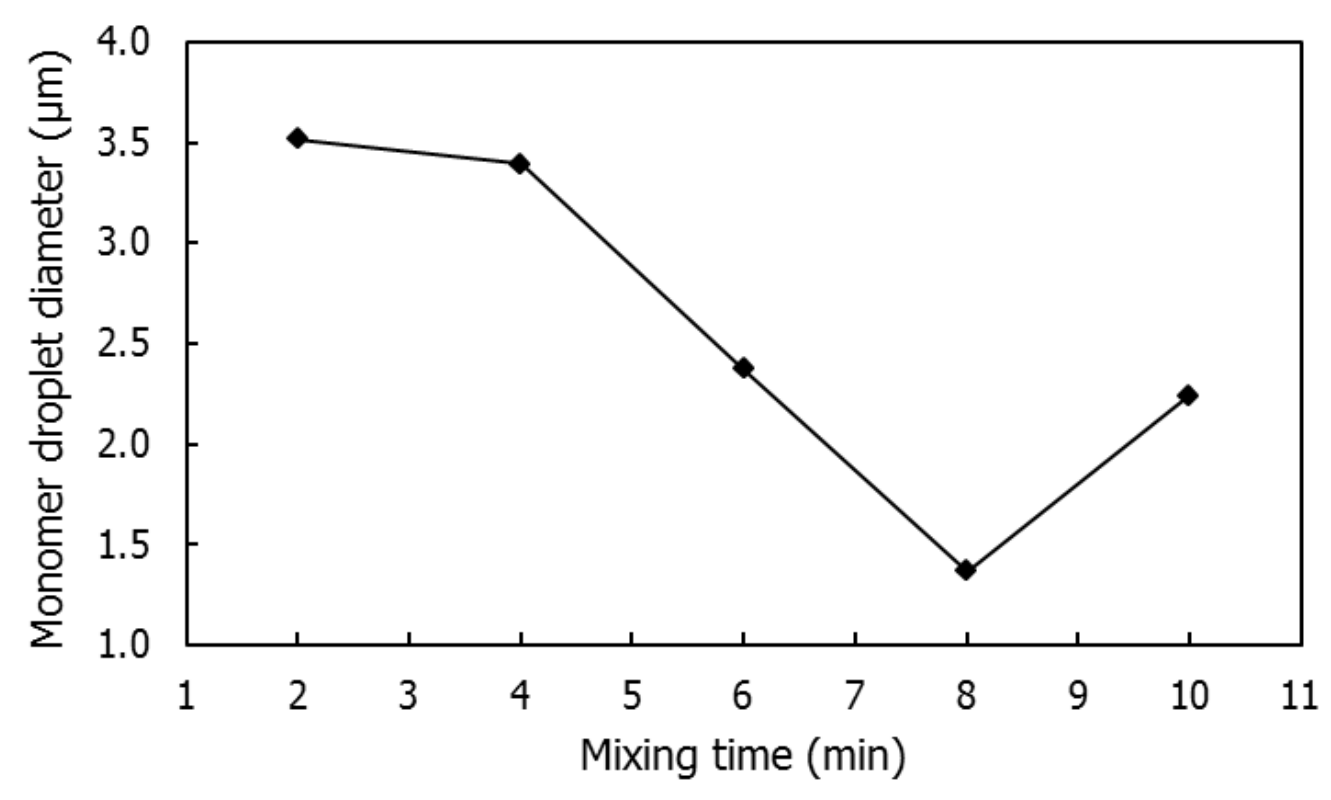

Figure 4.19 Effect of mixing time on W/O/W emulsion droplet size.

\subsection{Opaque Polymer Pigments}

The polymer particles were produced by free radical polymerization of the W/O/W multiemulsion. The polymerization reaction temperature was kept as low as possible in order to avoid phase inversion of surfactants. The other 
concern was the vapor pressure of W/O/W emulsion inner water phase where increased pressure might result to migrate or blast water droplets. For these reasons, reactions were performed at $55^{\circ} \mathrm{C}$ for 20 hours.

\subsubsection{Preliminary Study on Initiator}

The stabilized W/O/W emulsions were polymerized by using both benzoyl peroxide (BPO) and 2,2'azobisisobutyronitrile (AIBN). The temperature of polymerization was kept at $65^{\circ} \mathrm{C}$ when BPO was used as initiator and at $55^{\circ} \mathrm{C}$ when AIBN was used [126]; in both cases polymerization was carried for 20 hours. The scanning electron microscope (SEM) micrographs of polymer particles are given in Figure 4.20. 

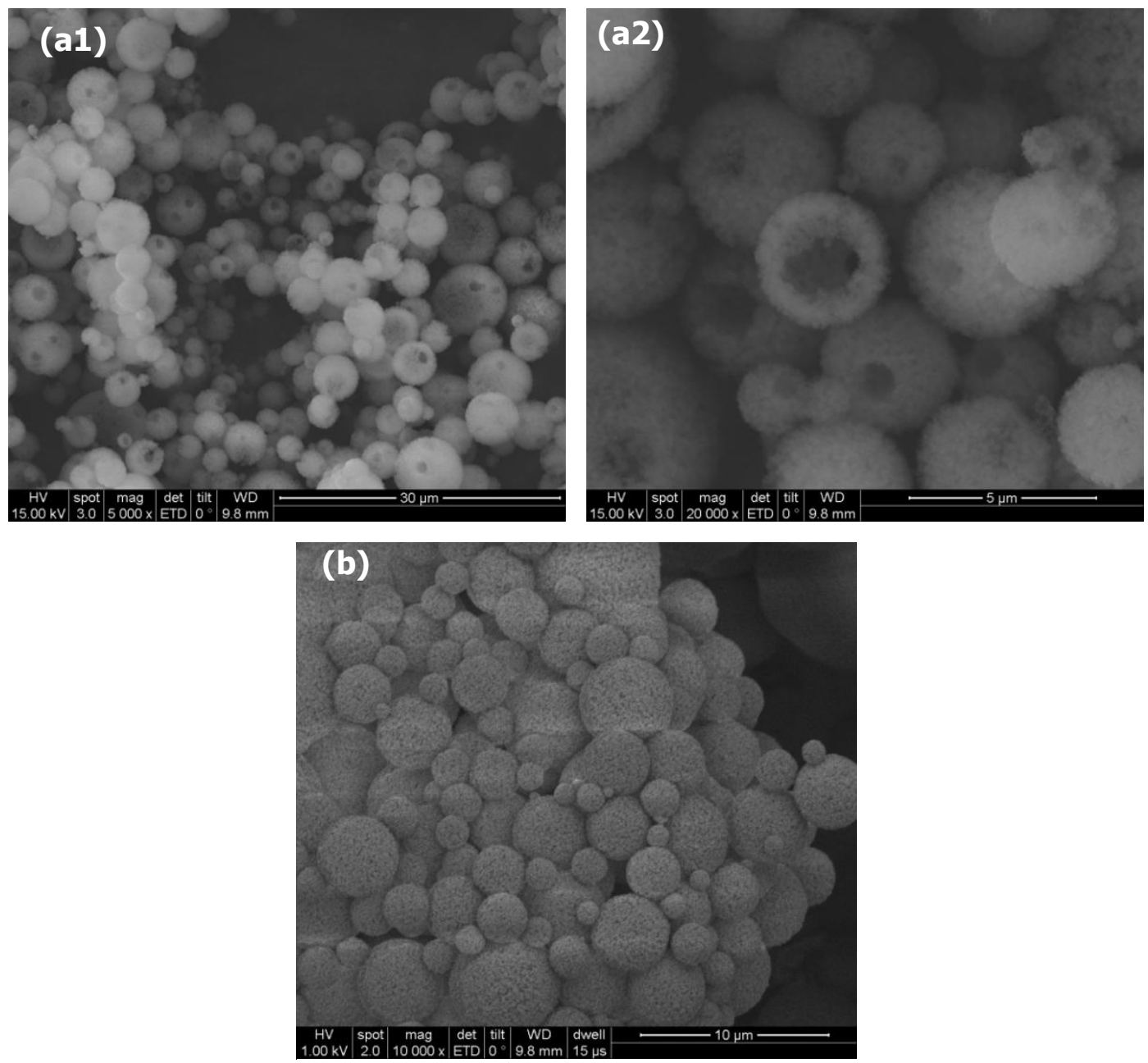

Figure 4.20 SEM micrographs of polymer particles, (a1, a2); with BPO, and (b) with AIBN.

The morphology of particles obtained was extensively affected by the type of initiator used. The ones obtained using BPO had loose and porous surface morphology; and some particles had holes as seen from Figure 4.20a1 and a2. The particles obtained by using AIBN as initiator did not have such defects as seen from Figure 4.20b. Therefore all polymerization experiments were conducted by using AIBN. 


\subsubsection{FTIR Spectrum of Polymer Pigment}

The Fourier Transform Infrared (FTIR) spectrum of polymer produced is given in Figure 4.21. The sharp intense peak at $1728 \mathrm{~cm}^{-1}$ is due to stretching of carbonyl group $(\mathrm{C}=0)$ of ester. The peak at 1141 corresponds to stretching vibration of $\mathrm{C}-\mathrm{O}$ (ester bond). The peaks ranging from 970 to $700 \mathrm{~cm}^{-1}$ are caused by the bending of $\mathrm{C}-\mathrm{H}$. In addition, $\mathrm{C}-\mathrm{H}$ stretching of aromatic groups appears in range of $2850-3100 \mathrm{~cm}^{-1}$. These peaks may belong to additives, i.e. surfactants and PVP.

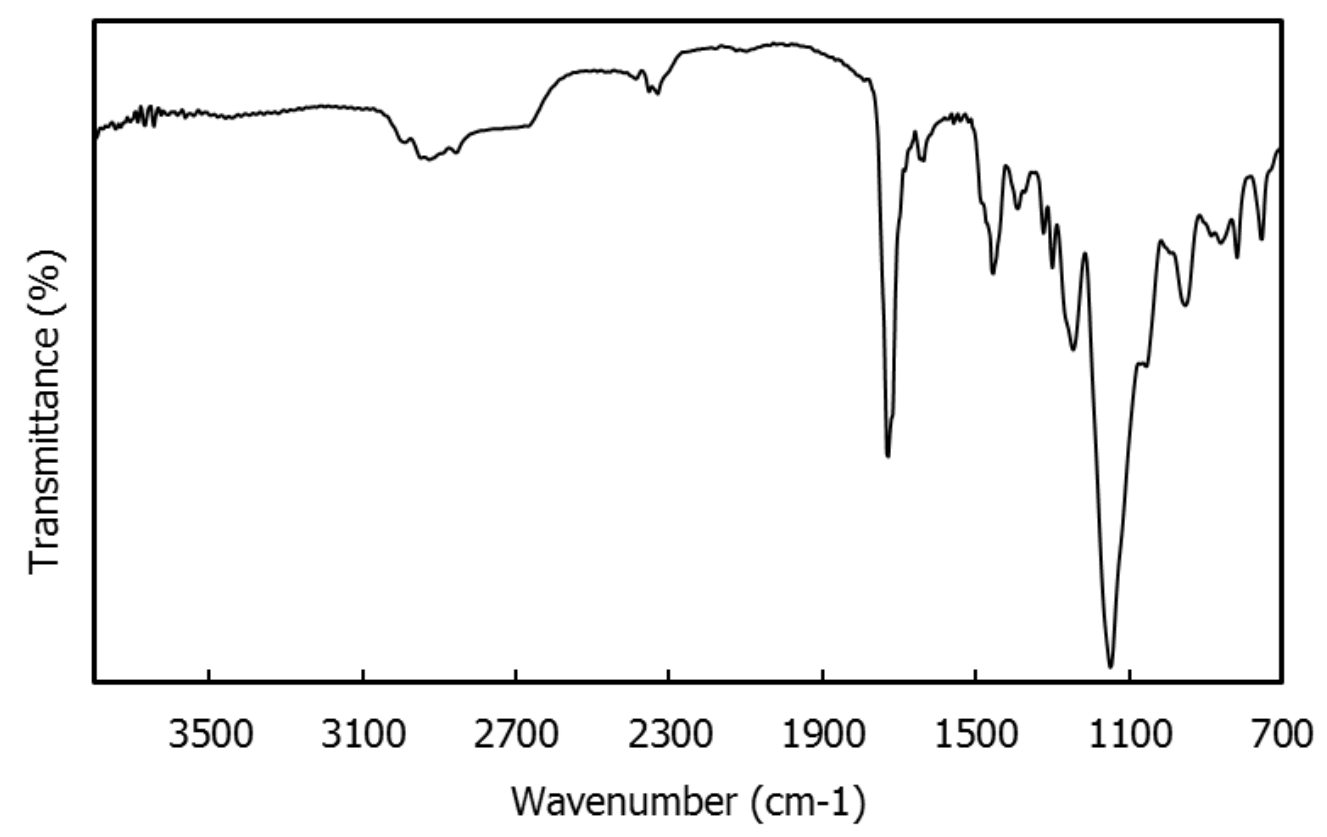

Figure 4.21 FTIR spectrum of the synthesized polymer pigment.

\subsection{Morphology of Opaque Polymer Pigments}

In this section, the morphology of produced opaque polymer pigments and the effects of parameters on hollow structure were investigated. The compositions of the opaque pigments examined are given in Table 4.3. 
Table 4.3 Compositions of opaque pigments.

\begin{tabular}{|c|c|c|c|}
\hline & $\mathbf{s} / \mathbf{m}$ & $\mathbf{w} / \mathbf{m}$ & $\begin{array}{c}\text { Thickener } \\
(\% \mathbf{w} / \mathbf{w})\end{array}$ \\
\hline OP1 & 0.125 & 0.1 & - \\
\hline OP2 & 0.125 & 0.2 & - \\
\hline OP3 & 0.125 & 0.3 & - \\
\hline OP4 & 0.075 & 0.2 & - \\
\hline OP5 & 0.175 & 0.2 & - \\
\hline OP6 & 0.125 & 0.2 & 0.25 \\
\hline OP7 & 0.125 & 0.2 & 0.5 \\
\hline OP8 & 0.125 & 0.2 & 1.0 \\
\hline OP9 & 0.125 & 0.2 & 1.5 \\
\hline
\end{tabular}

$\mathbf{s} / \mathbf{m}$ : Weight ratio of Span 80-Tween 80 (HLB 8) to monomer phase MMA:EGDMA (1:1). $\mathbf{w} / \mathbf{m}$ : Weight ratio of water to monomer phase MMA:EGDMA (1:1).

Thickener ( $\% \mathbf{w} / \mathbf{w})$ : Percent weight ratio of thickener (Polystyrene) in monomer phase.

\subsubsection{Effect of the Inner Water Phase Ratio}

The amount of water has significant effect on the stability of both W/O and W/O/W emulsions; it in turn affects the hollow structure of polymer particle. Voids (i.e. water droplets) can be captured inside the emulsions only if stability can be persistently accomplished. The previous stability results showed that high amount of water destabilized the W/O emulsion. On the other hand, the number of hollows increases with the increase of water/monomer ratio. In order to investigate the effect of water on hollow polymer structure, the $\mathrm{W} / \mathrm{O} / \mathrm{W}$ emulsions prepared at different water (encapsulated)/monomer ratios. 
The surface morphology of particles was investigated by SEM analysis (Figure 4.22). As observed from the micrographs, all the polymer particles have spherical structure with polydispersed size.
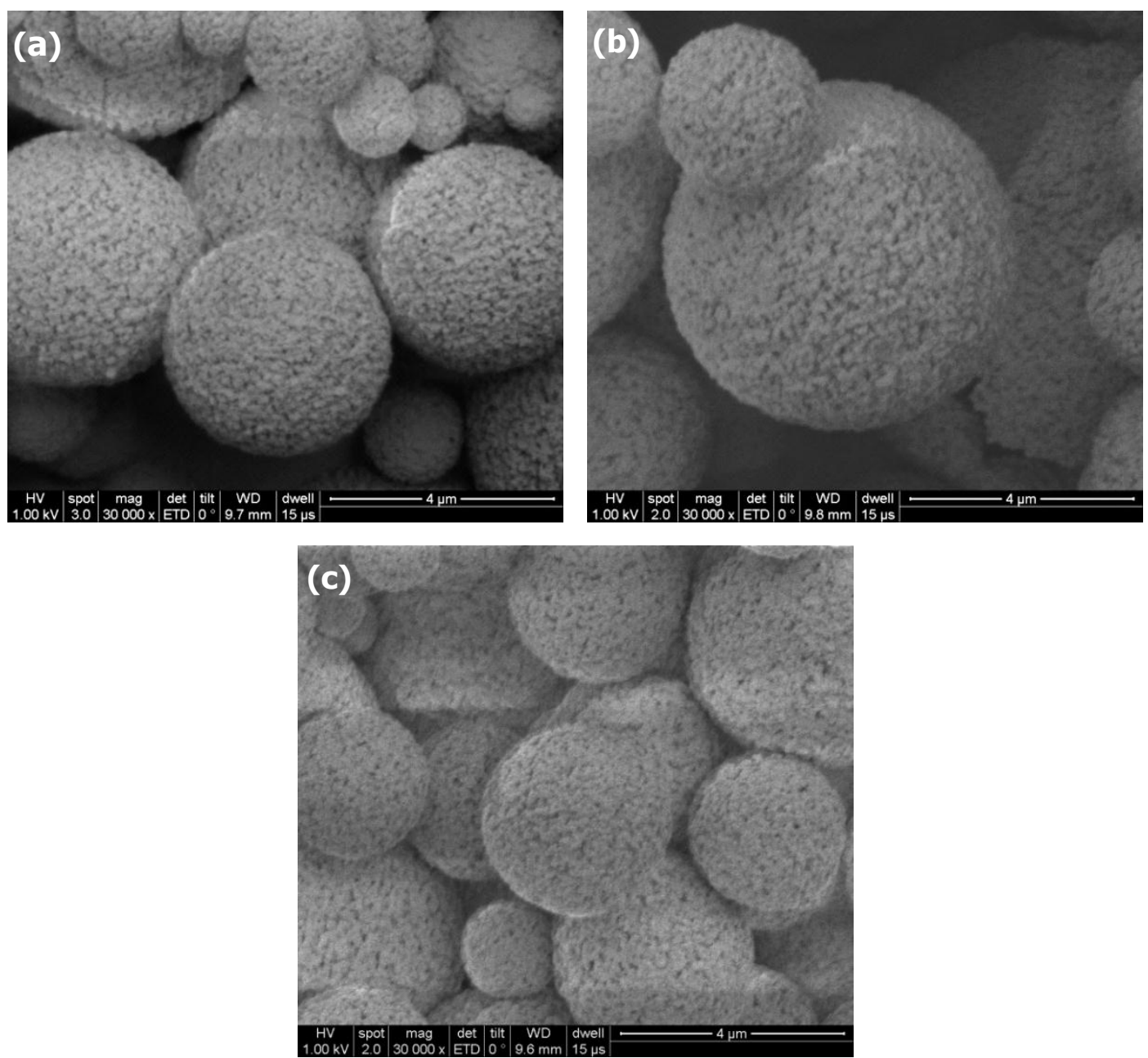

Figure 4.23 SEM micrographs of (a) OP1, (b) OP2, and (c) OP3.

The particles have a rough surface which is possibly the consequence of the high degree of crosslinking. The excessive crosslinking increases the porosity of polymer network systems. The very small particles formed may have either single hollow or no hollow as mentioned previously (see Figure 4.18). 
The multihollow structure of polymer pigment is clearly seen in the SEM micrograph of an OP2 particle (Figure 4.23). It is seen that larger voids also formed which might be caused by the coalescence or Ostwald ripening of the water droplets at early stages of polymerization.

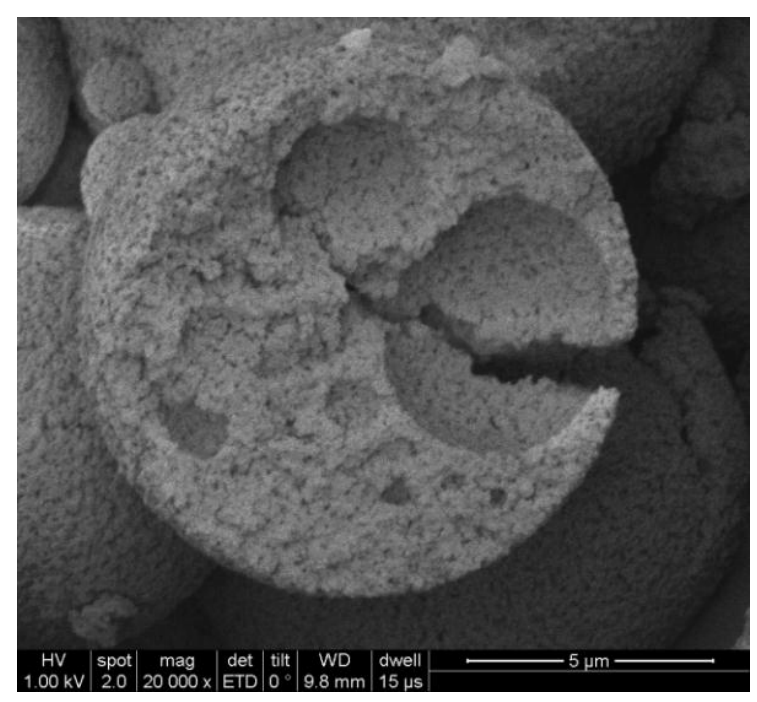

Figure 4.23 An OP2 particle.

In order to confirm the existence of voids inside the particles and examine the influence of water on hollow structure the TEM analysis of polymer particles were performed. In fact, the micron size particles are not appropriate samples for TEM analysis where relatively high thickness prevents the transmission of electrons. However, the presence of voids inside the particle lowers the wall thickness and makes possible to observe voids by contrast difference. The TEM micrographs of OP1, OP2, and OP3 are given in Figure 4.24. The lighter spherical zones in these micrographs represent the hollows. 

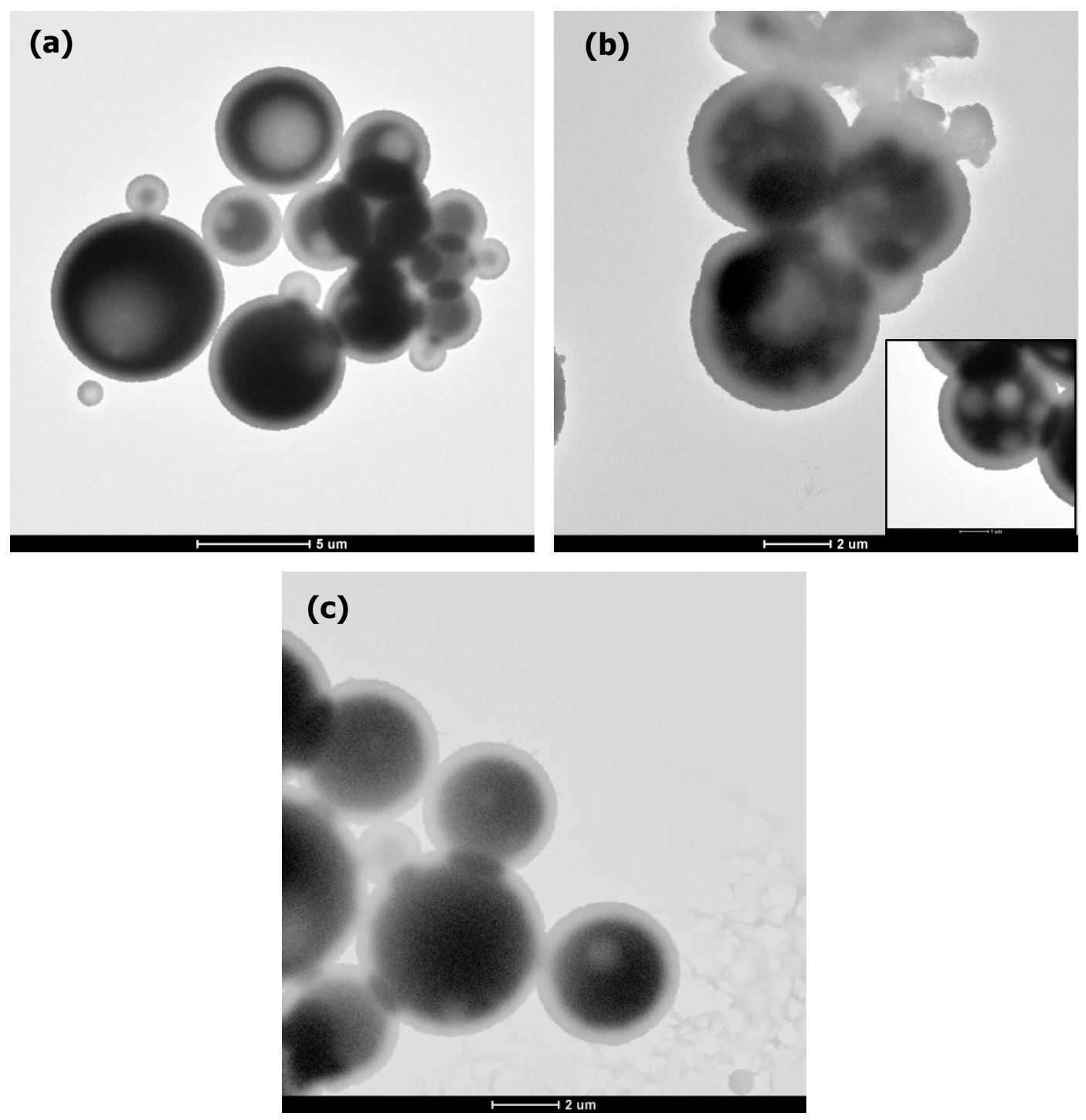

Figure 4.24 TEM micrographs of (a) OP1 (w/m:0.1), (b) OP2 (w/m:0.2), and (c) OP3 (w/m:0.3).

The TEM micrographs indicate that the number of voids per particle increased with the increase of the amount of water. This can be clearly seen from the comparison of OP2 (w/m:0.2) with OP1 (w/m:0.1). The number of the multihollows in OP1 is higher than the ones in OP2. In fact OP1 is dominated by single hollows while each particle in OP2 contains several hollows. On the other hand, further increase in the amount of water lowered the number of hollows as seen from in OP3 ( $\mathrm{w} / \mathrm{m}: 0.3)$ case. The reason 
might be the decreased $\mathrm{W} / \mathrm{O} / \mathrm{W}$ emulsion stability due to the excess amount of water which creates voids.

\subsubsection{Effect of Surfactants Used in W/O Emulsion}

The TEM micrographs of OP4 and OP5 are given in Figure 4.25, where, OP4 and OP5 had the surfactant (Span 80-Tween 80) mixture to monomer phase (MMA:EGDMA (1:1)) weight ratio of 0.075 and 0.175 , respectively.
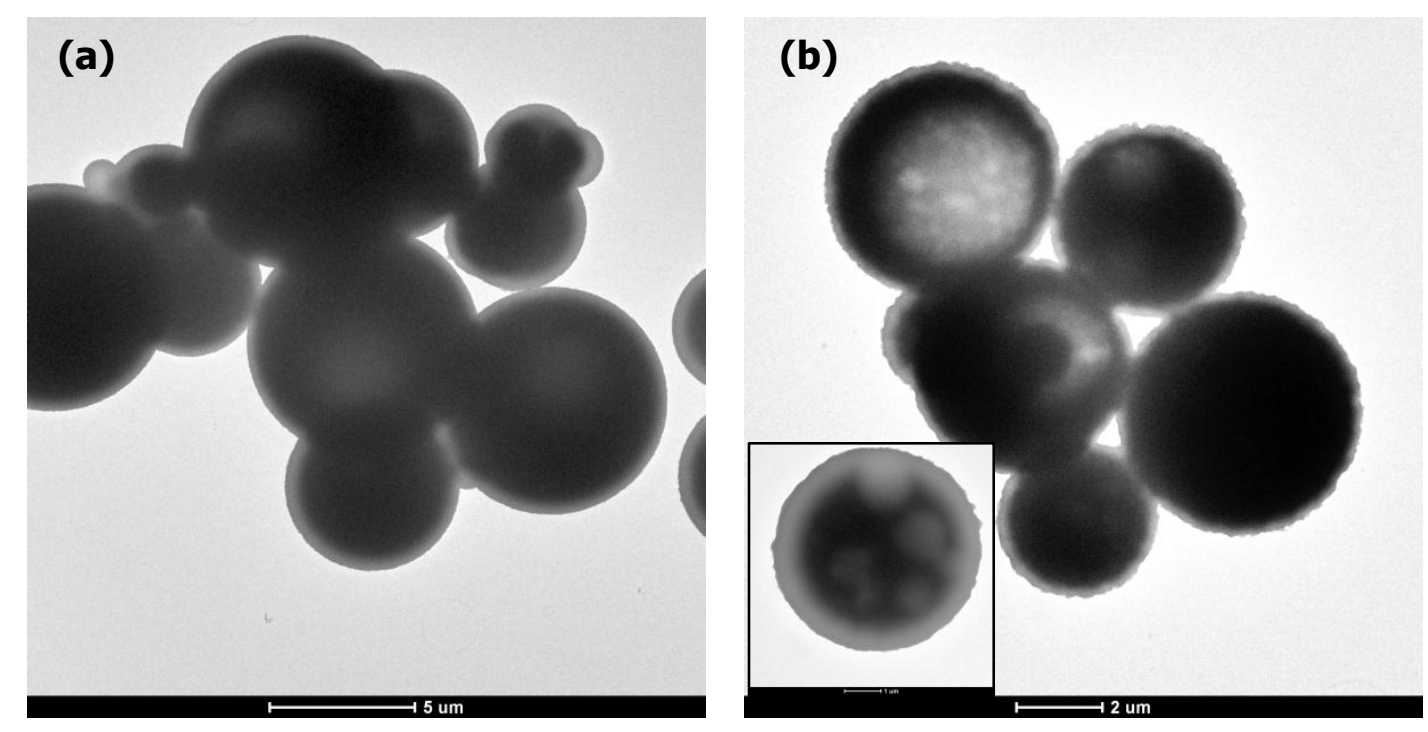

Figure 4.25 TEM micrographs of (a) OP4 (s/m:0.125) and (b) OP5 (s/m:0.175).

OP5 has larger number of multihollows than OP4. The reason is thought to be the increased interfacial film strength of the W/O emulsion with higher amount of surfactant molecules which provided higher stability. 


\subsubsection{Effect of Thickener}

In this study, a thickening agent was also used to enhance the $\mathrm{W} / \mathrm{O} / \mathrm{W}$ emulsion stability by increasing the viscosity of monomer phase. The increase of viscosity is expected to lower the Ostwald ripening. In order to increase viscosity, the solution of polystyrene (PS) in methyl methacrylate $(10 \% \mathrm{w} / \mathrm{w})$ was prepared and added to monomer phase. PS dissolved more easily in methyl methacrylate than polymethyl metacrylate. The viscosity change of solution with the amount of PS in monomer mixture is shown in Figure 4.26.

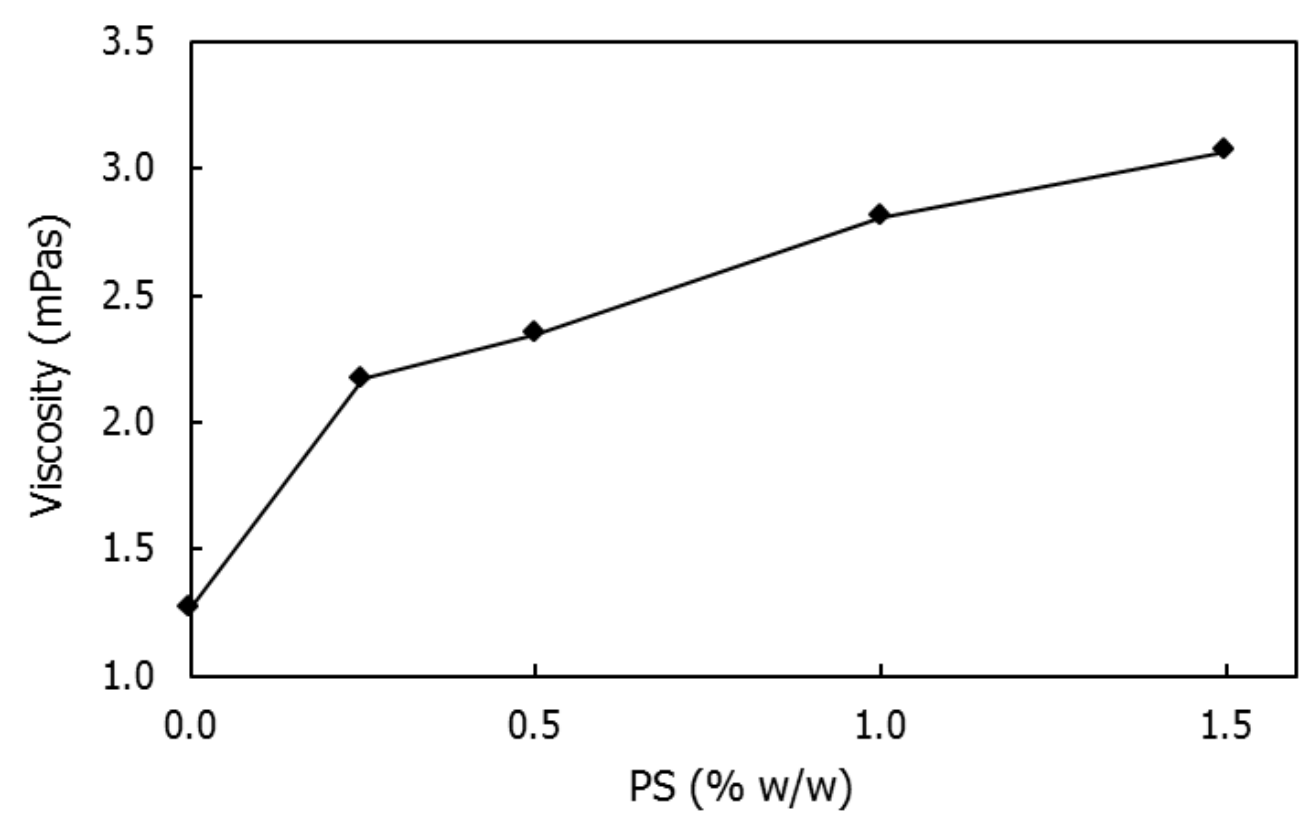

Figure 4.26 Effect of PS concentration on MMA:EGDMA (1:1) mixture.

The TEM micrographs of the synthesized polymer pigments OP6, OP7, OP8, and OP9 having PS are given in Figure 4.27. The TEM micrographs of PS containing specimens were not very clear. As observed from the TEM micrographs, the multihollow structured particles were also obtained when 
the PS content was low (OP6 and OP7). The high amounts of PS adversely affected the morphology as seen from Figure $4.27 c$ and $d$.
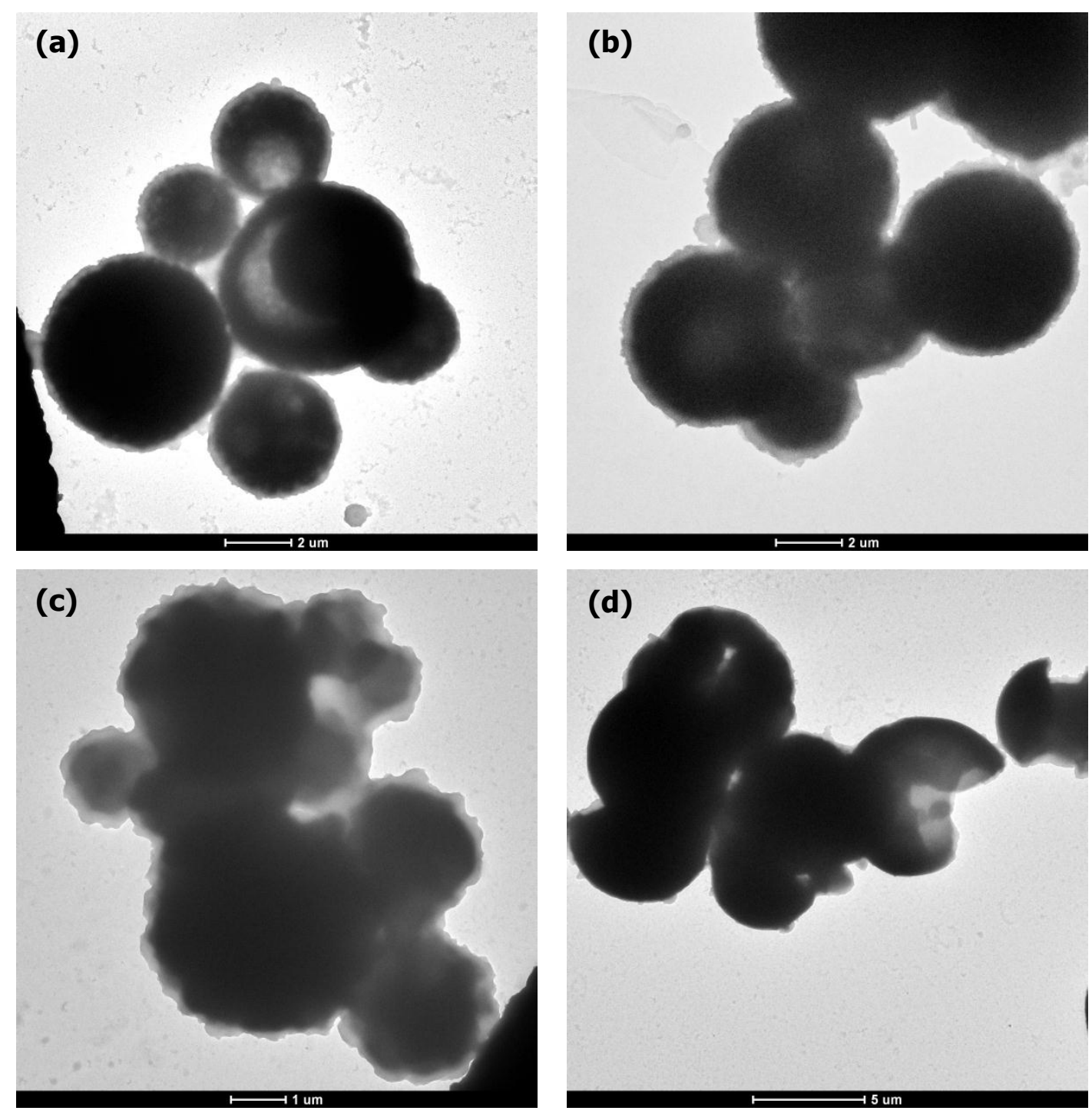

Figure 4.27 TEM micrographs of (a) OP6 $(0.25 \% \mathrm{w} / \mathrm{w})$, (b) OP7 $(0.5$ $\% \mathrm{w} / \mathrm{w})$, (c) OP8 (1\%w/w), and (d) OP9 (1.5\%w/w). 


\subsection{Opacity Measurements}

The opacity, the white appearance, and the hiding power depend on the scattering ability of hollow polymer particles. The voids act as scattering centers and deviate the direction of incident visible radiations. The opacity of the polymer pigments dependent both on the size of voids and on the number of hollows inside the particles.

The opacity measurements of synthesized polymer pigments are given in Table 4.4, where the opacity of $\mathrm{TiO}_{2}$ is given in the last column. The results show that the particles OP2, OP5, and OP6 which have high number of multihollows have highest opacities.

The existence of multiple voids inside a particle increase the number of polymer-air interface and create multiple scatterings which physically result in higher diffraction.

Table 4.4 Opacity measurement results of polymer pigments

\begin{tabular}{|l|l|l|l|l|l|l|l|l|l|l|}
\hline & OP1 & OP2 & OP3 & OP4 & OP5 & OP6 & OP7 & OP8 & OP9 & TiO $_{2}$ \\
\hline Opacity & 87.6 & 93.9 & 90.8 & 78.9 & 97.3 & 96.1 & 91.9 & 87.0 & 82.3 & 100 \\
\hline
\end{tabular}

Another property which influences the extent of opacity is the surface morphology of particles. Opacity increases as the surface roughness increases, because roughness generates different angle of reflections and increases diffraction. 


\subsection{Effect of the Amount of Pigment on Paint Opacity}

A commercial paint contains about $1 / 3$ resin and $2 / 3$ pigment in volume excluding solvent. In order to determine the effect of hollow polymers synthesized on the opacity of a paint the hollow pigments were added into water based styrene-acrylic resin. It was supplied by BETEK. The change of opacity with the amount of added hollow pigment was given in Figure 4.28. The opacity increases with the amount of loaded pigment. For comparison the opacity change with $\mathrm{TiO}_{2}$ is also given in Figure 4.28. At $50 \%$ loading the opacity of polymer pigment and $\mathrm{TiO}_{2}$ become almost equal. In the industry unless high gloss is needed relatively cheaper pigments with relatively low gloss such as calcite and extenders like barite $\left(\mathrm{BaSO}_{4}\right)$ are used in paints. So the multihollow polymer pigments can be a good substitute for such low gloss pigments and extenders.

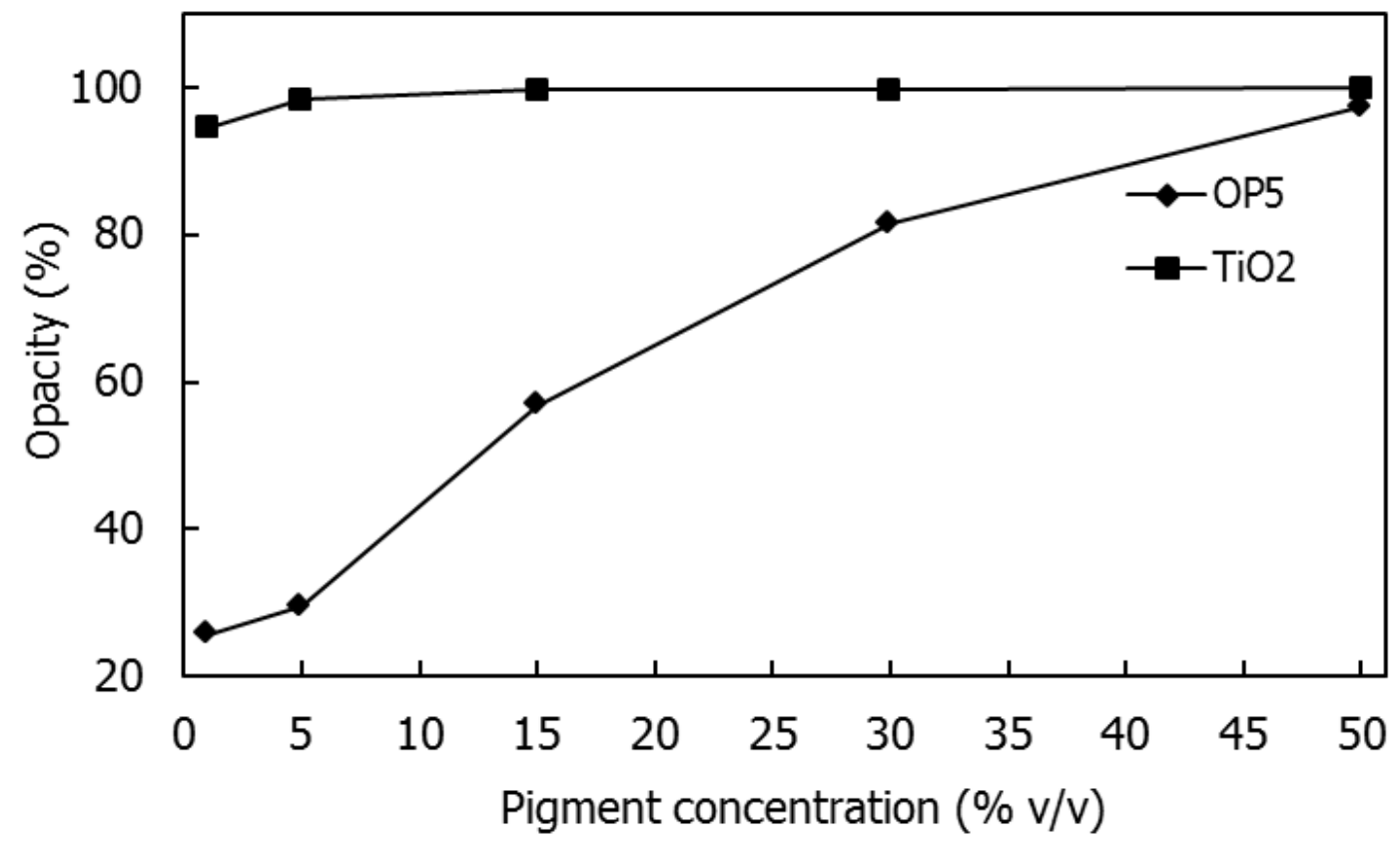

Figure 4.28 Effect of pigment concentration on paint opacity. 


\subsection{Gloss Measurements}

The results of the specular gloss measurements at incident angles of $20^{\circ}$, $60^{\circ}$, and $85^{\circ}$ are given in Table 4.5. The very low gloss values actually are due to the very high opacity of pigments synthesized.

Table 4.5 Gloss values of opaque polymer pigments.

\begin{tabular}{|l|c|c|c|}
\hline & $\mathbf{2 0}$ & $\mathbf{6 0}^{\circ}$ & $\mathbf{8 5}^{\circ}$ \\
\hline OP1 & 1.9 & 2.9 & 1.6 \\
\hline OP2 & 1.9 & 2.7 & 3.0 \\
\hline OP3 & 1.8 & 2.7 & 1.5 \\
\hline OP4 & 1.8 & 3.0 & 2.3 \\
\hline OP5 & 1.9 & 2.6 & 2.5 \\
\hline OP6 & 1.8 & 2.6 & 1.9 \\
\hline OP7 & 1.9 & 2.8 & 1.6 \\
\hline OP8 & 1.8 & 2.6 & 0.8 \\
\hline OP9 & 1.9 & 2.9 & 1.2 \\
\hline St-Ac Resin & 137.7 & 133.2 & 110.9 \\
\hline
\end{tabular}

St-Ac Resin: Styrene-Acrylic resin, without pigment addition.

\subsection{L*a*b Color Measurement}

In Table 4.6 and Figure 4.29 the color deviations of synthesized opaque polymer pigments are given when $\mathrm{TiO}_{2}$ is taken as the reference. As seen from Table 4.6 the opaque pigments OP2 and OP5 (which have low dL* values) have more close lightness and less total color difference (dE*) to $\mathrm{TiO}_{2}$ than the others. The shift of color to blue might be caused by the 
existence of polymer particles having diameters lower than $100 \mathrm{~nm}$. Below this diameter, particles make more Rayleigh scattering which inversely changes with the fourth power of wavelength of radiation. That is, blue component of visible light undergoes more scattering and starts to dominate the overall spectrum, and the color shifts to the blue side.

Table 4.6 The color properties of opaque polymer pigments compared to $\mathrm{TiO}_{2}$.

\begin{tabular}{|l|c|c|c|c|}
\hline & $\mathbf{d L} *$ & $\mathbf{d a} *$ & $\mathbf{d b} *$ & $\mathbf{d E} *$ \\
\hline OP1 & -18.93 & 0.86 & -1.92 & 19.05 \\
\hline OP2 & -9.49 & 0.53 & -2.22 & 9.76 \\
\hline OP3 & -15.17 & 0.82 & -1.91 & 15.31 \\
\hline OP4 & -19.00 & 1.27 & 0.46 & 19.05 \\
\hline OP5 & -8.38 & 0.44 & -1.78 & 8.58 \\
\hline OP6 & -11.26 & 0.30 & -2.47 & 11.53 \\
\hline OP7 & -15.79 & 0.75 & -1.38 & 15.87 \\
\hline OP8 & -20.27 & 1.06 & -0.09 & 20.30 \\
\hline OP9 & -28.96 & 1.25 & 0.48 & 28.99 \\
\hline
\end{tabular}




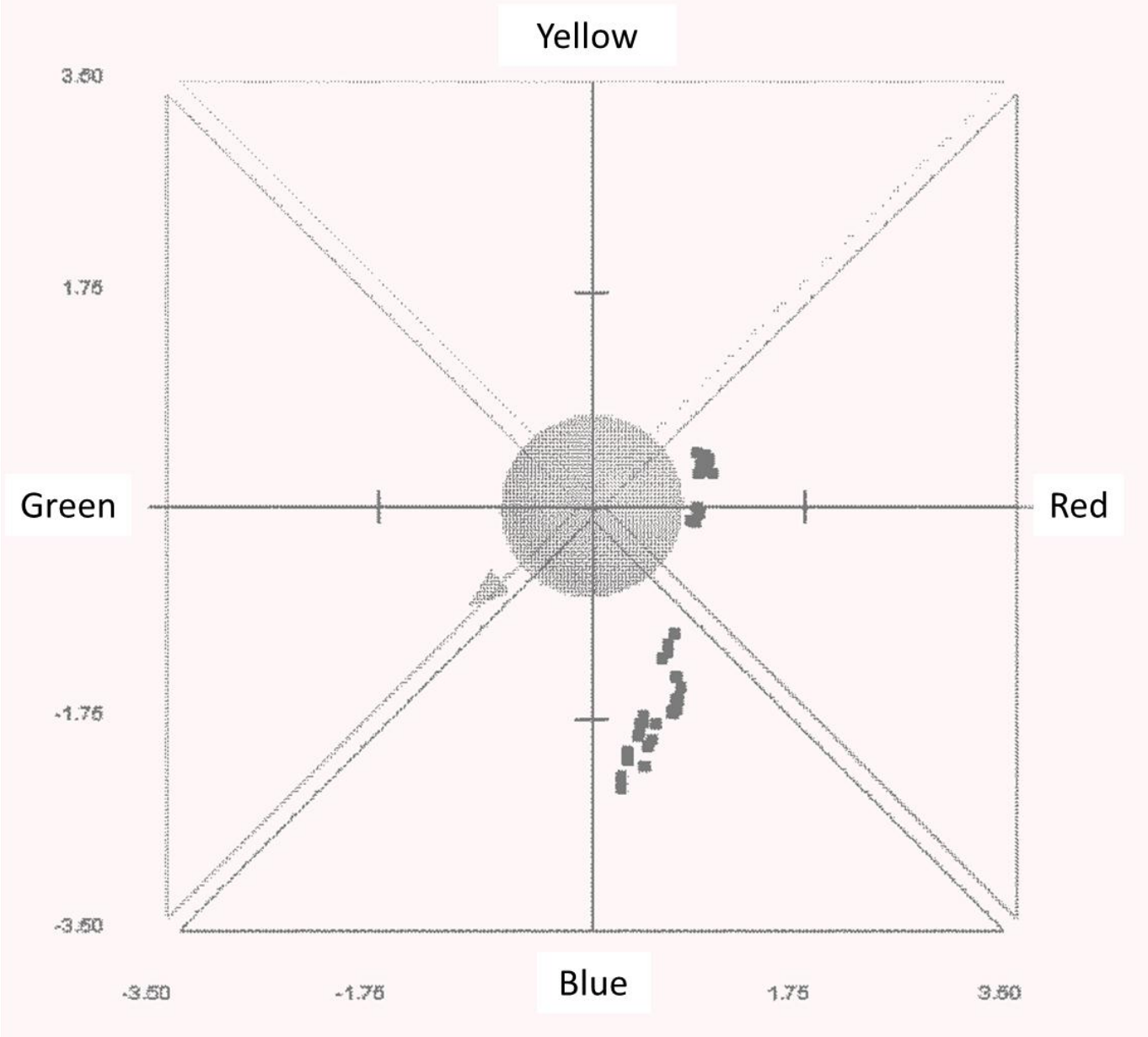

Figure 4.29 Illustration of the color properties of opaque pigments compared to $\mathrm{TiO}_{2}$. 


\section{CHAPTER 5}

\section{CONCLUSIONS}

1. The mixture of "Span 80-Tween 80" surfactants provided better emulsion stability than "Span 80-only" for W/O emulsion.

2. The surfactant mixture with the HLB values of 8 and 9 yielded better stability, and lowered the water droplet size.

3. By using ultrasonication submicron sized water droplets were obtained at $80 \mathrm{~W}$ power and in 30 seconds.

4. The optimum diameters of voids for high scattering efficiency were predicted by a mathematical model using the Mie scattering. Voids having a size distribution ranging within the wavelength of visible spectrum radiations are more effective than singular sized voids for light scattering.

5. Monomer/surfactant/water (M/S/W) weight ratio had significant effect on both W/O emulsion stability and on water droplet size. W/O emulsion having water droplet diameters close to wavelength of visible radiations was obtained with the $\mathrm{M} / \mathrm{S} / \mathrm{W}$ ratio of $75.5 / 9.4 / 15.1$.

6. The $\mathrm{W} / \mathrm{O} / \mathrm{W}$ emulsion was prepared by the dispersion of the $\mathrm{W} / \mathrm{O}$ emulsion in aqueous solution of hydrophilic surfactant Triton X-405. The increase of surfactant concentration, mechanical mixing speed, 
and time had reducing effect on the monomer droplet size of the W/O/W double emulsion. The optimum size for the monomer droplet which then formed polymer particles, was obtained at $1250 \mathrm{rpm}$ mixing for 4 minutes. Droplets were both large enough to include multiple water droplets.

7. The $\mathrm{W} / \mathrm{O} / \mathrm{W}$ emulsion was stabilized by using the $1 \% \mathrm{w} / \mathrm{w}$ PVP solution, and polymerized at $55^{\circ} \mathrm{C}$ for 20 hours to obtain opaque polymer particles successfully.

8. High degree of crosslinking due to EGDMA resulted in porous structure and rough surface.

9. Multihollow structured opaque polymer particles were successfully produced after carrying out a series of optimization experiments for the amount of water and surfactants.

10. The increase of the viscosity of monomer phase due to the use of a thickener (in this study, PS) slightly enhanced the double emulsion stability. However, further increase in viscosity had destructive effect on voids and particle sphericity.

11. The produced polymer pigments provided $97.3 \%$ opacity at $50 \% \mathrm{v} / \mathrm{v}$ without any other additive.

12. The polymer pigment particles had very low gloss (very high opacity). 


\section{CHAPTER 6}

\section{RECOMMENDATIONS}

1. The stability of $\mathrm{W} / \mathrm{O}$ emulsion can be investigated by different surfactant system.

2. The effect of void size on scattering efficiency can be studied experimentally by producing narrow size distributed hollows.

3. Opaque polymer particles can be colored by encapsulation of color pigments inside the voids. 


\section{REFERENCES}

1. Mie, G., Beiträge zur Optik trüber Medien, speziell kolloidaler Metallösungen. Annalen der Physik, 1908. 330(3): p. 377-445.

2. Mishchenko, M.I., Gustav Mie and the fundamental concept of electromagnetic scattering by particles: A perspective. JOURNAL OF QUANTITATIVE SPECTROSCOPY \& RADIATIVE TRANSFER, 2009. 110(14-16 SI): p. 1210-1222.

3. Helmuth, H., Gustav Mie and the scattering and absorption of light by particles: Historic developments and basics. Journal of Quantitative Spectroscopy and Radiative Transfer, 2009. 110(11): p. 787-799.

4. Bohren, C.F. and D.R. Huffman, Absorption and Scattering by a Sphere, in Absorption and Scattering of Light by Small Particles2007, Wiley-VCH Verlag GmbH. p. 82-129.

5. Hulst, H.C.v.d., Light scattering by small particles. New York (John Wiley and Sons), London (Chapman and Hall), 1957. Pp. xiii, 470; 103 Figs.; 46 Tables. 96s. Quarterly Journal of the Royal Meteorological Society, 1958. 84(360): p. 198-199.

6. Deng, W., et al., Morphological evolution of multistage polymer particles in the alkali post-treatment. European Polymer Journal, 2010. 46(6): p. 1210-1215.

7. McDonald, C.J. and M.J. Devon, Hollow latex particles: synthesis and applications. Advances in Colloid and Interface Science, 2002. 99(3): p. $181-213$.

8. Masahiro, N., Places of emulsions in drug delivery. Advanced Drug Delivery Reviews, 2000. 45(1): p. 1-4.

9. Axel, B. and G. Nissim, Recent Developments in Double Emulsions for Food Applications, in Food Emulsions2003, CRC Press.

10. Vasudevan, T.V. and M.S. Naser, Some Aspects of Stability of Multiple Emulsions in Personal Cleansing Systems. Journal of Colloid and Interface Science, 2002. 256(1): p. 208-215.

11. Schwuger, M.J., Surfactants and Interfacial Phenomena. Von M. J. Rosen. John Wiley \& Sons, New York 1978. 1. Aufl., XIV, 304 S., geb. $\$ 30.45$. Angewandte Chemie, 1979. 91(5): p. 451-451. 
12. Somasundaran, P., et al., Emulsions and Their Behavior, in Surfactants in Personal Care Products and Decorative Cosmetics, Third Edition2006, CRC Press. p. 149-175.

13. Tadros, T.F., Emulsion Science and Technology: $A$ General Introduction, in Emulsion Science and Technology2009, Wiley-VCH Verlag GmbH \& Co. KGaA. p. 1-56.

14. Engberts, J.B.F.N., Applied Surfactants. Principles and Applications. By Tharwat F. Tadros. Angewandte Chemie International Edition, 2005. 44(37): p. 5922-5922.

15. Tadros, T.F., ed. Emulsion Science and Technology. 2009, WILEY-VCH Verlag GmbH \& Co. KGaA: Weinheim.

16. Porras, M., et al., Properties of water-in-oil (W/O) nano-emulsions prepared by a low-energy emulsification method. Colloids and Surfaces A: Physicochemical and Engineering Aspects, 2008. 324(13): p. 181-188.

17. Peng, L.-C., et al., Optimization of water-in-oil nanoemulsions by mixed surfactants. Colloids and Surfaces A: Physicochemical and Engineering Aspects, 2010. 370(1-3): p. 136-142.

18. Song, M.-G., et al., Rapid Evaluation of Water-in-Oil (w/o) Emulsion Stability by Turbidity Ratio Measurements. Journal of Colloid and Interface Science, 2000. 230(1): p. 213-215.

19. Boyd, J., C. Parkinson, and P. Sherman, Factors affecting emulsion stability, and the HLB concept. Journal of Colloid and Interface Science, 1972. 41(2): p. 359-370.

20. Griffin, W., Classification of Surface-Active Agents by 'HLB'. Journal of theSociety of Cosmetic Chemists, 1949. 1: p. 311-326.

21. WC, G., Calculation of HLB Values of Non-Ionic Surfactants. Journal of theSociety of Cosmetic Chemists, 1954. 5: p. 259.

22. Paint and Coating Testing Manual, (Gradner-Sward Handbook, 14th Edition) edited by Dr. Joseph V. Koleske. 1995: p. 156-178.

23. Auger, J.-C., V. Martinez, and B. Stout, Theoretical study of the scattering efficiency of rutile titanium dioxide pigments as a function of their spatial dispersion. Journal of Coatings Technology and Research, 2009. 6(1): p. 89-97. 
24. Thiele, E.S. and R.H. French, Light-Scattering Properties of Representative, Morphological Rutile Titania Particles Studied Using a Finite-Element Method. Journal of the American Ceramic Society, 1998. 81(3): p. 469-479.

25. Gündüz, G., Boya bilgis12002, Ankara: TMMOB Kimya mühendisleri Odası.

26. Rong, Y., et al., Encapsulation of titanium dioxide particles by polystyrene via radical polymerization. Colloids and Surfaces A: Physicochemical and Engineering Aspects, 2005. 253(1-3): p. 193197.

27. Erdem, B., et al., Encapsulation of inorganic particles via miniemulsion polymerization. II. Preparation and characterization of styrene miniemulsion droplets containing TiO2 particles. Journal of Polymer Science Part A: Polymer Chemistry, 2000. 38(24): p. 4431-4440.

28. Peng, B., et al., Preparation of PS/TIO2/UF multilayer core-shell hybrid microspheres with high stability. Journal of Colloid and Interface Science, 2009. 329(1): p. 62-66.

29. Itou, N., et al., Cross-linked hollow polymer particles by emulsion polymerization. Colloids and Surfaces A: Physicochemical and Engineering Aspects, 1999. 153(1-3): p. 311-316.

30. Kowalski A., V.M., Polymeric pigment particles. US Patent 4427836, 1984.

31. Kowalski A., V.M., Core sheath polymer particles production useful as opacifying agent US Patent 446925, 1984.

32. Khan, A.K., B.C. Ray, and S.K. Dolui, Preparation of core-shell emulsion polymer and optimization of shell composition with respect to opacity of paint film. Progress in Organic Coatings, 2008. 62(1): p. 65-70.

33. McDonald, C.J., et al., Emulsion Polymerization of Voided Particles by Encapsulation of a Nonsolvent. Macromolecules, 2000. 33(5): p. 1593-1605.

34. Hahn, D.W., Light Scattering Theory. Department of Mechanical and Aerospace Engineering, University of Florida, 2009.

35. Skoog, D.A., F.J. Holler, and S.R. Crouch, Principles of instrumental analysis2007, Australia: Brooks/Cole : Thomson Learning. 
36. Matzler, C., MATLAB functions for Mie scattering absorption. Universitas Bernensis, Research report no. 2002-08, 2002.

37. Myers, D., An Overview of Surfactant Science and Technology, in Surfactant Science and Technology2005, John Wiley \& Sons, Inc. p. 128.

38. Nakashima, T., M. Shimizu, and M. Kukizaki, Particle control of emulsion by membrane emulsification and its applications. Advanced Drug Delivery Reviews, 2000. 45(1): p. 47-56.

39. Kei, W., et al., Bicontinuous Microemulsion Type Cleansing Containing Silicone Oil. II : Characterization of the Solution and Its Application to Cleansing Agent. Journal of Oleo Science, 2004. 53(11): p. 547-555.

40. Smulders, E., et al., Laundry Detergents, in Ullmann's Encyclopedia of Industrial Chemistry2000, Wiley-VCH Verlag GmbH \& Co. KGaA.

41. Walsh, D., Microemulsions.Background, New Concepts, Applications, Perspectives. Herausgegeben von Cosima Stubenrauch. Angewandte Chemie, 2009. 121(25): p. 4542-4542.

42. Peter A. Lovell, M.S.E.-A., ed. Emulsion Polymerization and Emulsion Polymers. 1997, John Wiley \& Sons Ltd: England.

43. Porras, M., et al., Studies of formation of W/O nano-emulsions. Colloids and Surfaces A: Physicochemical and Engineering Aspects, 2004. 249(1-3): p. 115-118.

44. Wang, L., et al., Design and optimization of a new selfnanoemulsifying drug delivery system. Journal of Colloid and Interface Science, 2009. 330(2): p. 443-448.

45. Fanun, M., Microemulsions : properties and applications2009, Boca Raton: CRC Press.

46. Ruckenstein, E., Microemulsions, Macroemulsions, and the Bancroft Rule. Langmuir, 1996. 12(26): p. 6351-6353.

47. Bancroft, W.D., The Theory of Emulsification, V. The Journal of Physical Chemistry, 1912. 17(6): p. 501-519.

48. Arai, $\mathrm{H}$. and K. Shinoda, The effect of mixing of oils and of nonionic surfactants on the phase inversion temperatures of emulsions. Journal of Colloid and Interface Science, 1967. 25(3): p. 396-400.

49. Myers, D., Emulsions, in Surfactant Science and Technology2005, John Wiley \& Sons, Inc. p. 280-322. 
50. Zatz, J.L., Encyclopedia of emulsion technology. Volume 3. Edited by Paul Becher. Marcel Dekker: New York. 1987. xi + 437 pp. ISBN 08247-1878-X. \$115.00. Journal of Pharmaceutical Sciences, 1989. 78(7): p. 607-607.

51. Sajjadi, S., Nanoemulsion Formation by Phase Inversion Emulsification: On the Nature of Inversion. Langmuir, 2006. 22(13): p. 5597-5603.

52. Kunieda, H., et al., The formation of ge/-emulsions in a water/nonionic surfactant/oil system. Colloids and Surfaces, 1987. 24(2-3): p. 225237.

53. Williams, J.M. and D.A. Wrobleski, Spatial distribution of the phases in water-in-oil emulsions. Open and closed microcellular foams from cross-linked polystyrene. Langmuir, 1988. 4(3): p. 656-662.

54. Williams, J.M., High internal phase water-in-oil emulsions: influence of surfactants and cosurfactants on emulsion stability and foam quality. Langmuir, 1991. 7(7): p. 1370-1377.

55. Chan Ik Park, W.-G.C., Seong Jae Lee, Emulsion stability of cosmetic creams on water-in-oil high internal phase emulsions. Korea-Australia Rheology Journal, 2003. 15(3): p. 125-130.

56. Nakashima, T. and M. Shimizu, Preparation of Monodispersed O/W Emulsion by Porous Glass Membrane. KAGAKU KOGAKU RONBUNSHU, 1993. 19(6): p. 984-990.

57. Kawakatsu, T., et al., The effect of the hydrophobicity of microchannels and components in water and oil phases on droplet formation in microchannel water-in-oil emulsification. Colloids and Surfaces A: Physicochemical and Engineering Aspects, 2001. 179(1): p. 29-37.

58. Vladisavljević, G.T. and R.A. Williams, Recent developments in manufacturing emulsions and particulate products using membranes. Advances in Colloid and Interface Science, 2005. 113(1): p. 1-20.

59. Sugiura, S., M. Nakajima, and M. Seki, Preparation of monodispersed emulsion with large droplets using microchannel emulsification. Journal of the American Oil Chemists' Society, 2002. 79(5): p. 515519.

60. Cappelezzo, M., et al., Stokes-Einstein relation for pure simple fluids. Journal of Chemical Physics, 2007. 126(22): p. 224516. 
61. Einstein, A., Über die von der molekularkinetischen Theorie der Wärme geforderte Bewegung von in ruhenden Flüssigkeiten suspendierten Teilchen. Annalen der Physik, 1905. 322(8): p. 549560.

62. Stokes, G.G., Mathematical and Physical Papers. 1904. 3.

63. Frising, T., C. Noïk, and C. Dalmazzone, The Liquid/Liquid Sedimentation Process: From Droplet Coalescence to Technologically Enhanced Water/Oil Emulsion Gravity Separators: A Review. Journal of Dispersion Science and Technology, 2006. 27(7): p. 1035-1057.

64. Laplace, P.S., ed. Mécanique céleste. Vol. 10. 1806.

65. Young, T., An Essay on the Cohesion of Fluids. Philosophical Transactions of the Royal Society of London, 1805. 95(ArticleType: research-article / Full publication date: 1805 /): p. 65-87.

66. Pellicer, J., V. García-Morales, and M.J. Hernández, On the demonstration of the Young-Laplace equation in introductory physics courses. Physics Education, 2000. 35(2): p. 126.

67. Binks, B.P., Chapter 1 Emulsions - Recent Advances in Understanding, in Modern Aspects of Emulsion Science1998, The Royal Society of Chemistry. p. 1-55.

68. C., W., Z. Electrochem. 35: p. 581.

69. Deryaguin, B.V.S., R.L., Kolloidn Zhurnal, 1961. 23: p. 33.

70. Saupe, A., Interfacial Phenomena. Von J. T. Davies und E. K. Rideal. Academic Press, New York-London 1963. Angewandte Chemie, 1965. 77(6): p. 276-276.

71. Smoluchowski, M.v., Phys. Chem., 1917: p. 92:129.

72. Ghannam, M.T. and M.Y.E. Selim, Stability Behavior of Water-in-Diesel Fuel Emulsion. Petroleum Science and Technology, 2009. 27(4): p. 396-411.

73. Myers, D., The Organic Chemistry of Surfactants, in Surfactant Science and Technology2005, John Wiley \& Sons, Inc. p. 29-79.

74. Peltonen, L., J. Hirvonen, and J. Yliruusi, The Behavior of Sorbitan Surfactants at the Water-Oil Interface: Straight-Chained Hydrocarbons from Pentane to Dodecane as an Oil Phase. Journal of Colloid and Interface Science, 2001. 240(1): p. 272-276. 
75. Opawale, F.O. and D.J. Burgess, Influence of Interfacial Properties of Lipophilic Surfactants on Water-in-Oil Emulsion Stability. Journal of Colloid and Interface Science, 1998. 197(1): p. 142-150.

76. Ghannam, M.T., Water-in-Crude Oil Emulsion Stability Investigation. Petroleum Science and Technology, 2005. 23(5-6): p. 649-667.

77. Chern, C.-S., Interfacial Phenomena, in Principles and Applications of Emulsion Polymerization2008, John Wiley \& Sons, Inc. p. 23-52.

78. Vander Kloet, J. and L. Schramm, The effect of shear and oil/water ratio on the required hydrophile-lipophile balance for emulsification. Journal of Surfactants and Detergents, 2002. 5(1): p. 19-24.

79. Al-Sabagh, A.M., The relevance HLB of surfactants on the stability of asphalt emulsion. Colloids and Surfaces A: Physicochemical and Engineering Aspects, 2002. 204(1-3): p. 73-83.

80. Márquez, A., G. Palazolo, and J. Wagner, Water in oil (w/o) and double $(W / O / W)$ emulsions prepared with spans: microstructure, stability, and rheology. Colloid \& Polymer Science, 2007. 285(10): p. 1119-1128.

81. Wangqi, $H$. and D.P. Kyriakos, W1/O/W2 and O1/W/O2 globules stabilized with Span 80 and Tween 80 . Colloids Surf A Physicochem Eng Asp, 1997. 125(2-3): p. 181-187.

82. Jiao, J. and D.J. Burgess, Rheology and stability of water-in-oil-inwater multiple emulsions containing Span 83 and Tween 80. AAPS pharmSci, 2003. 5(1): p. E7.

83. Matsumoto, S., Formation and Stability of Water-in-Oil-in-Water Emulsions, in Macro- and Microemulsions1985, American Chemical Society. p. 415-436.

84. Qi, X., L. Wang, and J. Zhu, Water-in-oil-in-water double emulsions: An excellent delivery system for improving the oral bioavailability of pidotimod in rats. Journal of Pharmaceutical Sciences, 2011. 100(6): p. 2203-2211.

85. Florence, A.T. and D. Whitehill, The formulation and stability of multiple emulsions. International Journal of Pharmaceutics, 1982. 11(4): p. 277-308.

86. Morais, J.M., P.A. Rocha-Filho, and D.J. Burgess, Influence of Phase Inversion on the Formation and Stability of One-Step Multiple Emulsions. Langmuir, 2009. 25(14): p. 7954-7961. 
87. Moulai-Mostefa, N. and A. Boumenir, Formulation of a Stable Multiple Emulsion via a One-Step Process Using Surface Properties of the Mixed Emulsifiers. Journal of Dispersion Science and Technology, 2010. 32(1): p. 102-108.

88. Ma, G., et al., Multi-scale structures in emulsion and microsphere complex systems. China Particuology, 2005. 3(6): p. 296-303.

89. Garti, N., Double emulsions - scope, limitations and new achievements. Colloids and Surfaces A: Physicochemical and Engineering Aspects, 1997. 123-124(0): p. 233-246.

90. Magdassi, S., M. Frenkel, and N. Garti, Correlation Between Nature of Emulsifier and Multiple Emulsion Stability. Drug Development and Industrial Pharmacy, 1985. 11(4): p. 791-798.

91. Geiger, S., et al., Kinetics of swelling-breakdown of a W/O/W multiple emulsion: possible mechanisms for the lipophilic surfactant effect. Journal of Controlled Release, 1998. 52(1-2): p. 99-107.

92. Garti, N., Progress in Stabilization and Transport Phenomena of Double Emulsions in Food Applications. LWT - Food Science and Technology, 1997. 30(3): p. 222-235.

93. Ohwaki, T., et al., Improvement of the stability of water-in-oil-inwater multiple emulsions by the addition of surfactants in the internal aqueous phase of the emulsions. International Journal of Pharmaceutics, 1993. 93(1-3): p. 61-74.

94. Schmidts, T., et al., Multiple W/O/W emulsions-Using the required $H L B$ for emulsifier evaluation. Colloids and Surfaces A: Physicochemical and Engineering Aspects, 2010. 372(1-3): p. 48-54.

95. Schmidts, T., et al., Influence of hydrophilic surfactants on the properties of multiple W/O/W emulsions. Journal of Colloid and Interface Science, 2009. 338(1): p. 184-192.

96. Jiao, J. and D.J. Burgess, Multiple Emulsion Stability: Pressure Balance and Interfacial Film Strength, in Multiple Emulsions2007, John Wiley \& Sons, Inc. p. 1-27.

97. Schmidts, T., et al., Development of multiple W/O/W emulsions as dermal carrier system for oligonucleotides: Effect of additives on emulsion stability. International Journal of Pharmaceutics, 2010. 398(1-2): p. 107-113. 
98. Aronson, M.P. and M.F. Petko, Highly Concentrated Water-in-Oil Emulsions: Influence of Electrolyte on Their Properties and Stability. Journal of Colloid and Interface Science, 1993. 159(1): p. 134-149.

99. Koroleva, M.Y. and E.V. Yurtov, Effect of Ionic Strength of Dispersed Phase on Ostwald Ripening in Water-in-Oil Emulsions. Colloid Journal, 2003. 65(1): p. 40-43.

100. Hino, T., Y. Kawashima, and S. Shimabayashi, Basic study for stabilization of $w / 0 / w$ emulsion and its application to transcatheter arterial embolization therapy. Advanced Drug Delivery Reviews, 2000. 45(1): p. 27-45.

101. Lutz, R. and A. Aserin, Multiple Emulsions Stabilized by Biopolymers, in Multiple Emulsions2007, John Wiley \& Sons, Inc. p. 85-120.

102. Dragana D. Vasiljevic, J.V.P., Marıja M. Primorac, Gordana M. Vuleta, Rhelogical and droplet size analysis of W/O/W multiple emulsions containing low concentrations of polymeric emulsifier Journal of the Serbian Chemical Society, 2009. 74(7): p. 801-816.

103. Ortega-Vinuesa, J.L., A. Martín-Rodríguez, and R. Hidalgo-Álvarez, Colloidal Stability of Polymer Colloids with Different Interfacial Properties: Mechanisms. Journal of Colloid and Interface Science, 1996. 184(1): p. 259-267.

104. Benichou, A., A. Aserin, and N. Garti, W/O/W double emulsions stabilized with WPI-polysaccharide complexes. Colloids and Surfaces A: Physicochemical and Engineering Aspects, 2007. 294(1-3): p. 2032.

105. ElShafei, G.M.S., et al., Environmentally friendly pesticides: Essential oil-based $w / o / w$ multiple emulsions for anti-fungal formulations. Industrial Crops and Products, 2010. 31(1): p. 99-106.

106. Kim, B.-S., J.-W. Kim, and K.-D. Suh, Poly(methyl methacrylate) multihollow particles by water in oil in water emulsion polymerization. Journal of Applied Polymer Science, 2000. 76(1): p. 38-44.

107. Lee, J.-E., et al., Polymer/Ag composite microspheres produced by water-in-oil-in-water emulsion polymerization and their application for a preservative. Colloid \& Polymer Science, 2004. 282(3): p. 295-299.

108. Lee, E., et al., Multihollow structured poly(methyl methacrylate)/silver nanocomposite microspheres prepared by suspension polymerization in the presence of dual dispersion agents. Colloid \& Polymer Science, 2008. 286(12): p. 1379-1385. 
109. Kim, J.-W., et al., Multihollow polymer microcapsules by water-in-oilin-water emulsion polymerization: morphological study and entrapment characteristics. Colloid \& Polymer Science, 2003. 281(2): p. $157-163$.

110. Bäumer, S., Handbook of Plastic Optics (2nd Edition), John Wiley \& Sons. p. 134-139.

111. Raymond B. Seymour, C.E.C., ed. Structure-Property Relationships in Polymers. 1984, Plenum Press: New York and London. 47-55.

112. Mark HF, B.N., Overberger CG, Menges G, Kroschwitz JI, Encyclopedia of Polymer Science and Engineering. 1985. 1: p. 234.

113. HR, K., ed. Handbook of polymer synthesis. Vol. Part A. 1992, Marcel Dekker: New York. 223.

114. Hildebrand J. H., S.R.L., Solubility of Nonelectrolytes. 3 ed1950, New York: Reinhold.

115. CRC handbook of solubility parameters and other cohesion paramaters1983.

116. Mahdi Jafari, S., Y. He, and B. Bhandari, Nano-Emulsion Production by Sonication and Microfluidization-A Comparison. International Journal of Food Properties, 2006. 9(3): p. 475-485.

117. Abismail, B., et al., Emulsification by ultrasound: drop size distribution and stability. Ultrasonics Sonochemistry, 1999. 6(1-2): p. 75-83.

118. Jafari, S.M., Y. He, and B. Bhandari, Production of sub-micron emulsions by ultrasound and microfluidization techniques. Journal of Food Engineering, 2007. 82(4): p. 478-488.

119. Lin, C.-Y. and L.-W. Chen, Emulsification characteristics of three- and two-phase emulsions prepared by the ultrasonic emulsification method. Fuel Processing Technology, 2006. 87(4): p. 309-317.

120. Santos, H.M., C. Lodeiro, and J.-L. Capelo-Martínez, The Power of Ultrasound, in Ultrasound in Chemistry2009, Wiley-VCH Verlag GmbH \& Co. KGaA. p. 1-16.

121. Brandrup J., I., Grulke, ed. Polymer Handbook, Fourth Eddition. 1999, John Wiley \& Sons, Inc.: New York. 571-582.

122. Bass, M. and O.S.o. America, Handbook of optics2001: McGraw-Hill. 
123. Illımination, I.C.o. Selected Calorimetric Tables, Relative spectral power distribution of CIE Standard Illuminant D65, Last visited on 08/07/2012.

124. Malacara, D., ed. Color Vision and Calorimetry, Theory and Applications. 2002, SPIE-The International Society for Optical Engineering: Washington. 131-147.

125. Tilley, R.J.D., Colour and optical properties of materials: an exploration of the relationship between light, the optical properties of materials and colour2000: John Wiley \& Sons. 1-22.

126. Saçak, M., Polimer Kimyasl, 2000, Ankara: Gazi Kitapevi. 
MATLAB CODES FOR SCATTERING EFFICIENCY CALCULATOR

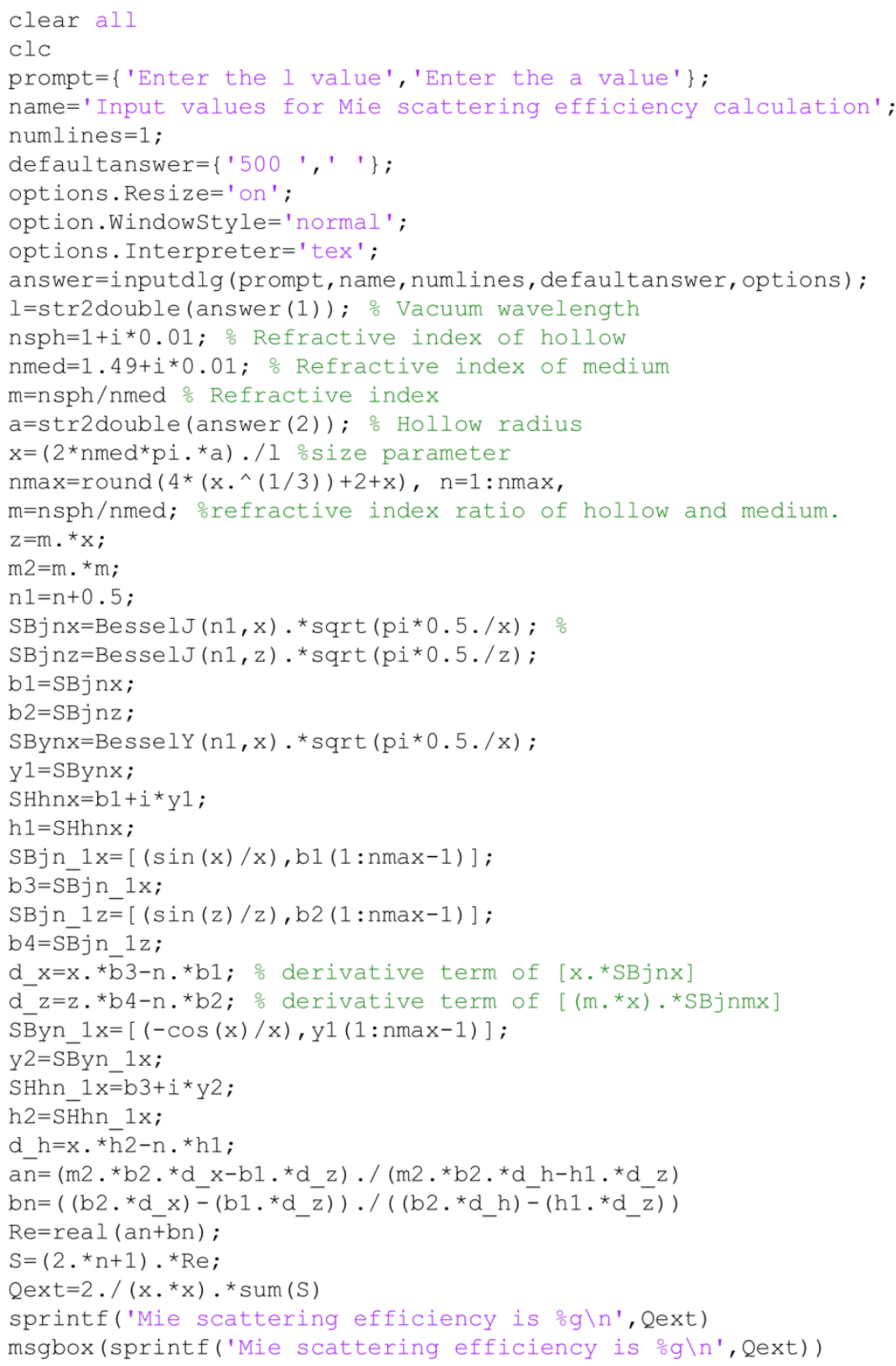

